University of Massachusetts Amherst

ScholarWorks@UMass Amherst

Masters Theses 1911 - February 2014

1982

\title{
The effect of naloxone on conditioned suppression in rats.
}

Michael Vigorito

University of Massachusetts Amherst

Follow this and additional works at: https://scholarworks.umass.edu/theses

Vigorito, Michael, "The effect of naloxone on conditioned suppression in rats." (1982). Masters Theses 1911 - February 2014. 2051.

https://doi.org/10.7275/4x61-5640

This thesis is brought to you for free and open access by ScholarWorks@UMass Amherst. It has been accepted for inclusion in Masters Theses 1911 - February 2014 by an authorized administrator of ScholarWorks@UMass Amherst. For more information, please contact scholarworks@library.umass.edu. 


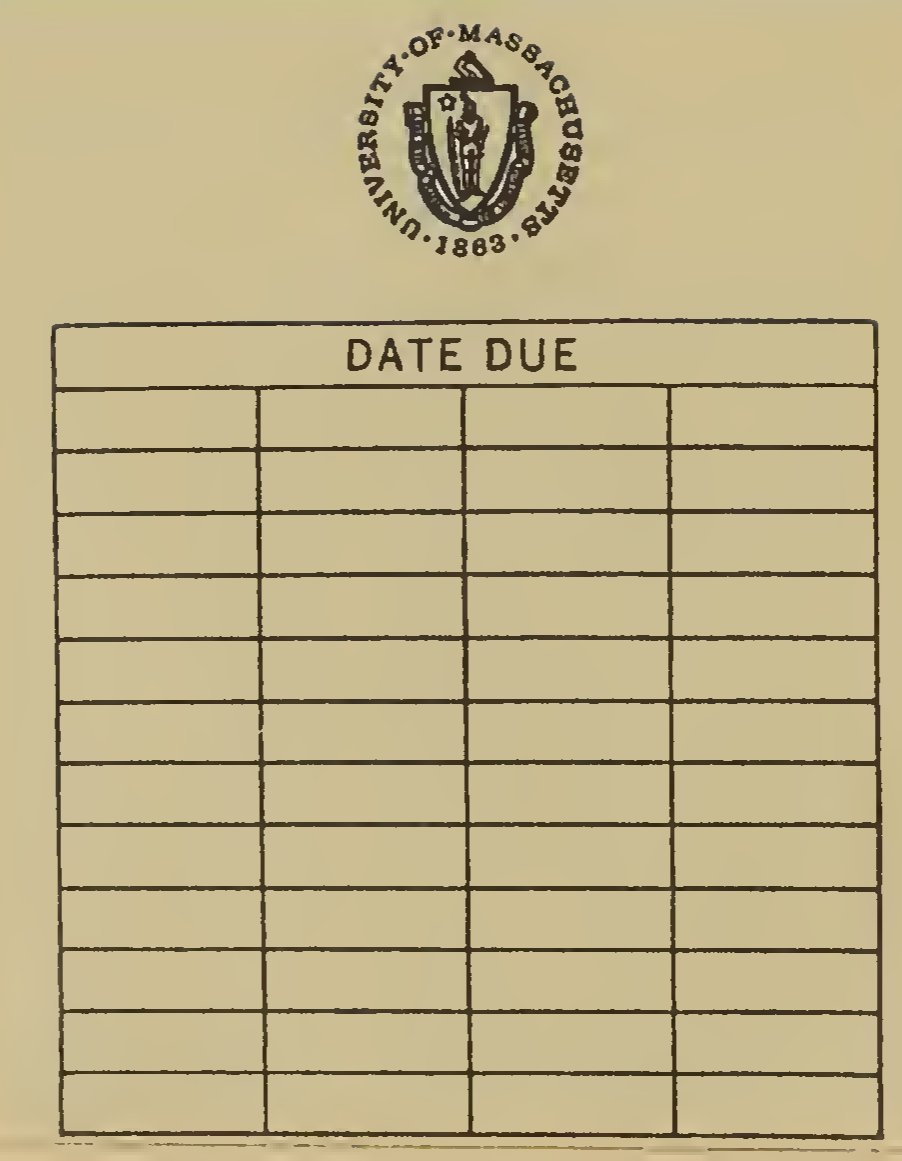

UNIV. OF MASSACHUSETTS/AMHERST LIBRARY

$$
\begin{aligned}
& \text { LD } \\
& 3234 \\
& \text { M268 } \\
& 1982 \\
& \text { V691 }
\end{aligned}
$$


THE EFFECT OF NALOXONE ON CONDITIONED SUPPRESSION IN RATS

A Thesis Presented

By

MICHAEL VIGORITO

Submitted to the Graduate School of the University of Massachusetts in partial fulfillment

of the requirements for the degree of

MASTER OF SCIENCE

May 1982

Psychology 
THE EFHECT OF NALOXONE ON CONDITIONED SUPPRESSION IN RATS

A Thesis Presented

By

MICHAEL VIGORITO

Approved as to style and content by:

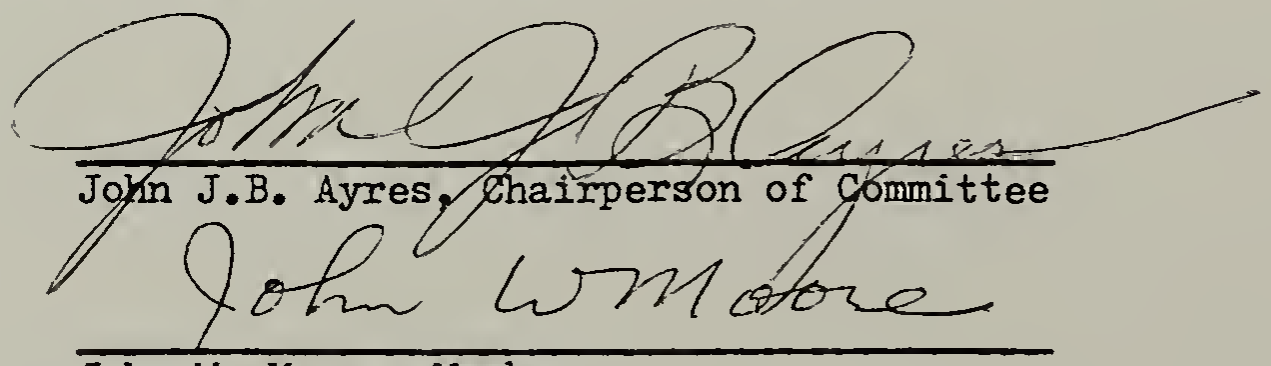

John W. Moore, Member

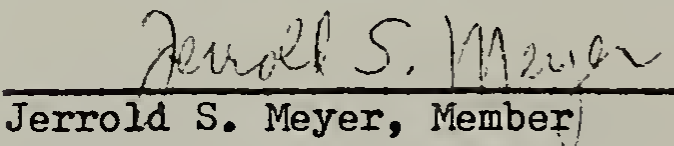

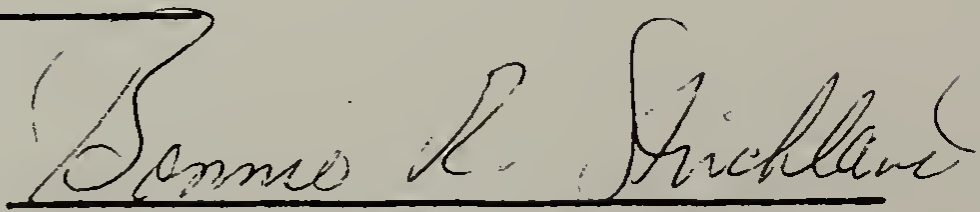

Bonnie R. Strickland, Department Head

Psychology 


\section{ACKNOWLEDGEMENT}

I would like to express my gratitude to $\mathrm{Dr}$. John J. B. Ayres, my thesis advisor, who provided support and guidance throughout this project. In addtition, I would like to thank Dr. John Moore and Dr. Jerrold Meyer, members of my committee, for their many valuble comments on the manuscript. Thanks are also due to Endo Laboratories for generously supplying naloxone hydrochloride and to John McElroy for showing me how to prepare the drug for use. Finally, I thank my wife, Carolyn, for having the confidence in my abilities that I often lacked, for endless hours of listening to my ideas and problems concerning the project, and for just being there when I needed her. 


\section{ABSTRACT}

A series of experiments was performed to determine the effects of naloxone on the acquisition of conditioned suppression in rats. Conditioned suppression acquisition functions are often nonmonotonic due to within-session performance decrements and to postasymptotic performance decrements. Naloxone given during acquisition increased post-US suppression (Experiment 1), depressed baseline response rates in a situation involving shock presentation (Experiments 1 and 2b), eliminated the postasymptotic performance decrement (Experiment 1), and caused greater resistance to extinction than did saline (Experiments 1 and $2 \mathrm{~b})$. Naloxone did not eliminate within-session decrements (Experiment 1 and $2 b$ ) and failed to affect extinction of conditioned suppression when administered only during extinction (Experiments 1 and 3 ). Naloxone slightly decreased baseline responding for sucrose reinforcement. (Experiment 2a), but this effect was a small one and did not confound the effects of naloxone on conditioned suppression. The results suggest that naloxone affects the acquisition of conditioned suppression by increasing the aversiveness of the shock US. The possible role of the activation of an endorphinergic system during fear conditioning is discussed. 
TABLE OF CONTENTS

ACKNOWLEDGEMMENT

iii

ABSTRACT . . . . . . . . . . . . . . . . . . . . . iv

LIST OF TABLES . . . . . . . . . . . . . . . . . . . vii

LIST OF ILLUSTRATIONS . . . . . . . . . . . . . . . . . viii

Chapter

I. INTRODUCTION . . . . . . . . . . . . . . .

Possible Endorphinergic Mechanisms In Fear

Conditioning . . . . . . . . . . . . . . .

Analgesic hypothesis . . . . . . . . . . .

Conditioned antinociception hypothesis . . . . .

The Perceptual-Defensive-Recuperative (PDR)

model ................... 20

Antianxiety hypothesis............ 24

The Role of Endorphins In Aversive Learning

and Memory . . . . . . . . . . . . . 25

Active avoidance ................. 27

Passive aroidance ................ 29

The effect of naloxone on avoidance behavior

in opiate-naive animals ........ 30

A caveat .................. 31

Scope and Purpose ...................... 34

II. EXXPERIMENT 1 ................... 36

Method ...................... 37

Results ....................... 44

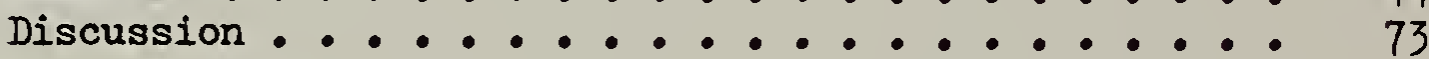

III. EXXPERIMENT 2A

Method ............... 84

Results ...................... 85

Discussion .................... 89

IV. EXPERTMENT 2B - . . . . . . . . . . . . 90

Method ...................... 91

Results and Discussion ............. 92

V. EXXPERTMENT 3................... 108

Method .................. 108

Results and Discussion ............... 110 
VI. GENERAL DISCUSSION ............ 116 BIBLIOGRAPHY . . . . . . . . . . 125 


\section{LIST OF TABLES}

1. Experimental Procedure for Experiment 1 .........

2. Tail Flick Latencies for Drug Days of Acquisition

in Experiment $1, \ldots . . . . . . .$.

3. Design of Experiment 2B .................. 


\section{LIST OF ILLUSTRATIONS}

1. Trial-by-Trial Mean Corrected Suppression Ratios for a Trace and Delay Conditioning Group, Short ITI . . • . 4

2. Trial-by-Trial Mean Corrected Suppression Ratios for a Trace and Delay Conditioning Group, Long ITI . . . . 7

3. Parameters Used to Produce WSDs Shown in Figure 1 (Panel A) and Figure 2 (Panel B) .......... 9

4. Trial-by-Trial Mean Corrected Suppression Ratios for the First Fight Days of Acquisition . . . . . . 45

5. Trial-by-Trial Mean Corrected Suppression Ratios for Group PC-N, PC-S, and C-S on the First Three Days of Acquisition ..................

6. Daily Mean Corrected Suppression Ratios for Groups PC-N and PC-S During Acquisition . . . . . . 52

7. Daily Pre-CS Rates During Drug Days of Acquisition .... 55

8. Daily Mean Normal Suppression Ratios During Extinction for Group PC-N and PC-S (Left Panel) and for Groups C-S-S and C-S-N (Right Panel) ........ 58

9. Daily Pre-CS Rates for Group PC-N and PC-S During Extinction ...................

10. Daily Pre-CS Rates for Groups C-S-N and C-S-S During Extinction ...................

11. Mean Daily Normal Post-US Suppression Ratios for Groups PC-N and PC-S During Acquisition ..........

12. Mean Tail Flick Latencies During Acquisition .......

13. Mean Baxpress Response Rates per Minute for Group Naloxone and Group Saline .............

14. Daily Mean Corrected Suppression Ratios During Acquisition for Groups Receiving Saline or Naloxone . . 95

15. Trial-by-Trial Corrected Suppression Ratios for the First Nine Days of Acquisition ...........

16. Mean Pre-CS Rates During Acquisition for Groups Receiving Saline or Naloxone ............

17. Dally Mean Normal Suppression Ratios During Extinction for Groups Receiving Saline or Naloxone During Acquisition .................

18. Daily Mean Corrected Suppression Ratios During Extinction for Groups Receiving Saline or Naloxone During Acquisition and Extinction .............

19. Mean Suppression Ratios During Acquisition (Top Panel)

20. Daily Pre-CS Rates During Extinction for all Groups in Experiment $3 \ldots \ldots$ 


\section{H A P T E R I}

INTRODUC TION

When a conditioned stimulus $(C S)$ is repeatedly followed by an unconditioned stimulus (US), the CS comes to elicit new responses. These new responses gain strength rapidly in the early trials, but later there is a gradual decrease in the magnitude of increments. This negatively accelerated conditioning function is believed by some to represent the strengthening of an association between the internal representations of the CS and the US (e.g., Konorski, 1948; Rescorla, 1974). Presumably, asymptotic performance reflects the maximum amount of learning that the US can support. However, many investigators have observed a diminution in the conditioned response (CR) with increasing CS-US pairings. Pavlov (1960), for example, reported that when the number of conditioning trials was increased, the salivary conditioned reflex in dog s diminished in strength and eventually vanished. Pavlov termed this phenomenon inhibition with reinforcement. Kimmel and Burns (1975) review several studies demonstrating CR decrements with increased conditioning trials in the eyelid, salivary, and GSR preparations.

Postasymptotic performance decrements (PADs) have al so been reported in the fear conditioning literature (e.g., Goldstein, 1960; Libby, 1951; Millenson \& Hendry, 1967; Overmier, Payne, Brackbill, Linder, \& Lawry, 1979; Sherman \& Maier, 1978). When 
Libby (1951) observed PADs, he proposed that they were due to "desensitization" or "adaptational effects of shock". Unfortunately, he did not test his hypothesis. More recently Sherman and Maier (1978) demonstrated nonmonotonic acquisition functions (i.e., PADs) with delay, trace, and simultaneous conditioning procedures. Moreover, in their study a control group showed that the decrement in excitatory conditioning was not due to the greater number of US presentations, but due to the CS-US pairings. Overmier et al. (1979), however, reported evidence suggesting that US habituation does result in PADs.

Another interesting phenomenon repeatedly reported in Pavlovian conditioning procedures is the within-session response decrement (WSD). Such decrements are observed under maintained acquisition conditions, and are defined by a greater $C R$ on the first reinforced trial of a session than on the remaining trials of the same session. WSDs have been found in a wide variety of conditioning procedures, such as salivary conditioning (Pavlov, 1960, Lecture 14) and eyelid conditioning in dogs (Hilgard \& Marquis, i935), eyelid conditioning in humans (Runquist \& Mdir, 1971) and GSR conditioning in humans (Epstein \& Eaum, 1971). One of the more recent and more robust demonstrations of WSDs has been provided in the fear conditioning literature by Ayres, Berger-Gross, Kohler, Miahoney, and Stone (1979). These authors examined trial-by-trial acquisition of conditioned suppression of barpressing under several conditions and found that in many cases 
the acquisition functions were not monotonic, but were characterized late in training by decreasing suppression across trials within each session. In several cases the observed decrements in suppression reflected computational artifacts that resulted from the use of the Annau-Kamin (1961) suppression ratio, $\underline{D} /(\underline{B}+\underline{D})$. Here $\underline{D}$ denotes the response rate during $C S$ presentation and $\underline{B}$ the baseline response rate during a period immediately before CS presentation (i.e., pre-CS rate). A score of 0 reflects complete suppression, while a score of .5 reflects no suppression to the CS. Note, however, that the observed nonmonotonicities can be interpreted as computational artifacts if the pre-CS rates fall across trials. That is, if the CS rates were to remain constant as the pre-CS rates dropped, the ratio would increase and be misinterpreted as reflecting decreasing suppression to the CS. To dismiss this computational artifact, Ayres et al. (1979) computed the suppression ratios with the pre-cs scores on Trial 1 for all rats as the baseline rate. Since the pre-cS rate would be the same for a given animal on every trial, nonmonotonicities could not be explained in terms of falling pre-CS rates. With the "corrected" Annau-Kamin ratio Ayres et al. demonstrated WSDs in both delay and trace proced ures.

Recently, I examined a number of conditions in an attempt to replicate the Ayres et al. findings. Figure 1 plots the trial-by-trial acquisition of conditioned suppression for two of 
Figure 1. Trial-by-trial mean corrected suppression ratios per day of acquisition. Circled points denote trials that differred significantly from the first trial in the same day. 


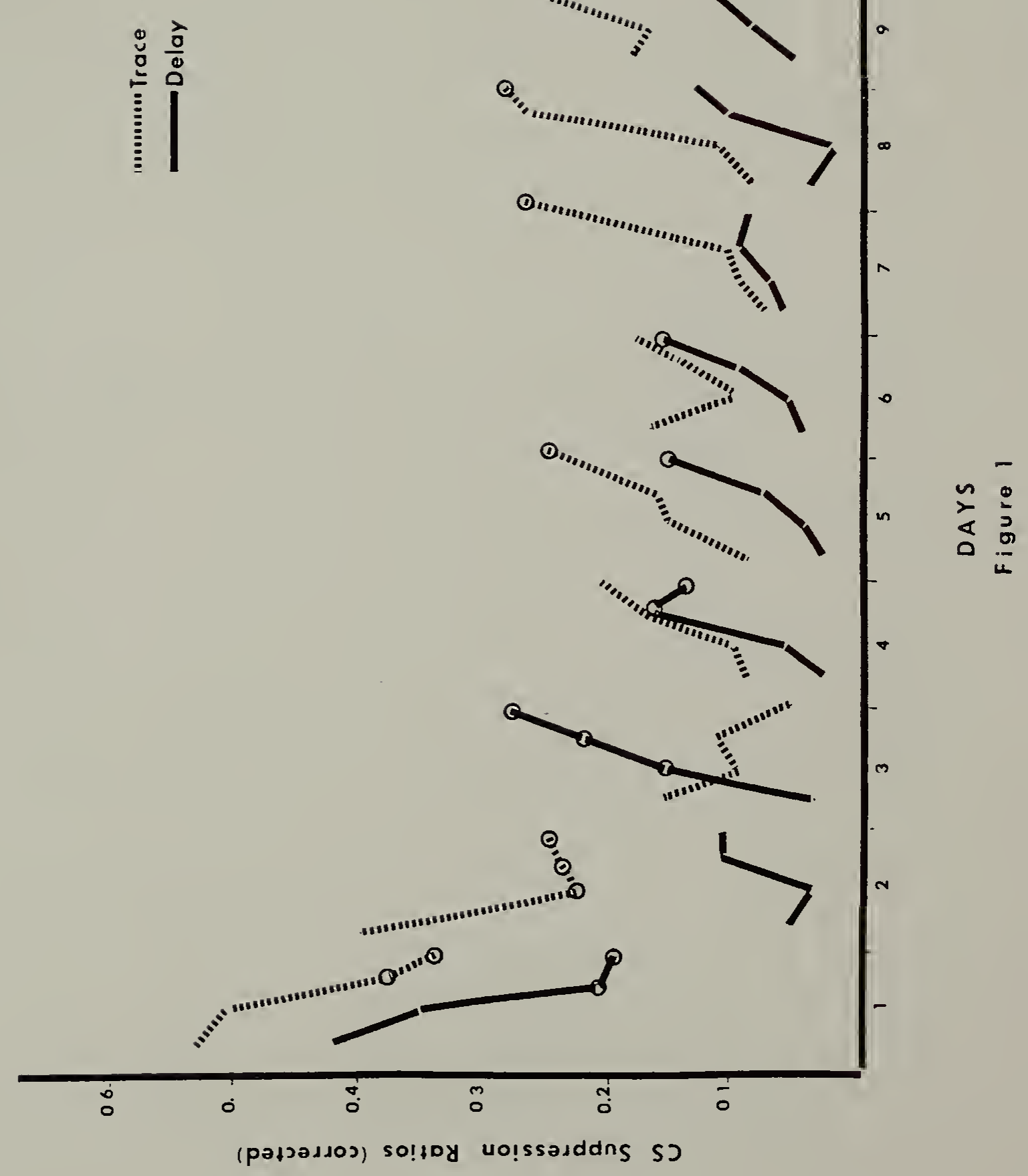


the conditions: trace conditioning and delay conditioning. The plot is in terms of the corrected ratio. The solid line and dashed 1 ine represents the delay and trace groups respectively. Breaks in the plot separate the data obtained in successive sessions. Each session was 30 min long and contained four CS-US trials (see Figure $3 a$ for details). The CS was a light and the US was a 1-mA, 1-sec footshock. Circled points denote trials in which suppression differed significantly $(p<.05$, tho-tailed t-test) from that obtained on the first trial of the same session. Early in training, both groups showed within-session increases in suppression. In subsequent sessions, however, suppression was maximal on the first trial but weakened generally across trials. These WSDs occurred in both delay and trace conditions. Another interesting characteristic of these nonmonotonicities is the recovery of the $C R$ on the first trial of a session following a session with decrements. In the delay group suppression ratios on the first trial were approximately $.03-.05$ on Day 2 through Day 9 despite the large decrements in the previous sessions. Suppression on the first trial of each session for the trace group showed some variability, but in general the suppression ratio was about . 10 . This between-session recovery of the $C R$ resembles the spontaneous recovery of conditioned responses that is observed in extinction proced ures.

Figure 2 presents the data of a delay and a trace group that 
Figure 2. Trial-by-trial mean corrected suppression ratios per day of acquisition. Circled points denote trials that differed significantly from the first trial in the same day. 
\begin{tabular}{ll}
$u$ & \multicolumn{1}{c}{} \\
$\alpha$ & \multicolumn{1}{c}{} \\
$\vdots$ & 0 \\
$\vdots$ &
\end{tabular}

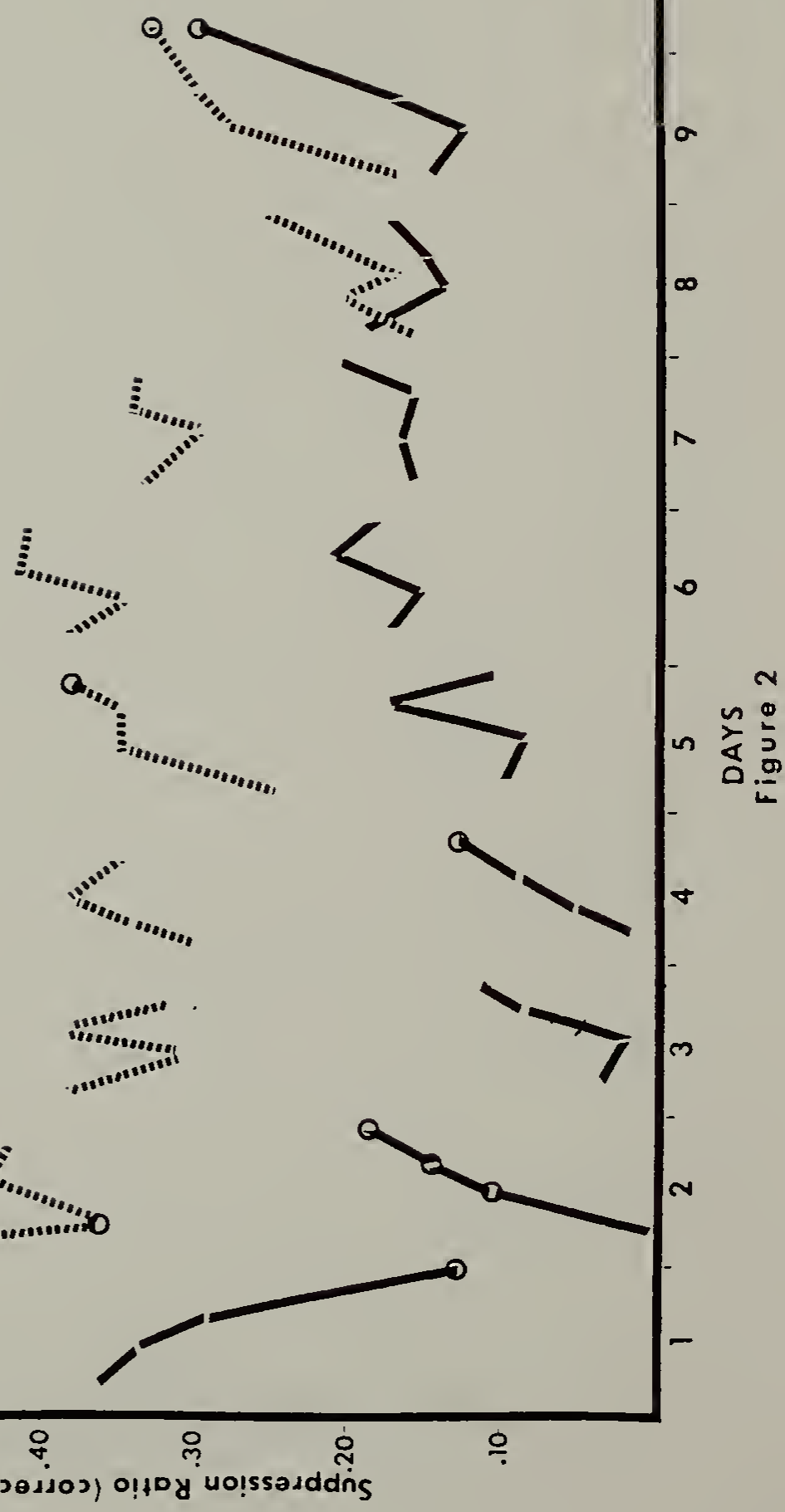


Figure 3. Parameters used to produce WSDs shown in Figure 1 (Panel A) and Figure 2 (Panel B). 
A

Delay
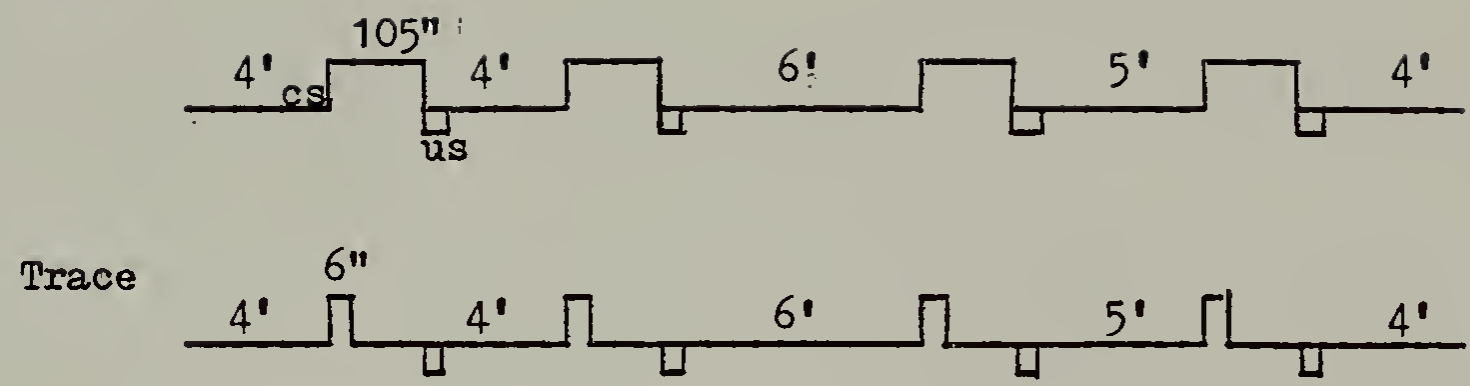

B

Delay

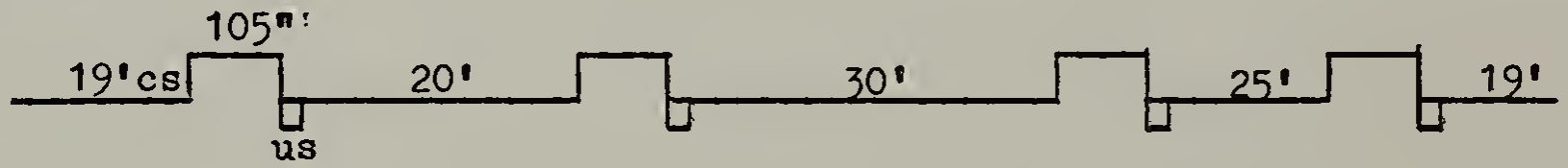

Trace

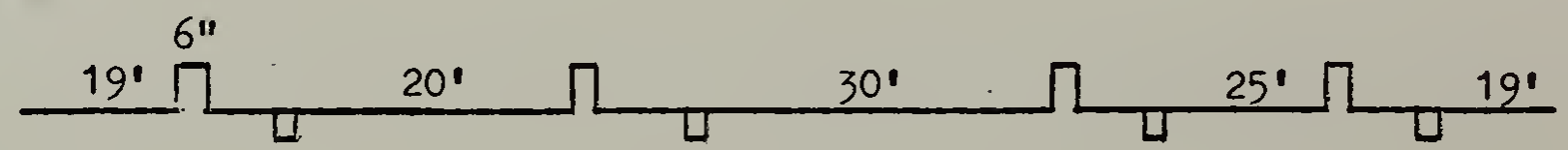


received four CS-US pairings in a 2-hr session. Rats in these groups.received the same treatment as the groups shown in Figure 1 except that the ITIs were much longer (see Figure $3 \mathrm{~b}$ ). The trace group showed a slow rate of acquisition of conditioned suppression. After 9 days of conditioning, suppression to the CS was still not complete. Significant WSDs occurred on Day 5 and Day 9. The delay group showed within-session increases in suppression on Day 1, but on Days 2 and 4 showed WSDs. Note, however, that on subsequent days the $C R$ did not recover on the first trial of the next session. This lack of recovery appears to be responsible for the observed between-session decrements (i.e., PADs).

Several theoretical formulations have been proposed concerning the WSD phenomenon (see Ayres et al., 1979). Hilgard and Marquis (1935) observed WSDs with recovery between sessions in an eyelid conditioning situation and interpreted the decrements as being a result of "repetitive work". They hypothesized that inhibitory or antagonistic properties that built up during the process of work dissipated overnight, allowing the $C R$ to be fully expressed the next day. This fatigue-like factor is similar to Hull's (1943) notion of reactive inhibition. Short-term US and CS habituation effects can al so be postulated to cause WSDs. Recent evidence suggests that CS habituation can occur during the course of Paviovian conditioning (Hall \& Pearce, 1979; Pfautz \& Wagner, 1976). 
Solomon and Corbit's (i 1974 ) opponent-process theory of motivation al so adequately accounts for WSDs. The theory suggests that the decrements are due to a growing b process that is triggered by, and is antagonistic to, an $\underline{a}$ process. The theory asserts that the manifest affective state of the animal is a result of the algebraic summation of the two opposing processes. In the conditioned suppression procedure the A state is fear, indexed by suppression of some ongoing behavior, and the growing $\underline{b}$ process is reflected by decreasing suppression within a session. Thus, in each session, as the inferred $\underline{b}$ process grows with each US presentation, the affective state looks less and less like an A state. It is also postulated that the brocess builds with use but weakens with disuse. Overnight, the $\underline{b}$ process returns to its original condition, accounting for recovery of the $C R$ on the first trial of the next session.

Another interesting theoretical formulation about the WSD phenomenon, in the conditioned fear situation at least, concerns the recently discovered endogenous ligands that interact with opiate receptors. These opioid peptides, the enkephal ins and endorphins, isolated from brain (e.g., Hıghes, 1975) and pituitary (e.g., Tschemacher, Opheim, Cox, \& Goldstein, 1975), have morphine-like pharmacological actions. Administration of both narcotic alkaloids and opioid peptides produces powerful analgesia that is reversed by naloxone, a pure opioid antagonist (Eelluzzi, Grant, Garsky, Sarantakis, Wise, \& Stein, 1976; 
Lewis, Bently, \& Cowan, 1971). These observations have led several investigators to postulate an endogenous opioid system that functions to modulate pain and/or fear (e.g., Hughes, 1975; Grevert \& Goldstein, 1977; Madden, Akil, Patrick, \& Earchas, 1977; Sherman \& Liebeskind, 1980). Indeed, the endorphins appear to be distributed in the brain in close proximity to brain stem sites that support stimulation-produced analgesia (see Sherman \& Liebeskind, 1980). An intriquing possibility, therefore, may be that WSDs and PADs in the conditioned suppression procedure simply reflect nociceptive decrements caused by stress-induced release of endogenous opioids. Alternatively, WSDs and PADs might reflect the endorphin's direct effect on fear itself wi thout producing antinociception.

\section{Possible Endorphinergic Mechanisms in Fear Conditioning}

Although a functional endorphinergic system has been hypothesized by many investigators, it is not clear exactly how the endorphin's affect an animal's response to painful stimuli. In the conditioned suppression procedure, stress-induced release of endorphins may produce nonmonotonicities by several different mechanisms. Let us consider the following three hypotheses.

Analgesic hypothesis. This hypothesis can take several forms. The simplest might be as follows: During the course of 
conditioning, aversive stimulation (e.g., electric shock) triggers or causes an increase in the the release of endogenous opioids such as endorphins. With repeated presentation of the aversive stimulus, the level of opioids increases with concurrent decreases in nociception, rendering the us less effective in supporting conditioning over trials within a session, thus causing the CR to partially extinquish. Overnight the opioid concentration returns to baseline and the "extinguished" CR spontaneously recovers on the first trial of the next session. Alternatively, it may be postulated that al though fear increases with each trial, as governed by the rules of Pavlovian conditioning, the release of endorphins allows the organism to better cope with pain, that is to tolerate the aversive US. Clinical studies on the psychological effects of the exogenous analgesic morphine, report a lack of concern or indifference to pain by individuals treated with the drug. Endogenous Iigands for the opiate receptors might also have similar effects. In support of this hypothesis Amir and Amit (1978) reported that immobilization stress in rats resulted in increased latencies to escape from a hot plate, but had no effect on paw lick responses. These authors suggested that the more primitive heat-elicited paw lick response primarily represents a sensory-perceptual component of pain, while the escape response is predominantly an affective response to pain. These data suggest that endorphins may be involved in the affective component but not the sensory component 
of pain related behaviors. In the conditioned suppression procedure the increase in endorphin levels may attenuate the affective component of pain without changing the animal's threshold for detecting pain. Decreased suppression may then arise from the increased tolerance to the aversive US.

An interesting finding directly relevant to the analgesic hypothesis is that it is only when coping behaviors are not available that stress-induced analgesic reactions are observed. Jackson, Maier, and Coon (1979) observed long-term analgesic reactions only in rats given inescapable shocks and not in rats given the same number of escapable shocks. This finding suggests that when coping behaviors are available to the animal, the endorphinergic system is not activated, or at least not maintained. If a coping behavior, however, is not available, as is in the case when inescapable shocks are presented, then the endorphinergic system is activated and maintained so as to allow the organism to better cope with the aversive event.

In view of the findings of Jackson et al. (1979), the varying effects of naloxone on pain sensitivity may be understood in terms of the specific paradigms used. Several investigators were unable to find any effect of nalox one on pain thresholds in opiate-naive subjects (e.g., Coldstein, Pryor, Otis, \& Larsen, 1976; El-Sobky, Dostrovsky, \& Wall, 1976) while others did observe increased pain sensitivity (e.g., Akil, Madden, Patrick, \& Barchas, 1976; Frederickson, Burgis, \& Edwards, 1977; Fanselow 
\& Eolles, 1979b). The former investigators used avoidance procedures to measure pain sensitivity. Perhaps, then, the avoidability of the USs in these procedures prevented the activation of an endorphinergic system. Indeed the investigators that did find increased pain sensitivity following naloxone administration used unavoidable stimulus presentations. In a more recent study, however, Mah, Siissa, and Anisman (1980) failed to find any differences in analgesia between groups of mice given avoidable or unavoidable shock. Both groups showed antinociception. Whether this discrepancy is due to the species used or other procedural differences is presently not clear.

It is important to note that al though both versions of the analgesic hypothesis assert that endorphins decrease the aversiveness of the painful stimulus, two different underlying mechanisms are suggested. The tolerance version suggests that the reaction to pain is affected (e.g., suffering or coping). The alternative version of the analgesic hypothesis suggests that the perception of, or sensitivity to the painful stimulus is altered (e.g., pain thresholds increase). Fur thermore, al though both versions of the analgesic hypothesis posit a nonassociative release of endorphins (triggered by the aversive stimulus), the version suggesting changes in pain sensitivity allows for associative changes in the CS, i.e., decreased aversiveness of the US produces lower levels of asymptotic conditioning. WSDs and PADs may result from such a mechanism. The distinction 
between these two versions of the analgesic hypothesis is of considerable theoretical importance. However, it is exceedingly difficult to separate the two, especially with animal subjects, and they are not separated by the experiments of this report. Were analgesia (as determined by tail flick tests) to be observed during Pavlovian conditioning, whether the analgesia would be due to increase in pain thresholds or to a change in the reaction to pain could not be determined.

Conditioned antinociception hypothesis. Hypotheses implicating an endorphinergic system in the mediation of nonmonotonic acquisition functions in aversive procedures can be even more complex than the hypotheses discussed thus far. Recent investigations suggest that the release of endorphins can be triggered by CSs paired with shock to produce conditioned antinociception (Chance, White, Krynock, \& Rosecrans, 1978; Fanselow, 1979; Fanselow \& Bolles, 1979a). Other studies have also demonstrated the release of endorphins by environmental cues paired with morphine to produce conditioned hyperthermia (Lal, Miksic, \& Smith, 1976; Sherman, 1979). Thus, antinociception may arise, not from a nonassociative, stress-induced release of endorphins (analgesic hypothesis), but may result from an analgesic system that critically depends on the subject's conditioning history. Indeed, WSDs do appear to vary with conditioning procedures in a manner consistent with such an 
account (Ayres et al., 1979; Ayres \& Vigorito, ınpublished observation).

Additional evidence that the release of endogenous opioids may be triggered by CSs paired with USs comes from studies of preference for signaled shock versus unsignaled shock (see Badia, Harsh, \& Abbot, 1979 for a review). When given a choice between a situation in which shocks are reliably preceded by a signal and one in which the shocks are not signaled, rats prefer the signaled situation. Preference tests usually consist of measuring the percentage of time the animal spends in the unsignaled compartment of a shuttle box. Rats have also been trained to barpress to obtain blocks of time where all shocks are signaled. One interesting interpretation of these data is that the signaled condition allows the animal to make some preparatory response that makes subsequent shocks less aversive (Perkins, 1968; Miller, Marlin, \& Eerk, 1977; Marlin, Sullivan, Berk, \& Miller, 1979). Al though skeletal responses have been observed during the signal preceding shock (Marlin, Berk, \& Miller, 1978), the use of fixed shock delivery electrode preparations suggest a central preparatory response (Miller. Daniel, \& Berk, 1974; Miller, Marlin, \& Berk, 1977; Marlin et al., 1979). Fanselow (1979) tested whether a conditioned release of endogenous analgesics occurs in the signaled condition, rendering subsequent shocks less aversive. This hypothesized central preparatory response cannot occur in the unsignaled 
condition. Rats injected with the opiate antagonist naloxone during training failed to show any side preferences when tested in the absence of shock. Control animals treated with saline preferred the signaled side of the shuttlebox. These results suggest that rats prefer the signaled condition because endogenous analgesics are triggered by CSs paired with shock, rendering subsequent shocks less aversive.

Another interesting finding is that signaled shocks are preferred over unsignaled shocks even though the former appear to elicit more fear (Collier, 1977; Harsh \& Badia, 1974; Fanselow \& Bolles, 1979a). Kimmel (1967) reported that adult humans rated aversive USs preceded by signals as more aversive than USz not preceded by signals even though the galvanic skin response to signaled shock was smaller. A recent study by Miller, Greco, Vigorito, and Narlin (note 4) reported similar findings with rats. Rats rated the aversiveness of high and low intensity shocks by pressing a "high" intensity bar or "low" intensity bar for water reinforcement. All shocks were presented through fixed tail-electrodes. When tail shock of an intermediate intensity was signaled by a $5-\sec$ noise, the rats rated the shock as being more aversive than when no noise preceded the intermediate intensity shock. Moreover, when given the choice, the rats preferred the signaled shock condition even though they rated those trials as more aversive than unsignaled shock trials. The se results might suggest that al though the CS comes to elicit 
fear through Pavlovian conditioning, the CS also elicits the release of endogenous opioids. This release of opioids makes the shock less aversive by increasing pain thresholds or by increasing pain "tolerance". However, the rats may have responded to signaled shocks as being more aversive than unsignaled shocks because the acquired aversiveness of the noise CS may have overshadowed any decrement in the aversiveness of the US caused by the conditioned release of sindorphins. Moreover, the rats may prefer the signaled condition because the shock USs are less aversive.

Thus the conditioned antinociception hypothesis differs from the analgesic hypothesisonly in that the former posits an associative release of endorphins (triggered by CSs as well as USs), while the latter proposes a nonassociative endorphinergic system ( triggered onl y by USs).

The Perceptual-Defensive-Recuperative (PDR) model. In the forgoing possible conditioned endorphinergic mechanisms it is assumed that shock-elicited pain is a US and that fear is the CR i.e., pain reinforces fear. An activated endorphinergic system attenuates the impact of the US and thus decreases the fear $C R$. Al though this pain-fear view is a popular one, it is not accepted by everyone. Bolles and Fanselow (1981) have suggested a model of pain and fear that rejects these assumptions. They argue that pain and fear are separate and competing motivational systems. 
Fear serves to organize species-specific defense reactions (e.g., flight or freezing) and to inhibit pain. According to the model, fear must inhibit pain since pain (another motivational system) activates recuperative behaviors that compete with defensive behaviors. Bolles and Fanselow (1981) funther assume that this inhibition of pain by fear is mediated via an endorphinergic system.

In this model fear is not elicited by the presentation of a painful stimulus but is elicited by the expectation of injurious stimulation. The model posits three phases to an aversive or traumatic event and has been termed the perceptual-defensive-recuperative (PDR) model. In a typical fear conditioning experiment a rat receives electric footshock that is usually preceded by a signal (CS). As the animal experiences the pain from the shock it learns that the painful event is predicted by the signal. This brief time of learning about the signal and the shock US is the perceptual/learning phase. Following shock the rat attempts to escape, freeze, or shows other signs of fear. This is the defensive phase. Since the shock is too weak to produce tissue damage, there is little pain following the dissipation of fear, therefore a recuperative phase does not occur in this laboratory setting. If tissue damage had occurred, the rat would perform behaviors that nurse the wounds during this phase. The main purpose of the perceptual/learning phase is to establish the CS quickly as a predictor of the US. Subsequently, 
whenever the US is presented, the animal then compares the occurrence of the US with the US anticipated by virtue of presentation of the signal. If a discrepancy between the anticipated and actual US is detected, the information is used to al ter future expectations.

Perhaps the PDR model can be better understood if one considers the sequence of critical events in natural settings. An animal that has encountered a dangerous situation e.g., a hungry cat) becomes frightened. If the animal is hurt, the fear that the animal is experiencing inhibits the pain from the wound so that it is able to defend itself by flight, attack, or freezing. Since pain is inhibited, recuperative behaviors will not be activated and compete with the defensive behaviors. Once the animal is out of danger, fear dissipates, removing the inhibition of pain and thus activating recuperative behaviors.

Nonmonotonicities in the acquisition of conditioned suppression $c a n$ also be explained within this theoretical framework. Suppose that in a conditioned suppression experiment a WSD is observed on Day 3 of training. The PDR model assumes that on Trial 1 of Day 3 the CS arouses the expectancy of the US, and therefore produces fear (i.e., conditioned suppression). The fear from the CS on Trial 1 then inhibits or attenuates the pain from the US on that trial by activating an endorphinergic system. Since the experienced pain from the US is attenuated compared to the expected US, a discrepancy occurs and subsequent expectations 
are al tered i.e., the rat now expects a less painful US. WSDs may reflect the changes in expectation of painful USs.

Al though the model can adequately explain WSDs, it does not account for the overnight recovery of conditioned suppression between sessions. One can, however, make an addition to the model to account for this overnight recovery. Rescorla's theory of extinction and spontaneous recovery (Rescorla \& Cunningham, 1978; Rescorla \& Cunningham, 1977; Rescorla \& Heth, 1975) suggests that changes in the representation of the US affects learning and performance in the fear conditioning procedure. During extinction of a CS there is a loss in strength of the CS-US association and there is a corresponding decrease in the US representation. However, this depressed US representation recovers with time, thereby increasing the ability of the extinquished CS to elicit a response. This increase in US representation may account for the phenomenon of spontaneous recovery. Sich a mechanism as described by Rescorla may be utilized by the PDR model to account for WSDs in the following way. Within a session the US representation is depressed because of the less painful US caused by the increase of endorphin release, but both the endorphin concentration and the US representation recover overnight, accounting for the increased suppression on the first trial of the next session. To account for PADs this model would have to argue that with prolonged training the highly active endorphinergic system does not recover 
to its original opioid concentration and thus causes elevated resting levels of opioids, and renders all shocks late in training less aversive than shocks early in training. There is some evidence suggesting that prolonged shock presentation elevates resting levels of central opioids (Madden, et al, 1977). With the elevated resting opioid level the US always feels less aversive than it did early in training, therefore the US representation is that of a weak US.

Antianxiety hypothesis. Grevert and Goldstein (1977), in a study with human subjects, suggested that the endorphins may have antianxiety properties. They found that naloxone affected the mood of subjects but not the rating of pain caused by the application of a painful tourniquet, i.e., reduced fear but not perception of pain. Thus, Grvert and Goldstein (1977) suggested that the endorphins may be involved in modulating fear and not pain. In a Pavlovian fear conditioning procedure the triggering of the endorphin system may decrease fear of the CS within a session to account for WSDs, and between sessions to account for PADs. However, Fanselow and Bolles (1979b) did not find support for Grevert and Goldstein's antianxiety hypothesis. They investigated the effect of naloxone on shock-elicited freezing in rats. Rats typically freeze following exposure to painful electric shock. This effect is a graded one such that the more intense the shock the greater the probability that a rat will 
freeze. Fanselow and Bolles found that naloxone was effective in increasing freezing in the rat (measured during an 8-min session following the final shock) when administered immediately before shock presentation. When naloxone was given only during the 8-min observation period that followed the final shock, freezing did not increase. Thus, naloxone did not increase post-shock freezing by directly affecting fear: naloxone increases freezing only when it is administered during acquisition when shocks are given. Nevertheless, the antianxiety $h$ ypothesis suggests that an endorphinergic system does not alter pain but may act directly on fear.

The Role of Endorphins In Aversive Learning and Memory

All the possible theoretical formulations discussed thus far imply that an endorphinergic system may be involved in modul ating learning in aversively motivated tasks. However, the influence of this system appears to be indirect; specifically endorphins affect learning by modulating the effectiveness of the aversive US during conditioning. Many of the experiments described earlier are consistent with this hypothesis. Riley, Zellner, and Dincan (1979) have recently reviewed the role of endorphins in animal learning and have also concluded that endorphins affect the learning based on a stressor by modulating 
the aversiveness of the stressor. However, it is also possible that endorphins have a more direct effect on learning by altering memory consolidation and retrieval processes, for example or perhaps they directly affect the associative machinery. Recent evidence has accumulated to support the view that endorphins have direct effects on learning and memory.

Research investigating the role of endorphins in learning usually consists of studies in which $\beta$-Lipotropin hormone $\beta$ -LPH), $\quad \beta-L P H$ fragments and enkephalins are administered before or after learning trials (usually aversively motivated tasks) and the effect of these peptides on the learned performance is assessed. $\beta$-LPH is a prohormone that is cleaved from a 1 arger protein called pro-opiomelanocortin. No physiological function of $\beta$-LPH has been found, however this prohormone is further cleaved to produce $\alpha$-endorphin, $\beta$-endorphin, and $\gamma$-endorphin. These $\beta$-LPH fragments appear to have several physiological functions, one of which may be the modulation of learning and memory processes. Although $\beta$-endorphin contains the Met-enkephalin sequence, the former is not a precursor of the latter. Pitative precursors have been identified that contain the Met-enkephalin sequence or a $7 / 1$ ratio of Met- and Leu-enkephalin sequences. The effects of post-trial administration of these endogenous opioids is taken as evidence of effects on memory consolidation. The effect of pre-trial administration is taken as evidence for direct effects on 
acquisition processes. That the se drug effects are al so shown to be time dependent has also been interpreted as evidence for a direct role of endorphins in learning and memory. As intriguing as this suggetion may be the available evidence is equivocal and difficult to interpret. Only a very brief review of this research will be attempted here.

The nature of the endorphin effects on aversive learning depend on the task used, the time of drug administration, the dosage of the drug, route of administration, and, of course, the type of endorphin. The two most widely used tasks are active avoidance and passive avoidance (sometimes termed "inhibitory avoidance") procedures. The peptides influence conditioned avoidance behavior when administered intercerebrally or systemically. The latter finding suggests that a primary site of action of enkephalins may be in the periphery. This hypothesis is further supported by recent reports that both Lev and Met-enkephal in are found in the adrenal medulla chromaffin cells (see Yang, Hexam, \& Costa, 1980). Whether the enkephal ins act peripherally or act centrally by entering the brain via areas that do not possess the blood-brain barrier has not yet been determined.

Active avoidance. Met- and Lev-enkephalin, as well as their D-ala analogues, when administered systemically before training in microgram amounts impair acquisition of an active avoidance 
response in rats. The longer chain endorphins contained within the $\beta$-LPH molecule such as $\alpha-, \beta-$, and $\alpha$-endorphin do not affect avoidance acquisition when given in concentrations of 10 to 100 $\mu \mathrm{g} / \mathrm{kg}$ (e.g., Rigter, Hannon, Messing, Martinez Jr., Vasquez, Jensen, Veliqutte, and MicGaugh, 1980; Rigter, Jensen, Martinez Jr., Messing, Vasquez, Liang, \& McGa ugh, 1980). Rigter et al (1980) also reported that the effects of enkephalins on active avoidance learning are time dependent. Enkephalins impair acquisition of avoidance responding only when given 5 min before training but not $15 \mathrm{~min}$ before training. Some studies have reported that these enkephalin effects are not reversible by naloxone or naltrexone (e.g., DeViled, Bohus, vanRee, \& Urban, 1978; Rigter, 1977; Rigter, Greven, \& Van Riezen, 1977), while others have reported naloxone reversible impairing actions of enkephalins. For example, Martinez and Figter (1980) gave rats , or $10 \mathrm{mg} / \mathrm{kg}$ of naloxone $5 \mathrm{~min}$ before training with $10 \mu \mathrm{g} / \mathrm{kg}$ of Leur or Niet-enkephalin. Naloxone did not reverse the impairing actions on active avoidance learning of Leu-enkephal in at either dose, but for Met-enkephalin the $10 \mathrm{mg} / \mathrm{kg}$ dose of naloxone did prevent impairment. Isquierdo, Perry, Dias, Sonja, El isabetsky, Carrasso, Orslingher and Netto (1981) reported that $\beta$-endorphin administered immediately after training impairs retention of a habituation and shuttle avoidance task. Furthermore, this impairment is reversed by naloxone.

The above studies suggest that Met- and Leu-enkephalin 
impair acquisition of an active avoidance response in a time dependent manner when given before training, whereas $\beta-, \alpha-$, and $\gamma$-endorphin have no effects. $\beta$-endorphin, however, impairs active avoidance when administered immediately after training. Al though $\beta$-endorphin effects are easily antagonized by naloxone, high doses of naloxone are needed to antagonize Met-enkephalin effects; naloxone does not antagonize Leu-enkephalin. This pattern of results suggests that the effects of endorphins and enkephalins on active avoidance behavior are mediated via different mechanisms.

Passive avoidance. In the passive avoidance task $\alpha$ - and $\gamma$-endorphins havedifferential effects on retention (Dewied, Kovacs, Bohus, Van Ree, \& Greven, 1978; Martinez \& Rigter, 1980). When administered before training, $\gamma$-endorphin enhances retention but has no effect when given after training; orendorphin has no effect on passive avoidance learning when given before or after training. Martinez and Rigter (1980) also found that $\beta$-endorphin produces retention deficits when given after training but has no effect when given before training. However, Dewied et al. (1978) reported that $\alpha$ - and $\beta$-endorphin administered after training enhanced passive avoidance learning. In the latter study subcutaneous injections were administered, whereas in the former study intraperitoneal injections were given, thus suggesting a possible importance of route of drug 
administration. D-ala-leu-enkephal in impairs active avoidance learning but facilitates learning of a passive avoidance response (Rigter, Jensen, Martinez Jr., Messing, Vasquez, Liang, \& Mcgaugh, 1980). Met- and Leu-enkephal in also reduce co -induced amnesia of a one-trial passive avoidance task (Rigter, 1978).

The effect of naloxone on avoidance behavior in opiate-naive animals. The concept of multiple opiate receptors is now generally accepted by researchers. Al though the evidence clearly favors the hypothesis that mu receptors are important for antinociception, delta receptors also play a role. The mu receptor is generally associated with morphine and delta receptors with enkephalins. Other studies also suggest that $\beta$-endorphin also binds to $\mathrm{mu}$ and delta receptors. If endorphins acting on mu receptors are involved in learning and memory, then naloxone should alter these processes because naloxone competitively binds to these receptors. Since systemic morphine injections have been observed to have amnestic effects (e.g., Messing, Jensen, Martinez, Vasque $z$, Somireu-Mourat, \& McGaugh, 1978), naloxone should enhance learning and/or memory. Messing et al (1979) reported enhanced retention of a one-trial passive avoidance task in rats given naloxone immediately after training. Naloxone did not affect active avoidance responding when given before or after training, but naloxone given immediately before training and $30 \mathrm{~min}$ after training increased the number of 
avoidance responses and decreased response latencies during testing. These results are not consistent with the results reported by Belluzzi and Stein (1977) who reported that intraventricular morphine injections enhanced active avoidance responding and that naloxone antagonized this effect. Hernandez and Powell (1980) found that naloxone treatment (iv injections) during acquisition of conditioned eye blink responding in rabbits had no effect on eye blink CRs (trials-to-criterion), percent trials on which eye blinks occurred or amplitude and latency of the eye blink UR. However, naloxone given during extinction resulted in increased eye blink CRs. Moreover, naloxone attenuated the bradycardia heart rate $C R$ accompanying aversive Pavlovian conditioning in acquisition and extinction, i.e., naloxone specifically affected conditioned heart rate deceleration. In all of the naloxone studies that reported enhanced learning, an alternative explanation of naloxones effect is pliusible. Naloxone may have increased the aversiveness of the US, and rence, enhanced learning. This alternate interpretation was regarded as unlikely by the se authors since in most cases naloxone was observed to have no effect during ac quisition.

A caveat. The studies reviewed above are usually cited as evidence for direct effects of endorphins on learning and/or memory. However there are several weaknesses in this conclusion. 
For example, D-ala-leu-enkephal in has opposite effects on the acquisition of active and passive avoidance responses. This observation argues against a general effect of endorphins on learning and memory processes. Rigter et al. (1980) suggested that the enkephalins may affect learning by increasing the tendency of rats to inhibit behavior prior to aversive stimulation, possibly through an increase in fear or arousal. More generally, pre-trial administration of endorphin may influence conditioned avoidance responding in other ways besides acting on processes related to acquisition of the response. Thus, endorphinsmay affect performance of the response, pain sensitivity, sensory processes, motivational processes, or emotional processes as previously noted. Al though most studies attempt to control for such possibilities, no study has been able to rule out all of the se potential explanations.

Many researchers have argued that studies investigating the effects of post-trial endorphin do not suffer from the problems inherent in pre-trial studies since the animals were trained in a normal state. Sich reassurances, however, may be unfounded. There are several studies in the animal learning literature that report retarded conditioning with presentation of post-trial events. For example, Kremer (1979) examined the effect of post-trial USs on conditioning to a target CS. His experiment used an "unblocking" design originally described by Kamin (1969). In Stage 1 of a blocking experiment animals are 
presented with CS-US pairings until substantial conditioned suppression to the CS is observed. In stage 2 the $C S$ is presented in compound with a second CS, and this compound is paired with a US. This procedure appears to block conditioning to the added CS. If the intensity of the US is increased during the compound phase, conditioning to the added, nonpretrained CS is observed. That is, unblocking occurs. Kremer (1979) found that an added unanticipated post-trial US attenuated the unblocking effect. In his study the interfering post-trial event was the US that served as the reinforcer during the compound phase of the experiment. Another series of experiments examined the effects of post-trial events on the acquisition of the nictitating membrane response in rabbits; here the post-trial event was a stimulus that was not the US or CS during conditioning. A $10-\mathrm{sec}$ light presentation that occurred after each tone-shock pairing yielded retarded conditioning in an experimental group compared to that seen in a control group that did not receive the post-trial light (Kettlewell \& Papsdorf, 1967). Snyder and Papsdorf (1968) confirmed these same observations using a white noise as the post-trial event when a $750 \mathrm{msec}$ ISI was used and not when a more optimal ISI of $350 \mathrm{msec}$ was used. Papsd orf and Kettlewell (1968) found that a post-trial noise stimulus had the greatest effect of retarding conditioning of the nictitating membrane response when it occurred 30 sec after a trial compared to $10 \mathrm{sec}$ after but had the least effect 
when presented 50 sec after a trial.

These animal learning experiments clearly indicate that post-trial events can retroactively interfere with learning. Thus, post-trial administration of endorphins may produce deficits in learning not because of direct effects on consolidation, but may retroactively interfere with learning or retrieval by producing an altered internal state with unique sensory consequences. Any firm conclusions on the direct effects of endorphins on learning would be premature.

\section{Scope and Purpose}

The major intent of the present research was to study the possibility that an endorphinergic system is activated by aversive USs in the conditioned suppression procedure: If some central endorphinergic system is activated by exposure to shock, then it is possible that this endorphin system might be responsible for the "US habituation" that occurs during Pavlovian conditioning. Habituation might occur in terms of antinociception or increased tolerance to the aversive US. This hypothesized endorphin system may be responsible for the nonmonotonicities (WSDs and PADs) observed in Pavlovian conditioning procedures that repeatedly present aversive USs.

The conditioned suppression situation is also a useful procedure with which to determine the effects of naloxone on pain 
sensitivity. Annau and Kamin (1961) demonstrated that the acquisition of conditioned suppression increased monotonically with US intensity during training. Resistance to extinction was also shown to be an increasing monotonic function of US intensity. Thus, if naloxone enhances nociception by blocking an endorphinergic system, subjects treated with naloxone during training should show greater suppression and greater resistance to extinction than subjects treated with saline. Fanselow (in press) reports evidence supporting this idea. Naloxone was observed to increase freezing that is seen after the presentation of footshock. This freezing effect was shown to be due to naloxone's ability to increase fear to the contextual stimuli that were present during shock presentation. Furthermore, naloxone increased the resistance to extinction of freezing behavior in the excitatory context. It would have been interesting to see if increased freezing was correlated with increased nociception, but Fanselow did not measure analgesia. Errman, Josephson, Schull, and Sparich (Note 1) examined the effects of naloxone during fear conditioning as indexed by suppression of licking at a water tube. The results showed increased resistance to extinction of the fear $C R$. However, the effect of naloxone on baseline licking was not described and may have biased the results. 
EXPERIMENT 1

In the first experiment of the present research two strategies were used to see if an endorphinergic system is activated during conditioned suppression training and if this system is responsible for nonmonotonic acquisition functions in the conditioned suppression situation. Briefly, subjects administered an ip injection of naloxone should show no, or reduced, WSDs and, with prolonged Pavlovian conditioning sessions, no or reduced PADs. Moreover, if naloxone increases the aversiveness of the shock US then rats treated with the drug during acquisition should show greater resistance to extinction than rats treated with saline.

On odd-numbered Pavlovian conditioning days each group was given tail flick tests just before a session and immediately after a session. The tail flick test (Dewey \& Harris, 1975) is the most widely used test for assessing nociceptive changes in animals. Increased tailflick latencies following exposure to inescapable shocks have been observed to persist for 1 to $2 \mathrm{~h}$ (Nadden et al., 1977) or even $24 \mathrm{~h}$ after shock exposure if the subject is reexposed to shock (Jackson, Maier, \& Coon; Maier. Coon, McDaniel, Jackson, \& Grau, 1979; Maier, Davis, Grau, Jackson, Morrison, Ma ye, Madden IV, \& Earchas, 1980). If WSDs reflect decreasing nociception, then the saline group should show 
greater tail flick latencies after a session than before a session, with the recovery of nociception overnight. Furthermore, increases in tail flick latencies should occur when WSDs are being observed. The group given naloxone should show no increase in tail flick latencies over sessions and no WSDs. Finally naloxone should prevent the appearance of a PAD. A comparison of tail flick latencies on Day 1 of acquisition with tail flick latencies on the last few days of acquisition (when PADs are being observed in the saline group) should yield nociceptive decrements in the saline animals but not in the naloxone animals. A third group of animals that received CSs alone also received tail flick tests on odd-numbered Pavlovian conditioning days. This group was included to assess the possibility that increases in tail flick latencies in the other groups might be due to other factors unrelated to enalgesia (e.g., passage of time, experience with barpressing, and repeated exposure to the tail flick apparatus).

Mie thod

Subjects. The subjects were 24 experimentally naive Holtzman albino rats, 90 days of age at the start of the experiment, and maintained at $80 \%$ of their ad lib. body weight throughout. All animals were housed individually in a continuously lighted room. 
Tap water was available in the home cage at all times.

Apparatus. Eight identical Model $C$ Gerbrands operant conditioning chambers, housed in ventilated plywood cubicles lined with acoustical tiles, served as the conditioning apparatus: The inside dimensions of each chamber were $23.2 \mathrm{x}$ $20.3 \times 19.5 \mathrm{~cm}$; the side walls and top were transparent Plexiglas, and the end walls were of aluminum. Each chamber contained a standard Gerbrands lever, $1.5 \times 5.0 \mathrm{~cm}$, centrally mounted on one end wall approximately $8 \mathrm{~cm}$ above the grid floor. A dipper receptacle was located in the lower left corner of the same wall and measured $5.5 \times 5.0 \times 5.0 \mathrm{~cm}$. The dipper was used to present reinforcement for barpressing-- a 4-sec presentation of a $\cdot 1-m_{i} l$ dipper cup containing $32 \%$ sucrose (by weight). The floor was composed of 18 stainless steel rods, $2 \mathrm{~mm}$ in diameter, mounted $1.3 \mathrm{~cm}$ apart center to center.

An 85-dB masking white noise was transmitted through a 10-cm-diam speaker mounted on the 1 id of each chamber. The CS was provided by illiminating a 7.5-W, $110-\mathrm{V}$ ac frosted bulb mounted on the rear wall of the cubicle. A large sheet of aluminum foil attached to the rear wall served to reflect the light from this lamp through the Plexiglas walls. No other source of illumination was provided. The US was a $1-\sec 1-m A$ scrambled shock delivered through the grid floors and was provided by eight Grason-Stadler shock sources (models E1064GS 
and 700 ).

The tail flick apparatus consisted of a wooden stage with a shallow grove cut along its center. A 300-W General Electric projector lamp was mounted above the stage. A condenser lens was placed in a fixed position approximately $8 \mathrm{~cm}$ above the stage and below the ligrt. The lens served to focus the light on the tail. The rat was placed in a plastic restraining cage and positioned so the tail rested on the groove. A switch turned on the light source and timer. When the heat became too intense, the rat deflected its tail and activated a photocell located in the groove. This action terminated the trial. The distance between the light source and stage was adjusted to produce control latencies of $7-9 \mathrm{sec}$.

Procedure. A summary of the experimental procedure for all groups is shown in Table 1. A conditioned suppression procedure was used; suppression of barpressing for sucrose reinforcement served to index the strength of conditioned fear. All rats were shaped to barpress for sucrose on Days 1 through 4. Day 1 was magazine training. On Days 2, इ, and 4 each response produced a 4-sec presentation of sucrose, and each session ended after the rat had received 90 presentations. On Days 5 through 10, responding was reinforced on a VI 2-min schedule, and each session was $30 \mathrm{~min}$ in duration.

Phase 1: At the start of Phase 1 the rats were assigned to 


\section{TABLE 1 \\ Experimental Procedure For Experiment 1}

\section{Shaping and VI Phase 1 Phase 2}

$\begin{array}{ccccc}\frac{\text { Groups }}{P C-N} & \frac{\text { Day 1 } 4}{\text { CRF }} & \frac{\text { Day } 5-10}{\text { VI-2 }} & \frac{\text { Day 11-27 }}{\text { CS-US }} & \frac{\text { Day 28-36 }}{\text { VI-2 }} \\ \text { PC-S } & \text { CRF } & \text { VI-2 } & \text { CS-US } & \text { VI -2 } \\ C-S & \text { CRF } & \text { VI -2 } & \text { CS } & \text { CS-US }\end{array}$

Phase 3

$\begin{array}{cc}\frac{\text { Groups }}{\mathrm{PC}-\mathrm{N}} & \frac{\text { Day } 37-41}{\mathrm{CS}-} \\ \mathrm{PC}-\mathrm{S} & \mathrm{CS}- \\ \mathrm{C}-\mathrm{S}-\mathrm{N} & \mathrm{CS}- \\ \mathrm{C}-\mathrm{S}-\mathrm{S} & \mathrm{CS}-\end{array}$


three groups matched for weight and baseline response rates. For Groups PC $-\mathrm{N} \quad(n=8)$ and PC $-S \quad(n=7)$ the next 16 days were Pavlovian conditioning days; the rats received four CS-US pairings each day while barpressing on a VI-2 min schedule. For both groups a 105-sec light CS terminated with the onset of a $1-\sec 1-m A$ electric footshock US. The session length was $30 \mathrm{~min}$ with the first trial occurring $4 \mathrm{~min}$ into the session and with additional ITIs of 4, 6 , and $5 \mathrm{~min}$. An IT I is defined here as the time between the US presentation on Trial $N$ and CS onset of Trial $N+1$. The parameters chosen for this experiment were those used to produce the results of the unpublished work shown in Figure 1. A third group, $C-S(n=8)$, received exactly the same procedure described for $\mathrm{PC}-\mathrm{N}$ and $\mathrm{PC}-\mathrm{S}$ except that all USs were omitted. The purpose of this CS-alone group was to serve as a tail flick control during Pavlovian conditioning.

The strategy for drug administration was to give Group $\mathrm{PC}-\mathrm{N}$ an $8 \mathrm{mg} / \mathrm{kg}$ ip injection of naloxone hydrochloride immediately before the start of the first session that was preceded by a session demonstrating a WSD. Group $P C-S$ was injected ip with an equal volume of saline immediately before the start of the session on the same day. The groups continued to receive their respective drug treatment immediately before each session for the remainder of the Pavlovian conditioning days. Thus, the appearance of the first WSD in Group PC-N marked the beginning of drug administration for all groups. Group $\mathrm{C}-\mathrm{S}$, which received 
CS-alone trials during this phase of the experiment, was injected with saline for the first 7 days of this phase, followed by 3 days of naloxone treatment and 3 more days of saline injections. This procedure served to determine if naloxone had any effect on baseline response rates in the absence of shock.

The tail flick tests were conducted for all groups on odd numbered days throughout all phases of the experiment. All tests occurred (with the rats restrained) just before drug administration and immediately following the end of a session. In each such test each rat received three tail flick trials with an interval between trials of approximately 1 min. Disring the intertrial interval the rat remained in the plastic restrainers.

Phase 2: Following the last day of Pavlovian conditioning, Groups $\mathrm{PC}-\mathrm{N}$ and $\mathrm{PC}-\mathrm{S}$ received 8 days of VI training. The pur cose of this procedure was to allow for recovery of baseline rates in Group $P C-N$, which showed severely depressed baselines during acquisition. Daily sessions were $30 \mathrm{~min}$ in duration, and barpressing was reinforced on a VI-2 schedule with no CS or US presentations. Eoth groups continued receiving drug injections during this training. During this phase, the third group, $C-S$, received Pavlovian conditioning trials. All rats in this group received saline injections prior to the start of each session. The CS and ITIs were the same as described for Groups PC $-\mathrm{N}$ and PC-S. Since Group C-S had previously received 64 CS-alone trials, a latent inhibition effect, that is, slower acquisition 
of suppression by Group C-S relative to Groups PC-N and PC $-S$ (Lubow \& Moore, 1959) was expected. One reason for giving Group $C-S$ conditioning trials at this point was to determine whether CS-preexposure would have an effect on the magnitude of WSDs.

Phase 3. After 8 days of VI recovery for Groups PC $-\mathrm{N}$ and PC-S and 8 days of Pavlovian conditioning for Group C-S, all groups underwent 5 days of extinction to the CS. Extinction trials consisted of four CSpresentations without USs during daily 30-min sessions. CS length and inter-CS intervals were the same as in the Pavlovian conditioning trials. During this extinction phase, Groups $P C-N$ and $P C-S$ continued to receive injections of naloxone and saline respectively. Drug treatment was continued to prevent possible generalization decrements due to drug-dependent learning effects (Overton, 1967). Group C-S was divided into two subgroups of four rats each, Subgroups $C_{-S}-S$ and $C-S-N$. Subgroup $C-S-N$ received naloxone injections during extinction, and Subgroup $C_{-} S-S$ was treated with saline during extinction. Group C-S was divided into subgroups in order to see if naloxone had any direct effect on already established conditioned fear. If endogenous analgesics directly enhance fear, then Group $\mathrm{C}-\mathrm{S}-\mathrm{N}$ should show greater resistance to extinction or greater suppression during extinction trials than should Group C-S $-S$. All injections consisted of $8 \mathrm{mg} / \mathrm{kg}$ of naloxone or an equivalent volume of saline.

Measures. Suppression to the CS was indexed in terms of the 
Annau-Kamin suppression ratio and the"corrected" ratio described earlier. The pre-cs rates were al so examined. Furthermore, suppression during a 1 -min period following the US was also investigated and was expressed using both Annau-Kamin and "corrected" suppression ratios. If naloxone has an effect on the aversiveness of USs, then this effect might be reflected in the response rates that occur immediately after US presentation.

\section{$\underline{\text { Results }}$}

On the last day of VI training, Groups $P C-N, P C-S$, and $C-S$ showed similar rates of barpressing; their mean rates were 13.7 , 13.9, and 13.3 responses per minute respectively. These rates did not differ significantly $[\underline{F}(2,20)<1]$.

\section{CS Suppression}

Light acquisition: Days 1-3 (Before Drug Treatment)

In Figure 4 the trial-by-trial acquisition of conditioned suppression to the Iight CS is presented for the first 8 days of conditioning for Groups $P C-N$ and $P C-S$. A rat from Group PC $-N$ was dropped from all analyses because it failed to barpress trroughout acquisition and extinction phases of the experiment. The acquisition data are plotted in terms of the corrected suppression ratio to eliminate any WSDs artifactually resulting 
Figure 4. Trial-by-trial plot of the corrected suppression ratios for the first 8 days of acquisition. The circled points indicate significant differences from Trial 1 within each day. The arrow marks the beginning of drug treatment. 


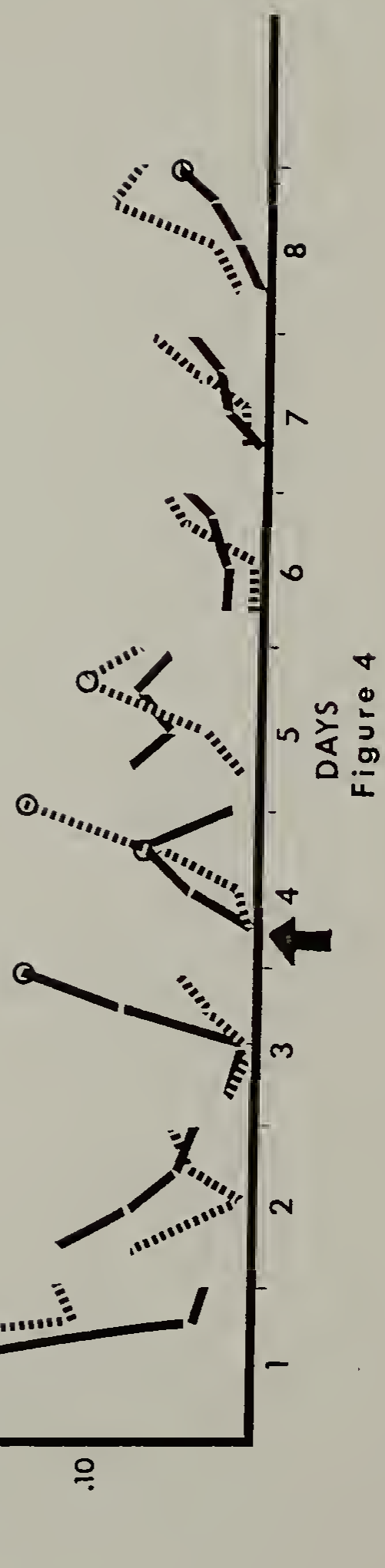


from falling pre-CS rates. Suppression to the CS was rapidly acquired in Groups $\mathrm{PC}-\mathrm{N}$ and $\mathrm{PC}-\mathrm{S}$, wi th mean ratios of .08 and .05 respectively on Day 2, and .06 and .02 respectively, on Day 3 . An analysis of variance (ANOVA) on the first 3 days yielded a significant Groups by Days interaction $[\underline{F}(2,24)=3.52, p=.05]$. This interaction reflected somewhat more suppression in Group PC $-N$ than in Group PC $-S$ on Day $1[\underline{t}(24)=2.00, p=.05]$. However, the two groups did not differ on Day $2,[\underline{t}(24)=1.1, p>.05]$ or on Day 3, $[\underline{t}(24)=1 \cdot 13, \underline{p}>\cdot 05]$.

Individual t-tests using the mean square error term from the analysis of variance were used to seek evidence for WSDs during the first 3 days of conditioning. Figure 3 shows a significant WSD in Group PC-N on Day 3. Suppression decreased from .01 on Trial 1 of Day 3 to. 16 on Trial 4 of Day 3. . Group PC-S, however, did not show a WSD on this day with suppression ratios of .08 and .05 on Trial 1 and Trial 4 respectively. Drug treatment began on the following day. All rats were injected with naloxone or saline immediately before the start of the session on Day 4 through Day 16. Group $\mathrm{PC}-\mathrm{N}$ received $8 \mathrm{mg} / \mathrm{kg}$ of naloxone, and Group $\mathrm{PC}-\mathrm{S}$ received an equal volume of saline injections.

Daring the first 3 days of Pavlovian conditioning, the pre-CS rates oropped in both groups. For Group PC-N a mean pre-CS rate of 12.4 resps/2 min on Day $1 \mathrm{fell}$ to 4.8 resps $/ 2 \mathrm{~min}$ on Day 3. Group PC -S had a rate of 11.8 resps/2 min on Day 1 and 
5.3 resps/2 min on Day 3. This decrease in pre-CS responding was statistically significant, $[\underline{F}(2,24)=11.02, \underline{p}<.01 \mathrm{j}$. However, the two groups did not differ in pre-cs rates as indicated by a nonsignificant Groups $x$ Days interaction, $[\underline{F}(2,24)<1]$.

Group C-S received 64 trials of CS-alone exposures during the 16 days when Groups PC $-\mathrm{N}$ and PC-S were given CS-US pairings. The CS-alone sessions were immediately followed by 8 days of CS-US pairings. An AlNOVA with all three groups for the first 3 days of acquisition was calculated. Only the first 3 days were used in the computations since Group $\mathrm{PC}-\mathrm{N}$ begen receiving naloxone injections on Day 4. The analysis yielded a significant Groups $x$ Days interaction $[\underline{F}(4,36)=3.06, \underline{p}<.05]$ indicating different rates of acquisition between groups. Fur ther group comparisons showed that Groups C-S suppressed less than PC $-\mathrm{N}$ on Days 1, 2, and $3(\mathrm{ps}<.05)$ and less than Group PC-S on Day 1 , $\underline{p}<.05$. These effects, shown in Figure 5, suggest that the CS-alone preexposure given to Group C-S prior to CS-US pairings produced a latent inhibition effect. Figure 5 also shows a significant WSD in Group $\mathrm{C}-\mathrm{S}$ on Day 3 of acquisition. Thus, the appearance of a WSD was not prevented by a latent inhibition effect. Al though a trend for WSDs was observed on subsequent days for Group $C-S$, none of the se trends approached statistical significance.

Light acquisition: Days 4 to 16 (Drug Days)

A Group $x$ Drug Days $x$ Trials ANOVA on Groups PC $-N$ and PC $-S$ 
Figure 5. Trial-by trial plot of the mean corrected suppression ratios for Groups $P C-N, P C-S$, and $C-S$ for the first 3 days of acquisition (non drug days). 


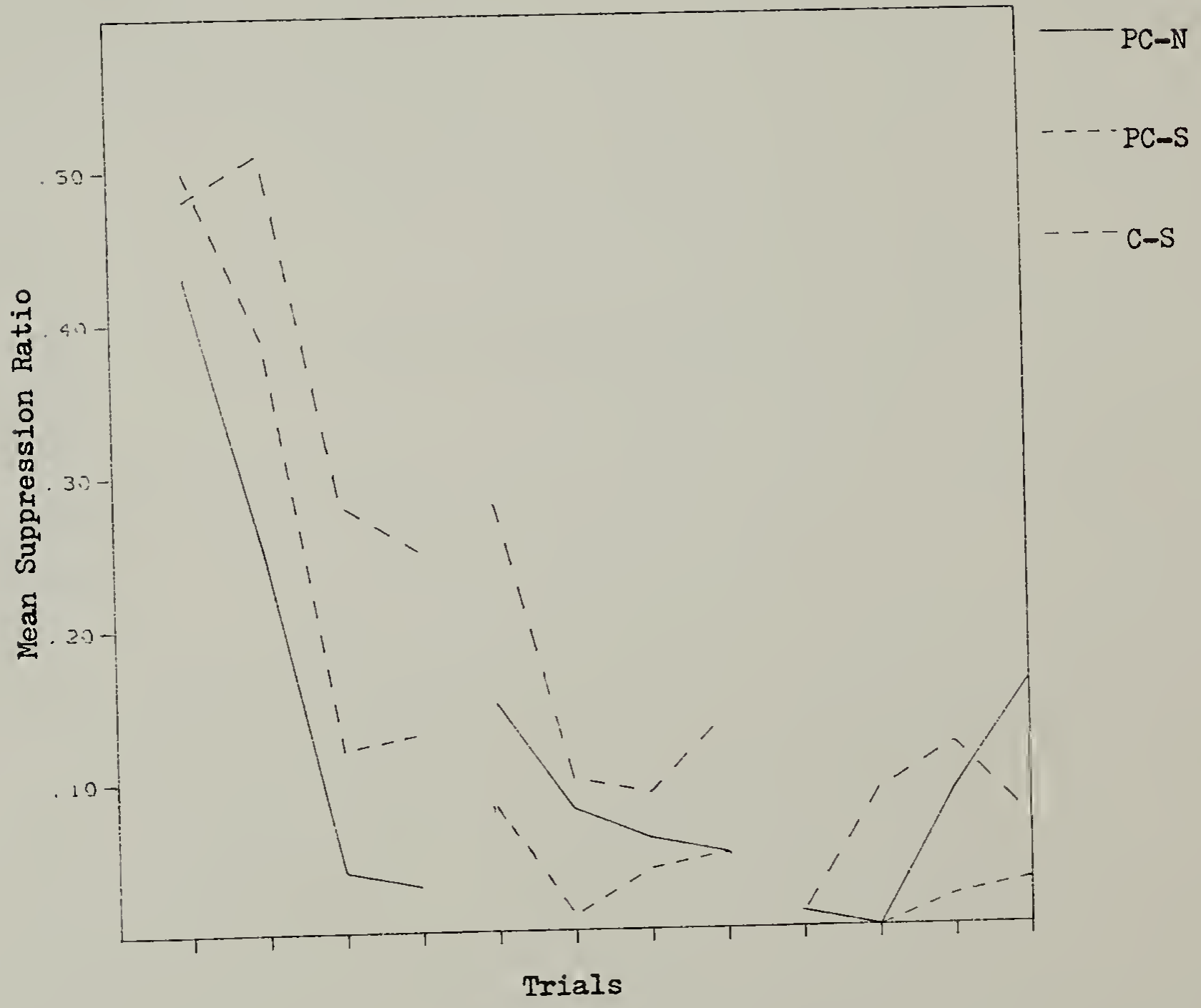

Figure 5 
revealed significant effects due to Groups, $[F(1,20)=5.12, p<.05]$ and the interaction of Groups with $\operatorname{Da} y \mathbf{s}[\underline{F}(12,144)=2.11, \underline{p}<.05]$ but no main effect of Days $[F<1]$. The interaction can be seen in Figure 6, which plots the mean suppression ratios per day for both groups. Asymptotic conditioned suppression was approached in Group PC $-N$ by Day $S \quad(M=.01)$, and suppression remained at this approximate value throughout acquisition. Group PC-S, however, showed decreasing suppression from Day $9(M=.05)$ to Day 16 $(M=.11)$ with the least amount of suppression on Day $13(M=.14)$. This observed postasymptotic decrement (PAD) in Group PC-S resulted in significant differences between Groups PC $-\mathrm{S}$ and $\mathrm{PC}-\mathrm{N}$ on Days 12, 13, 14, and 16 (t $s<.05)$. The groups did not differ on any other drug days. A Days $x$ Trials ANOVA on the last 9 days for Group PC-S alone further substantiates this PAD. A significant main effect of Days $\left[\underline{F}(7,42)=2.82, p^{<} .05\right]$ reflected the decline of suppression across the 9 days for this group.

A main effect of Trials, $[\underline{F}(3,36)=4.05, p<.05]$, and a nonsignificant Groups $x$ Trials interaction $[\underline{F}(3,36)=1.14, \underline{p}>$ $.05]$, suggests that WSDs occurred in both groups. Individual t-tests using the mean square error term from the ANOVA on drug days only were used to search further for WSDs. As can be seen in Figure 3, WSDs occurred in Group PC-S for the first time on Day 4 and again on Day $5, \mathrm{p}<.05$. However, al though a trend for WSDs was seen on subsequent days of saline treatment, a significant WSD was observed only on Day 12 (not shown). WSDs 
Figure 6. Daily mean corrected suppression ratios for Groups $P C-N$ and $P C-S$ during the acquisition phase of the experiment. The arrow marks the beginning of drug treatment. 
53

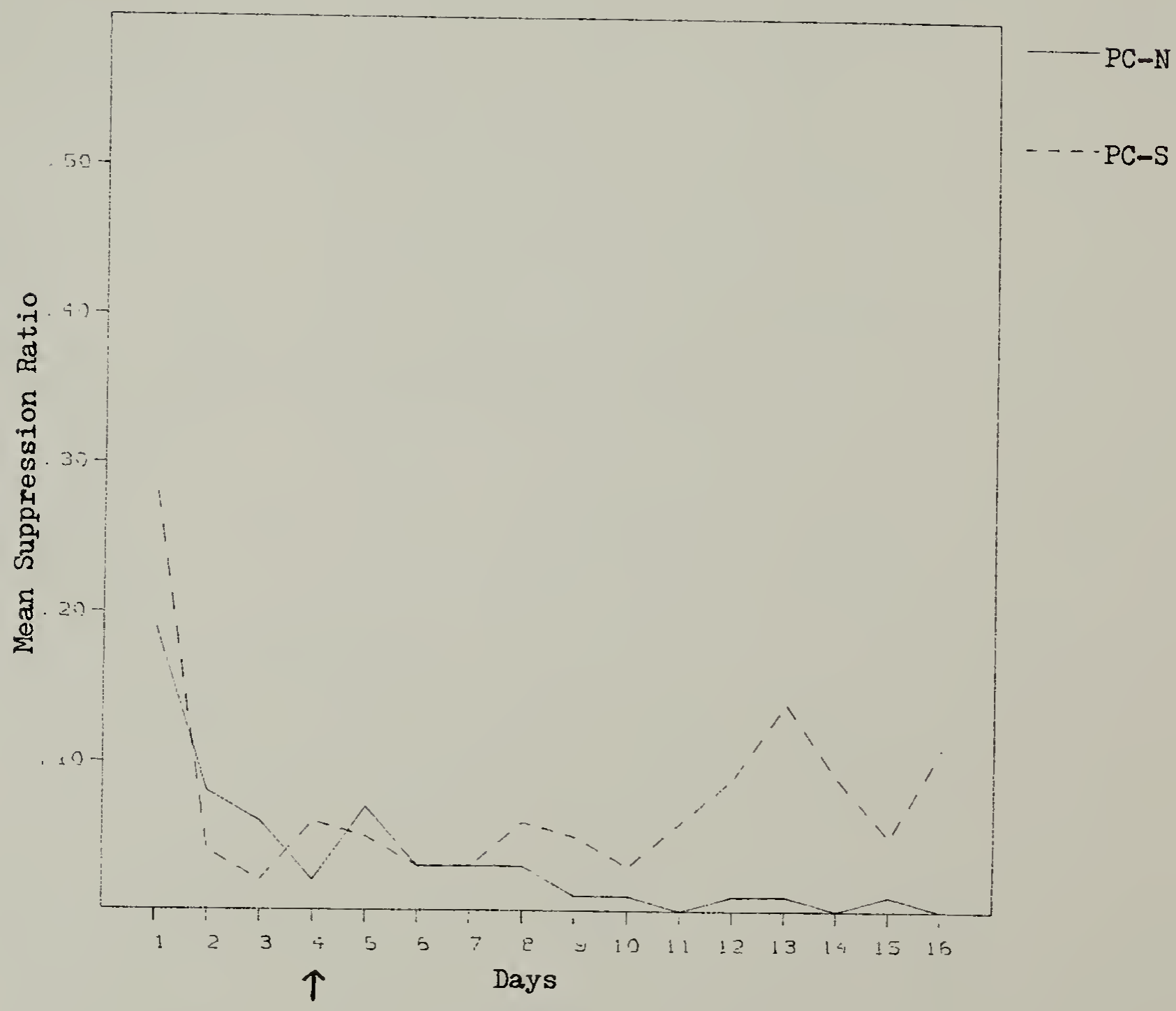

Figure 6 
were observed in Group PC $-\mathrm{N}$ on Day 4 and Day 8 only. A slight trend for WSDs was al so evident on most other days in this group. As mentioned earlier Group C-S also showed a trend for WSDs during Days 4-8 of acquisition.

Figure 7 presents daily pre-CS rates during drug days only (Days 4-16). Group PC-S showed relatively depressed baseline rates during the first few days of drug conditioning sessions ( Nean of first 4 days=7.6), but with subsequent drug conditioning sessions a gradual recovery of pre-CS rates occurred. Group PC $-\mathrm{N}$, however, showed severely depressed baseline rates during all conditioning sessions with a mean on the first 4 days of 2.2 resps/2 min to less than 1 resp/2 min on the last several days. This observation was confirmed by a significant Groups $x$ Dr us Days interaction $[\underline{F}(12,144)=5.91, \underline{p<.01] . ~ P a i r w i ~ s e ~ c o m p a r i s o n s ~}$ further indicated that the two groups' daily pre-cs rates differed significantly on Day $8, p<.05$ and on Days 9 through 16. ps $<.001$. Group comparisons on Days 4 through 7 did not reach statistical significance, ps $>.05$.

Easeline Recovery. Baseline response rates in Group $\mathrm{PC}-\mathrm{N}$ increased during the recovery period. On the last day of recovery the mean rate was $13.1 \mathrm{resps} / 2 \mathrm{~min}$. This increase was statistically significant $[\underline{t}(6)=4.69, \underline{p}<.01]$. Group PC $-S$ was barpressing at a high rate on the last day of acquisition ( $M=$ 28. 1 resps $/ 2$ mins). This rate increased to 48.9 resps.'2min by the last day of recovery $[\underline{t}(6)=3.39, p=.01]$. Group C-S was not 
Figure 7. Daily pre-CS rates during drug days of acquisition only. 


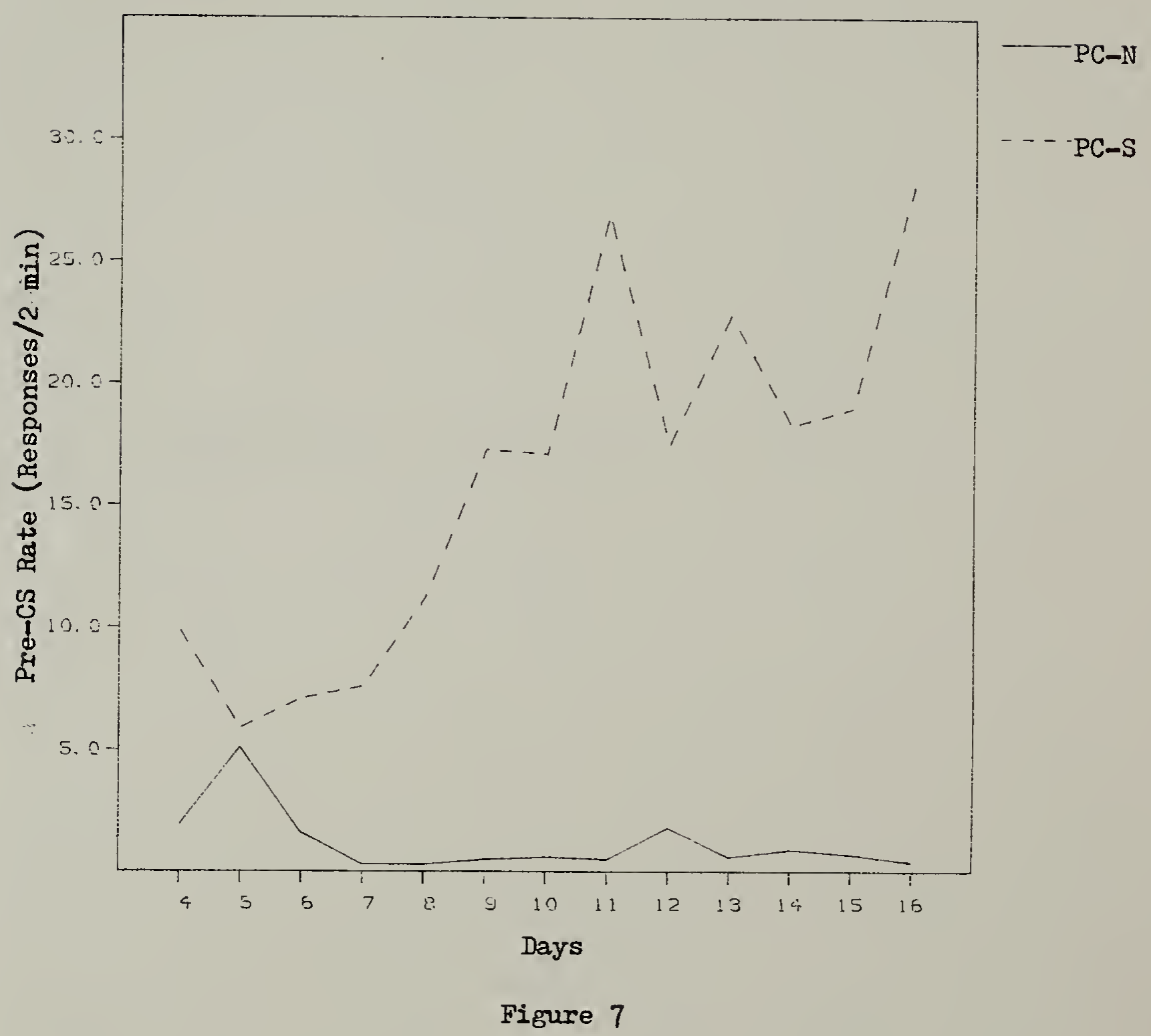


given any recovery session between acquisition and extinction stages of the experiment.

\section{Extinction.}

The left hand panel of Figure 8 presents the extinction data for Groups $\mathrm{PC}-\mathrm{N}$ and $\mathrm{PC}-\mathrm{S}$ plotted in terms of the normal suppression ratio. The predicted main effect of Groups $[F(1,12)$ $=$ 19.3, $\mathrm{p}<.001]$ was observed: Group $\mathrm{PC}-\mathrm{N}$ showed greater suppression to the CS than did Group PC-S throughout extinction. On Day 1 of extinction Group $\mathrm{PC}-\mathrm{N}$ had a mean suppression ratio of .02 , as against. 21 for Group PC-S. Both groups suppressed significantly less with repeated extinction sessions $[\mathrm{F}(4,48)=$ 15.85, $\mathrm{p}<.0013$, reflecting the extinction of conditioned suppression. A nonsignificant Groups $X$ Days interaction is consistent with the impression that both groups extinquished at the same rate.

Figure 9 presents the daily pre-cS rates during extinction for Groups $\mathrm{PC}-\mathrm{N}$ and $\mathrm{PC}-\mathrm{S}$. The pre-CS rate for Group $\mathrm{PC}-\mathrm{N}$ remained fairly constant throughout extinction at approximately $11.5 \mathrm{resps} / 2 \mathrm{~min}$. This baseline response rate is considerably higher than the baseline response rate observed during acquisition. However, Grours $P C-N^{\prime}$ s baseline responding during extinction was still depressed when compared to that of Group PC-S. The latter group's mean pre-CS rate during extinction was 45.5 resps/2 min, four times greater than that observed in Group $P C-N$. An ANOVA on the se extinction data indicated a significant 
Figure 8. Daily mean normal suppression ratios during extinction for Groups $P C-N$ and $P C-S$ (left panel) and for Groups C-S-S and C-S-N (right panel). 


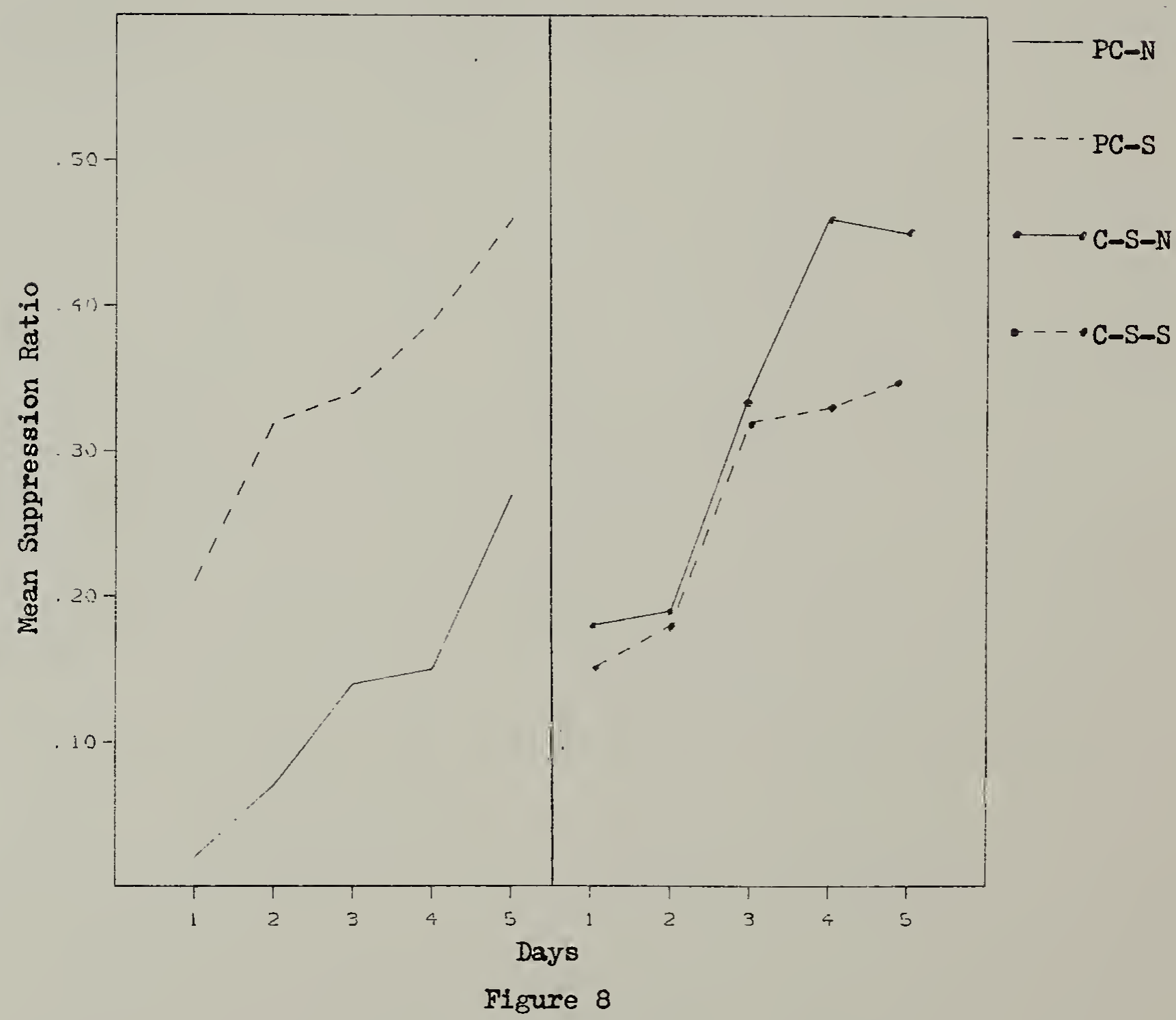


Figure 9. Daily mean number of responses per 2 min pre-CS period during extinction for Groups $\mathrm{PC}-\mathrm{N}$ and $\mathrm{PC}-\mathrm{S}$. 
61

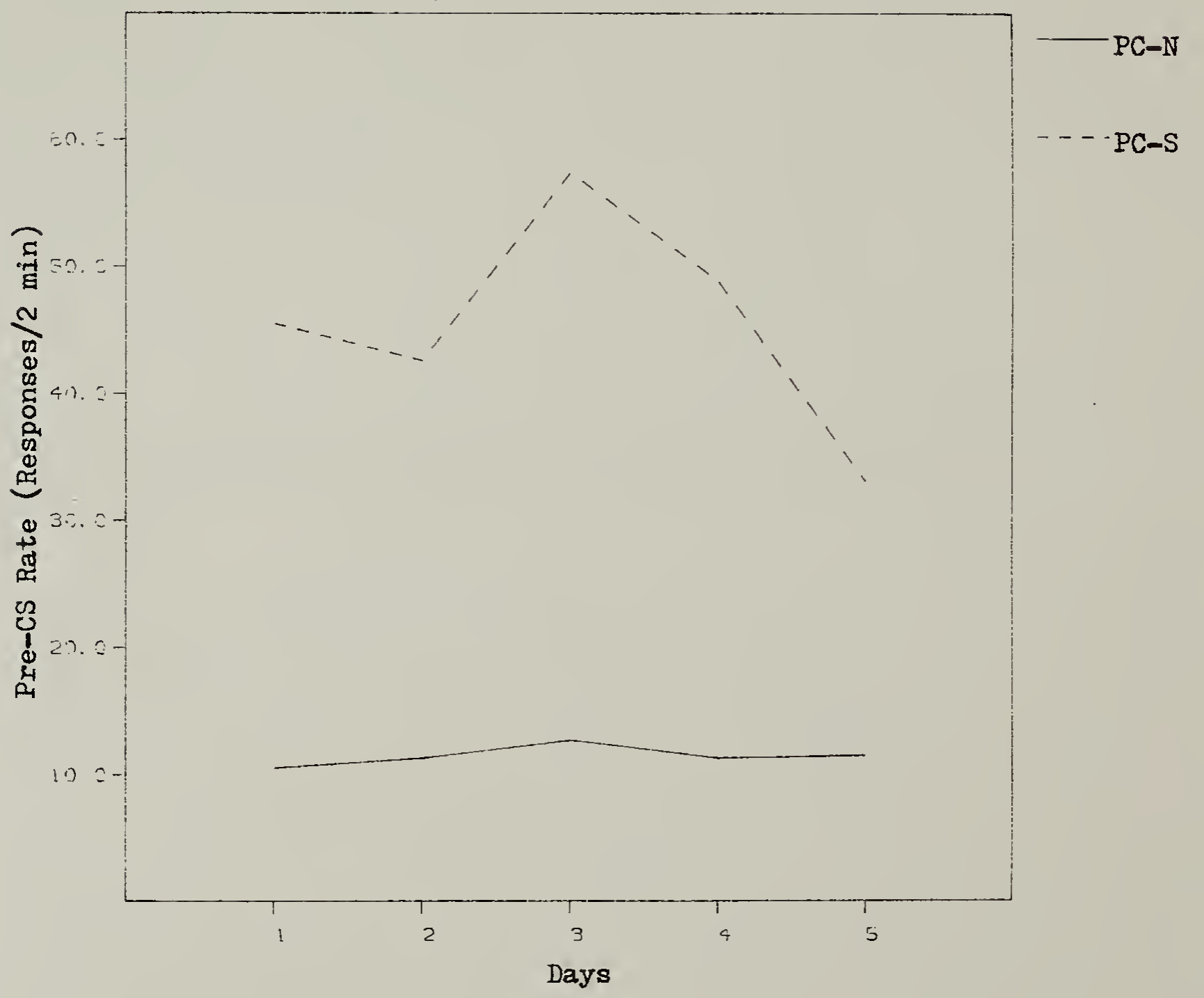

Figure 9 
main effect of $\operatorname{Groups}[\underline{F}(1,12)=12.28, \underline{p}<.005]$. A significant Groups $x$ Days interaction $[\underline{F}(4,48)=4.03, \underline{p}=.007]$ was also obtained. This interaction was mainly a result of between-session variability in Group PC-S and stable between-session baseline responding in Group PC-N. For example, the pre-CS rate for Group PC-S was 57.4 on Day 3 and 33.1 on Day 5. a difference of $22.4 \mathrm{resps} / 2 \mathrm{~min}$.

The extinction data for Groups $\mathrm{C}-\mathrm{S}-\mathrm{S}$ and $\mathrm{C}-\mathrm{S}-\mathrm{N}$ are presented in the right hand panel of Figure 8. Both groups suppressed less to the CS with repeated CS-alone presentations, $[\underline{F}(4,24)=$ 19.58, $\mathrm{p}<.001]$. A nonsignificant main effect of Groups, $F(1,6)$ (1] and a nonsignificant Groups $X$ Days interaction, $[\underline{F}(4,24)=$ 1.22, $p>10$, indicated that the groups did not differ during extinction.

Figure 10 presents the pre-CS rates for Groups C-S-S and $\mathrm{C}-\mathrm{S}-\mathrm{N}$. The figure shows that both groups had a similar baseline response rate on the first day of extinction ( $C-S-S=14.9$ resps/2 $\min ; \quad C-S-N=11.1 \mathrm{resps} / 2 \min )$. With subsequent extinction sessions the pre-CS rate increased in Group $C-S-S$ but remained unchanged in Group $\mathrm{C}-\mathrm{S}-\mathrm{N}$. On Day 5, the last day of extinction, the pre-CS rate for Group $\mathrm{C}-\mathrm{S}-\mathrm{S}$ and $\mathrm{C}-\mathrm{S}-\mathrm{N}$ were 28.8 and $13.6 \mathrm{resp} / 2 \mathrm{~min}$, respectively. Thus, Group C-S $-\mathrm{S}$ showed recovery of baseline responding with repeated extinction sessions, but Group $\mathrm{C}-\mathrm{S}-\mathrm{N}$ failed to show any recovery. An ANOVA on the pre-cS rates revealed a significant Groups $X$ Days 
63

Figure 10. Trial-by-trial mean responses per 2-min pre-CS period during extinction for Groups $\mathrm{C}-\mathrm{S}-\mathrm{N}$ and $\mathrm{C}-\mathrm{S}-\mathrm{S}$. 
64

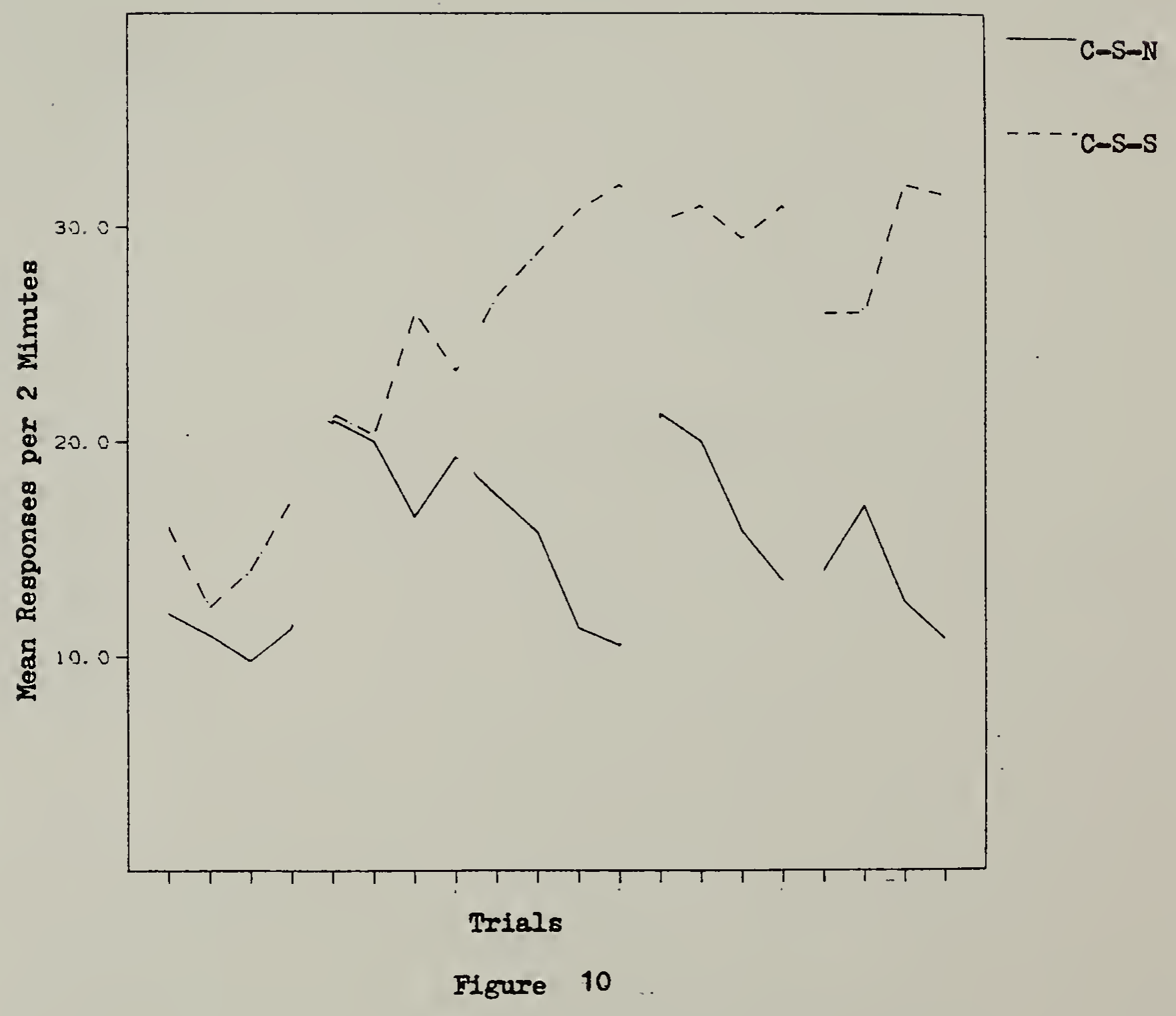


interaction, $\underline{F}(4,24)=5.32, \underline{p}=.003]$, supporting this observation.

\section{Post-US Sippression}

Response rates in the $1-$ min period following shock delivery were first converted to a suppression ratio, $2(\underline{D}) /(\underline{B}+2(\underline{D}))$, where $D$ denotes the number of responses during the 1 -min interval that followed US termination and $\underline{B}$ the number of responses in the 2-min period immediately before CS onset. Figure 11 presents post-US suppression on all days of Phase 1 for Groups PC $-\mathrm{N}$ and PC-S. Each point on the graph represents the mean of four trials. The break in the plot separates the first 3 non-drug days from the remaining 13 drug days. The figure suggests that on the first 3 days, the non-drug days, post-us suppression weakened across days for both groups. However, an ANOVA on the first 3 days alone indicated that this effect did not reach statistical significance $[\underline{F}(2,24)<1$.$] A significant main$ effect of $\operatorname{trials}[\underline{F}(3,36)=13.43, \mathrm{p}<.05]$ revealed that post-US suppression decreased within a session for both groups. When the post-US rates were recomputed into corrected suppression ratios the main effect of trials was not significant $[\underline{F}(3,36)=1.92, \underline{p}>$ -10]. Thus, post-US suppression decreased within a session because of falling pre-cs rates and not because of decreasing suppression following shock USs. 
Figure 11. Mean daily normal post-US suppression ratios during acquisition for Groups $\mathrm{PC}-\mathrm{N}$ and $\mathrm{PC}-\mathrm{S}$. 
67

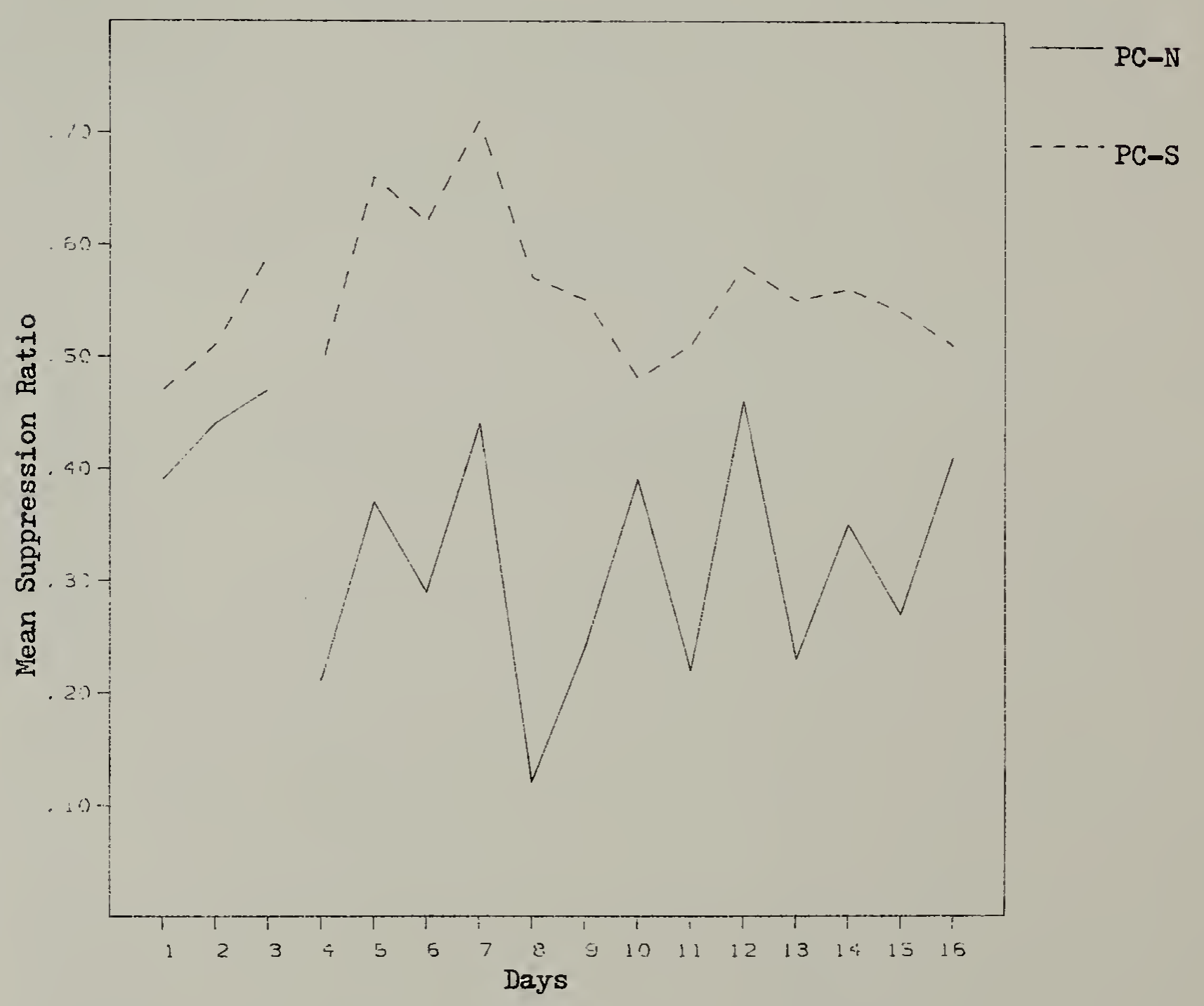

Figure 11 
An inspection of post-US suppression during drug days in Figure 11 shows that Group $P C-N$ suppressed more after US presentation than did Group PC-S during all drug days. An ANOVA on drug-days only yielded a significant main effect of Groups [ $\underline{F}(1,12)=7.14, \underline{p}<.05]$ supporting this observation. A comparison of post-US suppression on the last non-drug Pavlovian conditioning day (Day 3) and the first drug Pavlovian conditioning day ( $\mathrm{Day} 4$ ) for Group $\mathrm{PC}-\mathrm{N}$ indicates that naloxone administration increased the degree of suppression following a US, $[\underline{t}(6)=3.11, \underline{p}<.05]$. For Group PC-S, however, post-US suppression was similar on Day 3 and Day 4, [ㅌ⑹<1]. During drug days, Group PC $-N$ continued to show post-US suppression greater than that observed on the last day of Paviovian conditioning with no drug ( $\mathrm{Day} 3$ ), despite the fact that the magnitude of suppression fluctuated widely from day to day. In contrast, for Group PC-S, no daily mean post-US suppression ratio was ever lower than .49; in fact the daily mean ratios reached a high of .72 on Day 7 before eventually stabilizing at approximately .55 for the last 6 days. Thus, Group PC-S showed a small acceleration of barpressing following us presentation, whereas Group PC $-\mathrm{N}$ showed increased suppression of barpressing following US presentation.

\section{Tail Flick Latencies}

Figure 12 preserits the mean tail flick latencies per session 
Figure 12. Mean tail flick latencies per session during the acquisition phase of the experiment. 


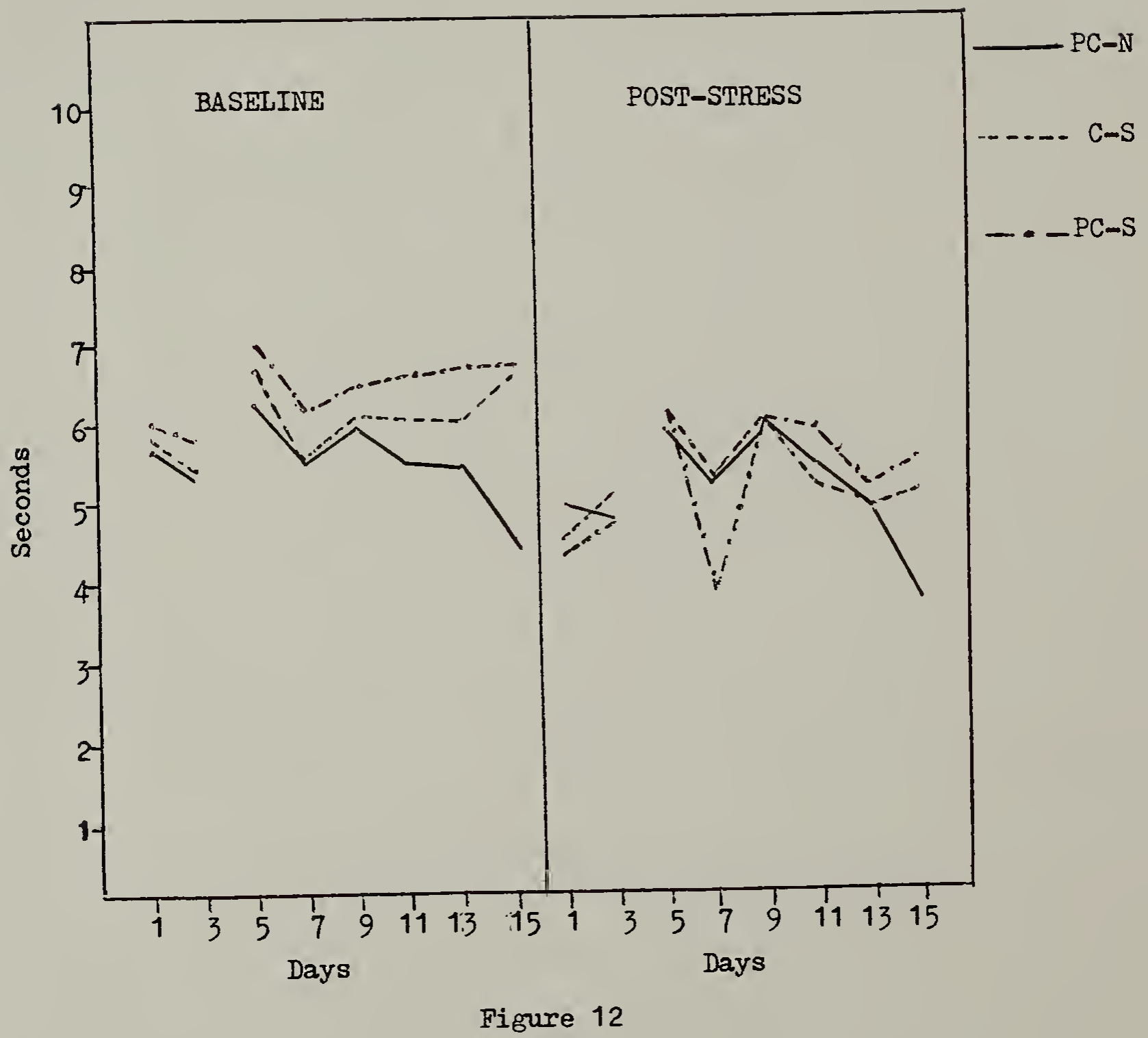


during Phase 1. The latency measures just before the start of a Pavlovian conditioning session (baseline) are on the left side of the figure: tail flick latencies after a Pavlovian conditioning session (post-stress) are plotted on the right side of the figure. Non-drug days (Days 1 and 3) are separated from drug days (Days 4-15) by a gap in each section of the figure. An ANOVA on the first 2 days yielded a significant Days $x$ Test Trial interaction $[\underline{F}(1,19)=8.85] \underline{p}<.05]$ and a marginally significant Groups $x$ Test Trial interaction $[\underline{F}(2,19)=3.60, \underline{p}=.05]$. No other interactions or main effects proved significant. The Days $x$ Test Trial interaction reflected the greater decrease in tail flick latencies following Pavlovian conditioning trials on Day 1 compared to Day 2. On Day 1 the mean baseline tail flick latency was 5.9 and post-stress latency was 4.7. Mean baseline latency on Day 2 was 5.6 and post-stress 1 atency was 5.1 . The Group $x$ Test Trial interaction was a result of a greater decrease in tail flick latencies from baseline following Pavlovian conditioning sessions for Group PC-S than for Groups $\mathrm{PC}-\mathrm{N}$ and $\mathrm{C}-\mathrm{S}$.

Table 2 lists the tail flick latencies for drug days during acquisition. A $3 \times 5 \times 2$ ANOVA $(3$ Groups $X 5$ Days $X 2$ Test Trials) yielded a significant Groups X Test Trials interaction $[\underline{F}(2,19)=5.89, \quad \underline{p}<.05]$. This interaction reflected greater decreases in tail flick latencies from baseline tests to post-stress tests in Group PC-S than for Groups $\mathrm{PC}-\mathrm{N}$ and $\mathrm{C}-\mathrm{S}$. 


\section{TABLE II}

Tail flick latencies for baseline and post-stress tests during Phase 1 of Experiment 1

\begin{tabular}{|c|c|c|}
\hline & Ba seline & Post-stress \\
\hline $\begin{array}{r}5 \quad C-S \\
P C-S \\
P C-N\end{array}$ & $\begin{array}{l}6.16 \pm .69 \\
7.04 \pm 1.34 \\
6.68 \pm 1.00\end{array}$ & $\begin{array}{l}5.84 \pm .95 \\
6.12 \pm .96 \\
6.03 \pm .76\end{array}$ \\
\hline $\begin{array}{r}C-S \\
7 \quad P C-S \\
P C-N\end{array}$ & $\begin{array}{l}5.51 \pm .81 \\
6.11 \pm .54 \\
5.51 \pm .21\end{array}$ & $\begin{array}{l}5.16 \pm .46 * \\
3.96 \pm .50 \\
5.41 \pm .38 *\end{array}$ \\
\hline $\begin{array}{r}\mathrm{C}-\mathrm{S} \\
9 \mathrm{PC}-\mathrm{S} \\
\mathrm{PC}-\mathrm{N}\end{array}$ & $\begin{array}{l}6.00 \pm .84 \\
6.43 \pm .81 \\
5.85 \pm .66\end{array}$ & $\begin{array}{l}5.90 \pm .97 \\
5.98 \pm 1.04 \\
5.75 \pm .32\end{array}$ \\
\hline $\begin{array}{r}C-S \\
11 P C-S \\
P C-N\end{array}$ & $\begin{array}{l}5.91 \pm .74 \\
6.31 \pm .60 \\
5.35 \pm .25\end{array}$ & $\begin{array}{l}5.24 \pm .45 \\
5.87 \pm 1.07 \\
5.40 \pm .19\end{array}$ \\
\hline $\begin{array}{r}C-S \\
P C-S \\
P C-N\end{array}$ & $\begin{array}{l}5.83 \pm .64 \\
6.47 \pm .76 \\
5.30 \pm .28\end{array}$ & $\begin{array}{l}5.02 \pm .21 \\
5.17 \pm .48 \\
4.94 \pm .38\end{array}$ \\
\hline $\begin{array}{r}C-S \\
P C-S \\
P C-N\end{array}$ & $\begin{array}{l}6.30 \pm 1.23 \\
6.46 \pm .78 \\
4.38 \pm .60 * 0\end{array}$ & $\begin{array}{l}5.03 \pm .81 \\
5.41 \pm .81 \\
3.73 \pm .23 * 0\end{array}$ \\
\hline
\end{tabular}

* statistically significant from PC-S ( $<<.05)$

- statistically significant from C-S $\left(p^{<.05)}\right.$ 
This decrease in tail flick 1 atencies in Group PC-S is directly opposite the expected result. The activation of an endorphinergic system should increase latencies from baseline to post-stress tests. However, this effect may be a result of a Type I error since a large drop in tail flick latencies from baseline to post-stress tests occurred on Day 7 whereas on all other days this difference was much smaller. A Groups X Days X Test $\operatorname{Tr}$ ials interaction $[\underline{F}(10,95)=2.31, \underline{p}<.05]$ was al so observed. This interaction can be described as follows. Tail flick latencies during baseline tests decreased over days in Group $\mathrm{PC}-\mathrm{N}$ but not in Groups $\mathrm{PC}-\mathrm{S}$ and $\mathrm{C}-\mathrm{S}$. Group $\mathrm{PC}-\mathrm{N}$ differed significantly from PC-S on Days 11, 13, and 15 and from Group C-S on Day 15 (all ps<.05). This reduction of tail flick 1 atencies al so occurred during post-stress tests for Group PC-N. However, this group had lower tail flick latencies than Groups PC-S and C-S only on Day 15 (ps<.05). This was 1 argely due to the greater drop in latencies from baseline to post-stress tests in Group $\mathrm{PC}-\mathrm{S}$ than in $\mathrm{PC}-\mathrm{N}$.

\section{Discussion}

If naloxone antagonizes an endorphinergic system that normally renders shock USs later in training less aversive than the initial US presentations early in training, then one would 
expect animals treated with naloxone to experience a more aversive US throughout training than animals treated with saline. Thus, rats treated with naloxone should show more conditioned suppression during acquisition and extinction, fewer WSDs and 2 weaker PAD than should rats treated with saline. Nalox one rats should also show more suppression to contextual cues (i.e., reduced baseline responding) and more post-US suppression.

The following evidence suggests that naloxone did indeed act to increase US aversiveness.

1)Increased CS suppression during acquisition in naloxone-treated rats. Group $\mathrm{PC}-\mathrm{N}$ showed greater suppression during the CS than did Group PC-S for all drug-treatment days during acquisition. This is especially evident during the last few days of acquisition where a PAD was observed in Group PC-S but not in Group PC $-\mathrm{N}$.

The PAD could reflect long-term CS habituation or long-term US habituation. The present result favors the latter interpretation. Thus, the PAD may be due to the activation of an endorphinergic system with prolonged training. An increase in endorphin activity may render the US less aversive (and therefore less effective) and thereby produce decrements in the $C R$. Blocking this opiate system with an antagonist such as naloxone prevents the PAD by maintaining US aversiveness. If the PAD were due to CS habituation, then one would not expect differences between Groups $P C-N$ and $P C-S$ since they each experienced the same 
number of exposures to the CS and since there is no reason to believe that naloxone would alter the salience or effectiveness of a nonaversive event such as a light CS.

2) Increased post-US suppression during acquisition in naloxone-treated rats. Group $\mathrm{PC}-\mathrm{N}$ yielded greater post-shock suppression than did Group PC-S. Post-shock suppression has been extensively studied in our laboratory. We repeatedly find that post-US suppression declines over the course of conditioned suppression training (Ayres \& Vigorito, note 2). One interpretation of this result is that it reflects the decline of US effectiveness over the course of conditioning. The fact that naloxone prevented this decline in post-US suppression suggests that the US maintained its original aversiveness in Group $P C-N$ but not in Group PC $-S$.

3) Severely depressed baseline rates in naloxone treated rats. Group $P C-N$ showed severely depressed baseline response rates during conditioning. In the early trials of conditioned suppression training one typically finds suppression to the CS as well as depressed baseline response rates. This depressed rate of responding is thought to reflect conditioning of fear to static background cues (e.g., Dweck \& Wagner, 1970). With subsequent trials, however, the baseline responding is observed to increase, reflecting extinction of fear to the background cues while conditioning to the $\mathrm{CS}$ is maintained (Odling-Smee, 1975). The amount of conditioning to the background cues can be 
monipulated in several ways, one of which is by increasing the intensity of the shock US (Annau \& Kamin, 1961). The depressed baseline response rate in Group $\mathrm{PC}-\mathrm{N}$ suggests that naloxone increased the aversiveness of the shock USs presumably by blocking an endorphinergic system. It is possible, however, that this observed depression in baseline responding may be a direct effect of naloxone on the response rate for sucrose reinforcement. Thus, it may not reflect an al tered aversiveness of the US. Let us turn to some evidence on this point.

During Phase 1 Group C-S was injected with saline for the first 7 days followed by 3 days of $8 \mathrm{mg} / \mathrm{kg}$ of naloxone treatment. This procedure was instituted to see if naloxone had any effect on baseline response rates in the absence of shock. The mean response rate for the last 3 days of saline treatment and the mean of the 3 days of naloxone treatment was 28.9 and 24.3 resps/2 min, respectively. Al though a paired t-test indicated that this difference approached statistical significance $[\underline{t}(7)=2.35, \underline{p}=.05]$, this difference of only $4.6 \mathrm{resps} / \mathrm{min}$ between naloxone and saline conditions in the absence of any shock is a very small one, particularly in comparison to the differences obtained when shock was present (see Figure 7). Thus, it appears that naloxone had only a small effect on baseline responding in the absence of shock. Moreover, the fact that Group $\mathrm{PC}-\mathrm{N}$ showed significant recovery of baseline responding during the recovery sessions even though naloxone was 
still being administered, suggests that the severely depressed baseline rates were not completely due to an effect of naloxone on responding for sucrose reinforcement.

4) Enhanced suppression during extinction in naloxone-treated rats. The extinction data showed more suppression in Group $\mathrm{PC}-\mathrm{N}$ than in Group PC-S. The baseline response rates during extinction were considerably higher than the baseline response rates during acquisition. This again confirms that the depressed baseline rates during acquisition were not all due to naloxone's effect on responding for sucrose. Nevertheless, the response rate for Group $\mathrm{PC}-\mathrm{N}$ remained significantly lower than that for Group PC-S.

Conditioned suppression of responding is influenced by the baseline response rates. For example, animals with higher baseline rates tend to show more conditioned suppression than do animals with low baseline response rates (Blackman, 1968). Thus, if the low response rate in Group $\mathrm{PC}-\mathrm{N}$ confounded the extinction data, then the confound should have produced less suppression in Group PC-N than in Group PC-S. This clearly was not the case.

Naloxone did not eliminate WSDs. Eoth Groups $P C-N$ and $P C-S$ showed a trend for WSDs on most of the Pavlovian conditioning days. However, significant WSDs were observed on Day 4, 5, and 12 for Group PC-S and on Days 4 and 8 for Group PC-N. It is not clear why so few significant WSDs were observed at least in Group $P C \rightarrow S$. The parameters used in this experiment were the same as 
those of a previous experiment that produced many WSDs (see Figure 1).

WSDs may not reflect the increase within a session of endorphins, and hence, are not affected by naloxone. It is plausible that WSDs are a result of short-term CS habituation. Al ternatively, short-term US-habituation effects that are not mediated via an endorphin system may be involved. Indeed, there are now many reports of stress-induced analgesia that is not naloxone reversible (e.g., Chance \& Rosecrans, 1979). The idea that two functionally distinct analgesic mechanisms are activated by different temporal aspects of the same stressor is intriguing and warrants further study (cf. Lewis, Cannon, \& Liebeskind, 1580).

If, as suggested here, WSDs and PADs are a result of antinociception, then the appearance of nonmonotonicities in the acquisition of conditioned suppression should be correlated with the observation of increased tail flick latencies in Group PC-S. Experiment 1 failed to find any changes in tail flick latencies in Group PC-S or PC $-\mathrm{N}$ consistent with this view. There are several possible reasons why increased nociception in Group PC $-S$ was not observed. If one compares the studies reporting stress-induced analgesia, as measured by the tail flick procedure, with the present experiment, one finds that these other studies usually used much more intense shocks and that the number of shocks given to the animals were many magnitudes 
greater than the four USs per session given here. Perhaps the tail flick procedure is not sensitive enough to detect small increases in nociception that may occur in a mildly stressful situation. It is clear that as little as one shock US can trigger the endorphinergic system (Fanselow \& Bolles, 1979b), but many USs per session may be necessary to detect increased nociception with the techniques presently available.

An alternative explanation is that the failure to detect hypoalgesia was a result of "nociceptive learning". Nociceptive learning refers to a phenomenon in which, spon reexposure to a painful stimulus such as heat to the paws from a hot plate, the animal shows an accelerated response to the source. That is, when an animal is repeatedly exposed to a painful source used to detect analgesia, the animal learns to respond to the source of the pain by decreasing its latency to respond. Since the rats in the present experiment were repeatedly exposed to the tail flick test, nociceptive learning may have masked any increase in hypoalgesia. Moreover, it has also been shown that naloxone treatment can facilitate nociceptive learning (Ramabadran, Gillon, and Jacob, 1979). Indeed Group PC $-\mathrm{N}$ had significantly lower tail flick latencies on the last 3 baseline test days than did Group PC-S. This facilitation of nociceptive learning by naloxone is consistent with the hypothesis that naloxone causes hyperalgesia. Presumably, Group PC $-N$ showed greater nociceptive learning than Groups PC-S and $C-S$ because the radiant heat sorce 
projected on the tail was more painful for Group PC-N than for the rats given saline.

Finally, this experiment also showed that when naloxone is given only during extinction, it does not enhance suppression. This result suggests that naloxone does not affect fear directly and thus fails to support the antianxiety hypothesis (Grevert \& Goldstein, 1977). In order for naloxone to increase conditioned suppression the drug must be administered during acquisition when the shock USs are given. 
There was some indication in Experiment 1 that naloxone reduced baseline responding for sucrose. Many papers have reported that nalox one reduces food, water, and sucrose intake in many species. Naloxone decreases food intake in food deprived rats (e.g., Holtzman, 1979) and in nondeprived rats (e.g., Brands, Thornkill, Hirst, \& Gawdy, 1979). Naloxone al so reduces food intake that is stimulated by $\mathrm{L}$-ala-met-enkephal in (Baile, Keim, Della-Fera, \& Mclaughlin, 1981). Naloxone appears to affect water consumption more than food consumption (Holtzman, 1979). Water intake is reduced by naloxone in squirrel monkeys (Erown \& holtzman, 1981) and in water deprived and nondeprived rats and mice (e.g., Stapleton, Ostrowski, Merriman, Lind and Reid, 1975; Carey, Ross, \& Enns, 1981). Intake of 10\% sucrose is also reduced by this drug in deprived as well as nondeprived rats (e.g., Stapleton et al, 1975; Ostroviski, Foley, Lind, \& Reid, 1980). This reduction is weak but reliable at doses as low as $.065 \mathrm{mg} / \mathrm{kg}$ ip but is very 1 arge with doses of $1-20 \mathrm{mg} / \mathrm{kg}$ (W., Lind, Stapleton, \& Reid, 1981).

It has been suggested that naloxone reduces food'solution intake by producing malaise (Foster, Morrison, Dean, Hill, \& Frenk, 1981) or by producing a conditioned taste aversion (e.g., Stolerman, Pilsher, \& D'Mellow, 1978). However, Ostrowski et al 
(1980) have demonstrated that naloxone's ability to establish conditioned taste aversion does not covary with its ability to suppress sucrose intake. Belluzzi and Stein (1977) suggested that the endorphins may be neurotransmitters of reinforcement associated with drive reduction: naloxone may affect food/solution intake by causing drive reduction. That naloxone's effect of depressing intake is stereospecific clearly suggests that the opiate receptors are the site of action. However, the finding that naloxone decreases drinking in animals with open gastric fistulas (Rockwood, Siviy, \& Reid, 1981) and decreases drinking when drive reduction is not a factor (i.e., in nondeprived animals) argues against a drive reduction view and suggests that some other central regulatory process may be involved.

Al though the evidence that naloxone decreases intake is strong, the appetitive task in Experiment 1 differs from the tasks used in the above mentioned studies in several important ways. First, all of the studies examining the effects of naloxone on intake used animals that were allowed free consumption. That is, the animals were allowed to ingest freely as much as possible of a fixed amount of food or solution during a restricted period of time. In Experiment 1 the rats were required to barpress on a VI 2-min schedule for sucrose; thus the availability of sucrose was dependent on a schedule of reinforcement. Responding for sucrose on a schedule may 
attenuate naloxone's effect of reducing sucrose intake. Al though Gillert and Sparber (1977) reported that naloxone depressed responding for food in rats on an FR schedule, Young (1980) found no effect of naloxone with a dose as high as $10 \mathrm{mg} / \mathrm{kg}$ in rats responding for food on a VI 1 min schedule. No studies that I am aware of have examined the effects of naloxone on operant responding for sucrose. Second, in the above cited studies the animals were either not deprived at all or were always deprived of the same food or solution whose intake was being measured. In Experiment 1 the rats were deprived of food but not water, and they responded for sucrose (sugar-water) reinforcement. Third, since the rats were on a VI 2-min schedule during a 30-min daily session, each rat could never satiate itself. In the aforementioned studies the subjects were allowed 15 to $240 \mathrm{~min}$ of continuous exposure to the food or solution, thus allowing sufficient time for satiation. If naloxone has its effect by lowering a satiation threshold, then the small amount of sucrose consumed on a VI 2-min schedule may not show this effect.

Because of these procedural differences between Experiment 1 and other studies examining the effects of naloxone on intake, it is not clear how large an effect naloxone had on barpressing in Experiment 1. Thus, Experiment $2 a$ investigated the effects of $4 \mathrm{mg} / \mathrm{kg}$ and $8 \mathrm{mg} / \mathrm{kg}$ of naloxone on operant responding for sucrose solution. 


\section{Me thod}

Subjects and Apparatus. Thirty-two Holtzman rats, 120 days old at the start of the experiment, served as subjects. These rats had been used in a previous experiment in which they received 17 unsignal ed 1.0-mA shocks in a shuttlebox. They had also been trained to lick sucrose from a spout in the shuttlebox. Conditioning chambers were used in the present experiments and were identical to those of Experiment 1. In Experiment $2 a$ no cSs or USs were presented.

Procedure. In Experiment $2 a$ all rats were shaped and trained to barpress on a VI 2-min schedule. On the first 4 days the rats were shaped to bar press for a 4-sec presentation of sucrose as in Experiment 1. On Days 4 and 5 responding was reinforced on a VI 1-min schedule. On Day 6 the schedule was increased to VI 2 and so remained throughout the study. Daily sessions were 30 min. Days 6 through 11 were preliminary barpress training days designed to stabilize baseline responding. On Day 12 the rats were divided into two groups $(n=16)$ matched roughly for response rate and body weight. Group $\mathrm{Naloxone}$ received $8 \mathrm{mg} / \mathrm{kg}$ injections of naloxone just before the start of the session on Days 12, 13 , 
and 14. Group Saline received an equivalent volume of saline on the same days. No drugs were administered on the next 2 days. On these days the rats were given the usual 30-min session of barpressing. However, immediately before the start of the session on the following 2 days, Days 17 and 18, Group Naloxone received $4 \mathrm{mg} / \mathrm{kg}$ of naloxone, and Group Saline was administered sal ine.

Results

Figure 13 presents the rate of barpressing during the 7 th through 15th day of the VI 2-min schedule. The figure is divided into four sections by dashed lines. The first section represents the mean responses per minute for Days 7 and 8 combined for Groups Naloxone and Saline. No drugs were given on these 2 days. As can be seen in the figure both groups responded at approximately the same rate, $[\underline{t}(30)<1]$. The next section of the figure represents the response rate for both groups on Days 9, 10, and 11. Group Naloxone received $8 \mathrm{mg} / \mathrm{kg}$ of naloxone on these days, and Group Saline received saline injections. Independent t-tests performed on each day separately indicated that the two groups did not differ significantly on any day, $p$ values for each day are shown in Figure 13. A comparison of Group Naloxone's mean response rate for Days 7 , and 8 combined versus the response rates on Drub Days 9, 10, and 11 
Figure 13. Mean barpress response rates per minute for Group Naloxone and Group Saline during Experiment 2a. 

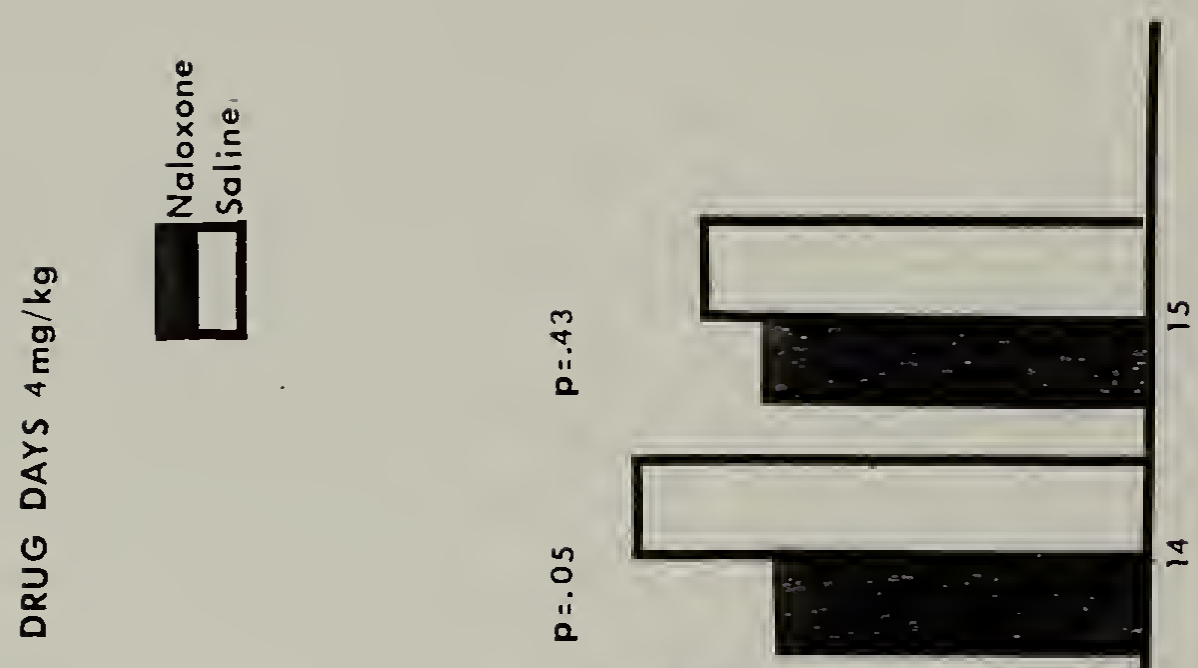

0
2
0
0
Z
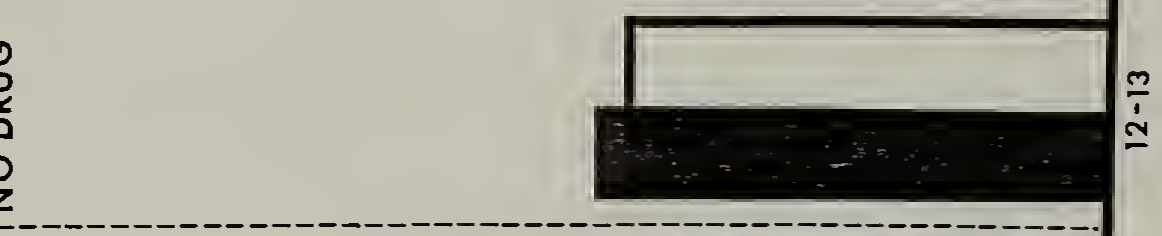

$\frac{m}{0}$
$\frac{0}{2}$
$\frac{1}{0}$
0

$\underset{\infty}{\stackrel{0}{*}}$

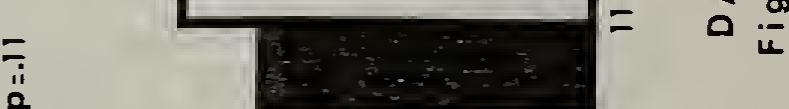

$\frac{1}{2}$

$\stackrel{0}{0}$
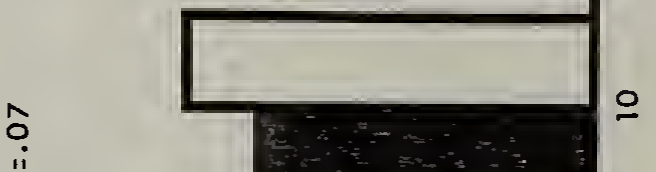

2

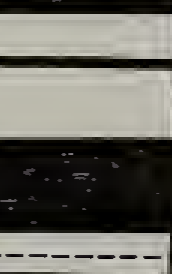

0
2
0
0
$z$

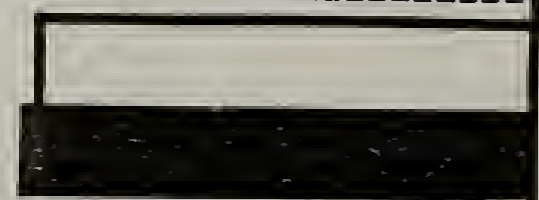

$\stackrel{\infty}{n}$
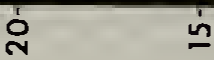

으

ofnu!u dad sassadd dog 
indicates that drug treatment decreased the rate of responding. This rate decreased from a mean of 14.0 resps/min for Days 7 and 8 to 11.1, 8.5, and 8.7 resps/min on Days 9, 10, and 11 respectively. Dependent $\underline{t}$-tests indicated that the drop in responding was significant on Day 10 and 11 , [ps $<.05]$, but not on Day $9 \underline{t}(15)=1.95, p=.07]$. However, Group Sal ine al so showed a drop in response rates during Drug Days from a mean of 13.1 on Day 7 and 8 combined to $12.3,11.6$, and 11.7 resps/min on Day 9 , 10, and 11 respectively. Dependent $\underline{t}$-tests indicated that saline administration decreased responding significantly on all 3 days $[\mathrm{ps}<.05]$. Days 12 and 13 were nondrug days. On both days both groups showed increases in responding to a combined mean of 14.3 resps/min for Group Naloxone and a combined mean of 13. 3 resps/min for Group Saline. These rates do not differ from the rates observed on Days 7 and 8 combined. During the last two drug days, Days 14 and 15, $4 \mathrm{mg} / \mathrm{kg}$ injections of naloxone again decreased the rate of responding to 9.9 and $10.2 \mathrm{resps} / \mathrm{min}$ on Days 14 and 15 respectively. A comparable decrease was not produced by saline. Only on Day 15 was responding significantly lower than on nondrug days in Group Saline (11.9 resps/min), [ $\underline{t}(15)=.60, p<.05]$. Independent $\underline{t}$-tests on each day yielded a marg inally significant difference on Day 14, $[\underline{t}(30)=2.04, p=.05]$, but not on Day 15, $[\underline{t}(30)<1]$. 


\section{Discussion}

Experiment $2 a$ investigated the effect of naloxone on responding on a VI 2-min schedule for sucrose reinforcement. Nalox one decreased the response rate but so did saline. Groups Naloxone and Saline did not differ on any of the days when 8 $\mathrm{mg} / \mathrm{kg}$ of naloxone was administered and differed on only one of the 2 days when $4 \mathrm{mg} / \mathrm{kg}$ naloxone was administered. The effect of saline on operant responding is not totally surprising. There are several reports of saline effects on performance and learning. Gattoni and Izquierdo (1973), for example, found that post-trial injections of saline $(0.9 \% \mathrm{NaCl})$ disrupted performance of rats in a Lashley III maze for food. This effect was attributed to the aversive properties of the injection procedure itself.

In view of the results of Experiment $2 a$ it is unlikely that naloxone's relatively small effect of decreasing baseline responding for sucrose reinforcements confounded the observed effects of naloxone on CS-elicited suppression and baseline suppression in Experiment 1. 


\section{H A P T E R IV}

\section{EXPERIMENT 2B}

In Experiment I naloxone eliminated the PAD but did not eliminate WSDs. Unfortunately, not many WSDs were observed in either group. The purpose of Experiment $2 \mathrm{~b}$ was to try to produce more WSDs by slightly decreasing the shock intensity. A second purpose was to determine whether naloxone has any state-dependent effects on learning. A state-dependent effect of naloxone would manifest itself as a significant decrease in the amount of conditioned suppression from the last day of acquisition to the first day of extinction in rats that received a change in the drug condition, compared to rats that did not undergo a change. Sich a possible state-dependent effect of naloxone was examined using a $2 \times 2$ design in which two groups were treated with the same drug (naloxone or saline) during acquisition and extinction, and the other two groups experienced a change in drug administered during acquisition and extinction. Previous research has failed to find state-dependent effects of naloxone on preference-for-signaled shock (Fanselow \& Bolles, 1979a) or shock-elicited freezing (Fanselow, in press) in rats or eye blink CRs in rabbits (Hernandez \& Powel1, 1980). State-dependent effects of nal ox one on conditioned suppression of barpressing have not been studied. 
Me thod

Subjects and Apparatus. The rats of Experiment 2 a served as subjects. The apparatus and the light CS were unchanged.

Procedure. Experiment $2 \mathrm{~b}$ began immediately after Experiment $2 \mathrm{a}$. On the ist day all rats were allowed one more day of barpressing with no drug administration. On the following day they were divided into four groups, .5-N, .5-S, .8-N, and .8-S (all ns=8). Each group was given 17 daily 30-min Pavlovian conditioning sessions. The proced ure for Pavlovian conditioning was the same as in Experiment 1 (see Figure 3a) except for US intensity. For Groups . 5-N and .5-S the US was a 1-sec, .5-mA shock; for Groups $.8-\mathrm{N}$ and $.8-\mathrm{S}$ the US was a 1-sec, .8-mA shock. Groups .5-N and . 8-N received a $4 \mathrm{mg} / \mathrm{kg}$ injection of $\mathrm{nal}$ ox one immediately before the start of each Pavlovian conditioning session, whereas Groups .5-S and .8-S received an equivalent volume of saline. The groups were matched in terms of rate of responding on the last VI day. Also, each group contained four rats that had received naloxone during Experiment $2 a$ and four that had been treated with saline.

Following the 17 days of Pavlovian conditioning, all four groups were given 2 days of barpress recovery. Recovery, as in 
Experiment 1, consisted of allowing the rats to barpress during a 30-min session on the VI 2-min schedule with no CS or US presentations.

The next 5 days were Pavlovian extinction days. During extinction a two-factor design was used to assess the importance of state-dependent learning. All rats were reassigned to four groups such that the two factors were presence or absence of naloxone during Pavlovian conditioning and presence or absence of naloxone during extinction. Table III shows this design. Thus, half of the rats that received naloxone during Pavlovian conditioning received saline during extinction (Group $\mathrm{N}-\mathrm{S}$ ); the other half continued to receive naloxone (Group $N-N$ ). Of the rats that received saline during Pavlovian conditioning, half received naloxone during extinction (Group $S-N$ ), and the other half received saline (Group $S-S$ ). The groups were al so matched on pre-CS rates during the last recovery day, prior experience with naloxone during Experiment $2 a$ and US intensity during Pavlovian conditioning.

Results and Di scussion

During the acquisition of conditioned suppression no effect of shock intensity was observed; therefore, shock intensity was not included as a factor in the statistical analysis. 


\section{TABLE 3}

\section{Experimental Design for Experiment $2 \mathrm{~b}$ $\mathrm{N}=\mathrm{Nal}$ oxone-treated rats \\ $S=S a l$ ine-treated rats}

\section{EXT INC TION}

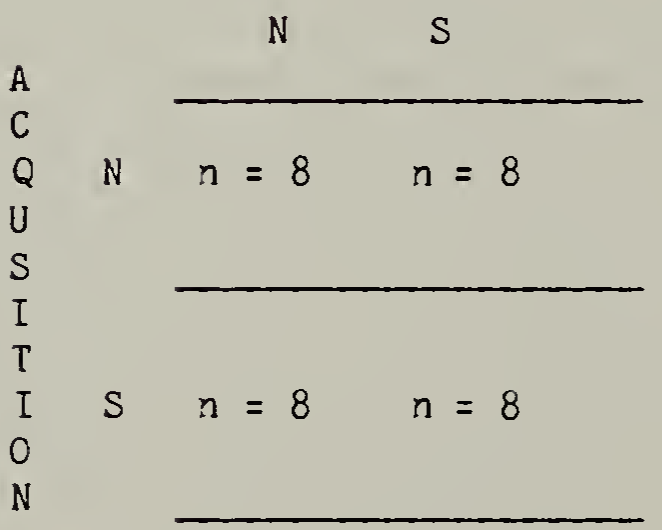


Acquisition. Figure 14 presents the daily mean corrected suppression ratios during acquisition for the groups receiving naloxone or saline. Both groups acquired conditioned suppression $[\underline{F}(15,450)=12.54, \underline{p}<.001]$ and at similar rates $[\underline{F}(15,450)=1.16$, p>. 10]. Why a PAD was not seen in Group Saline is not clear. We have recently observed in our laboratory that PADs are consistently produced with very weak shocks (e.g., 4 mA, .5 sec), but with shocks that are more intense and greater in duration PADs are unreliably produced. It is quite possible that if the present experiment were extended a few days, a PAD might have emerged.

Many more WSDs were observed in this experiment than in Experiment 1. Figure 15 presents a trial-by-trial plot of the corrected suppression ratios for the first 9 days of acquisition. Significant WSDs were observed for Group Saline on Days 3 through 9 and on Days 13 and 14 (all ps<.05). Naloxone did not el iminate WSDs, thus replicating the results of Experiment 1.

Figure 16 presents the pre-cS rates during acquisition. Group Naloxone had lower response rates than Group Saline. This depressed baseline responding was confirmed by a significant main effect of Groups $[\underline{F}(1,30)=8.18, \underline{p}<.01]$. A significant main effect of Days $\left[\underline{F}(15,450)=7.72, R^{4} .001\right]$ but a nonsignificant Days 
Figure 14. Daily mean corrected suppression ratios for groups receiving saline or naloxone during acquisition in Experiment $2 b$. 
96

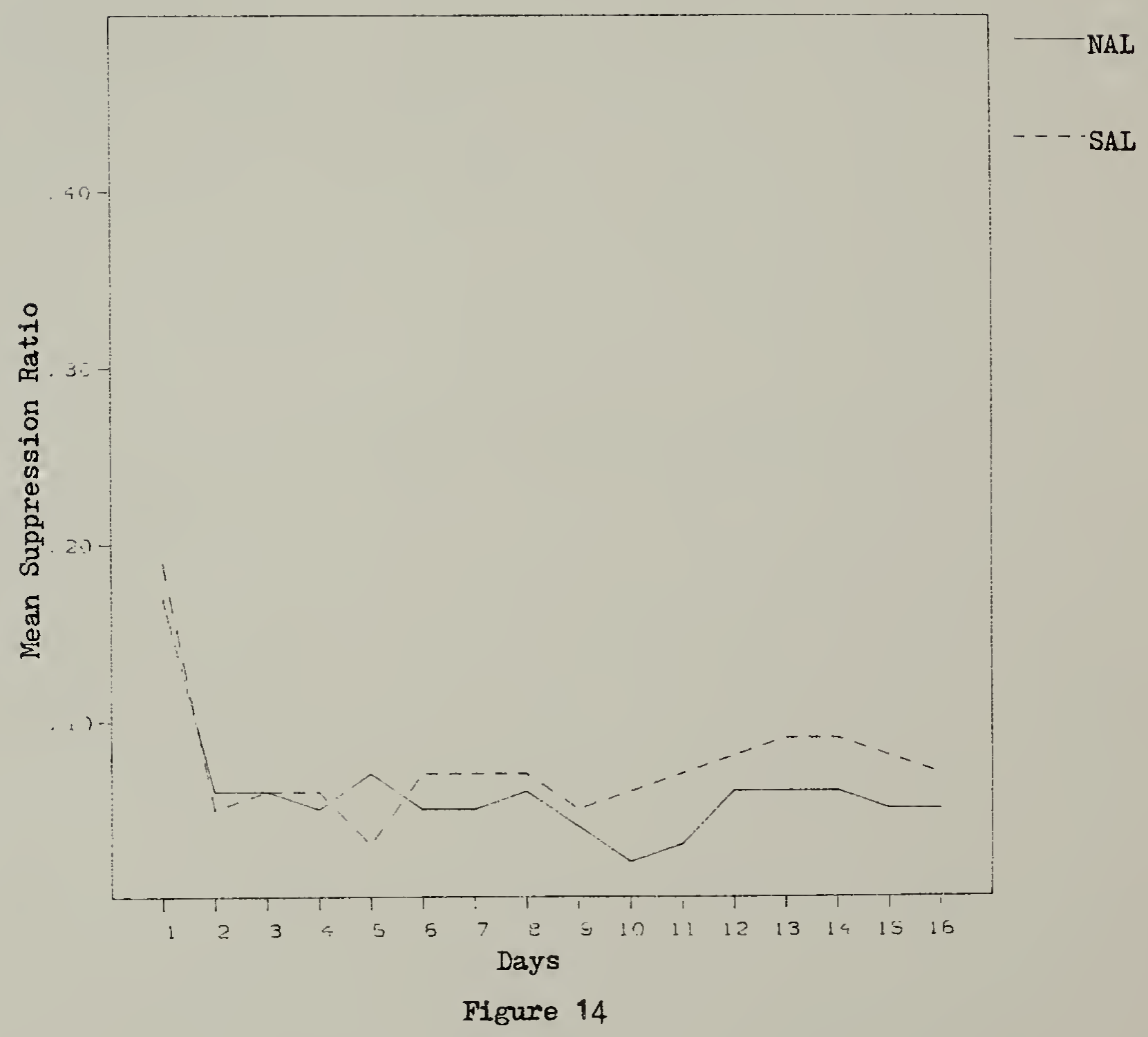


Figure 15. Trial-by-trial plot of corrected suppression ratios for the first 9 days of acquisition in Experiment $2 b$. 

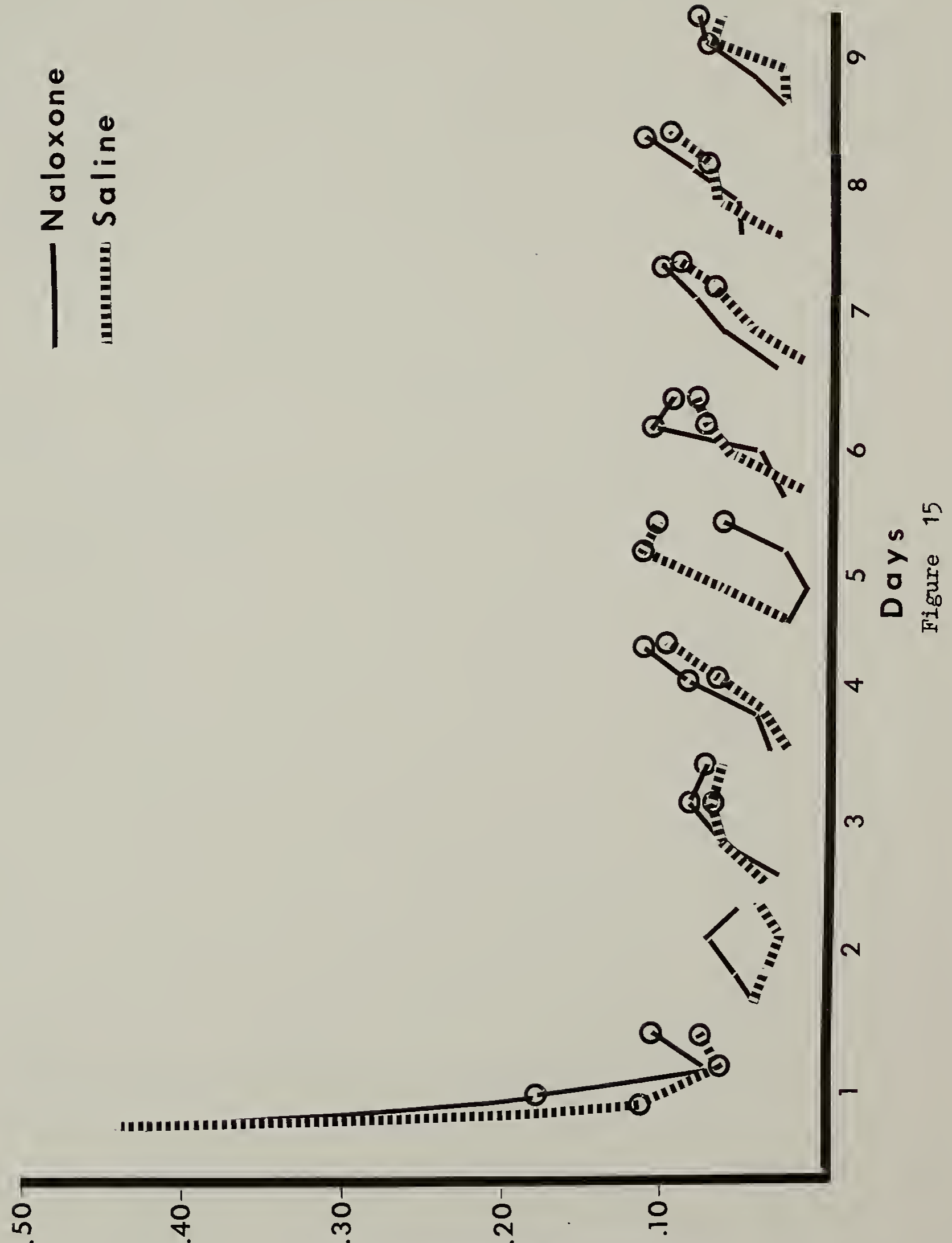

o! f Dy uo!ssalddns udow 
Figure 16. Pre-cS rates during the acquisition phase of Experiment $2 b$. 


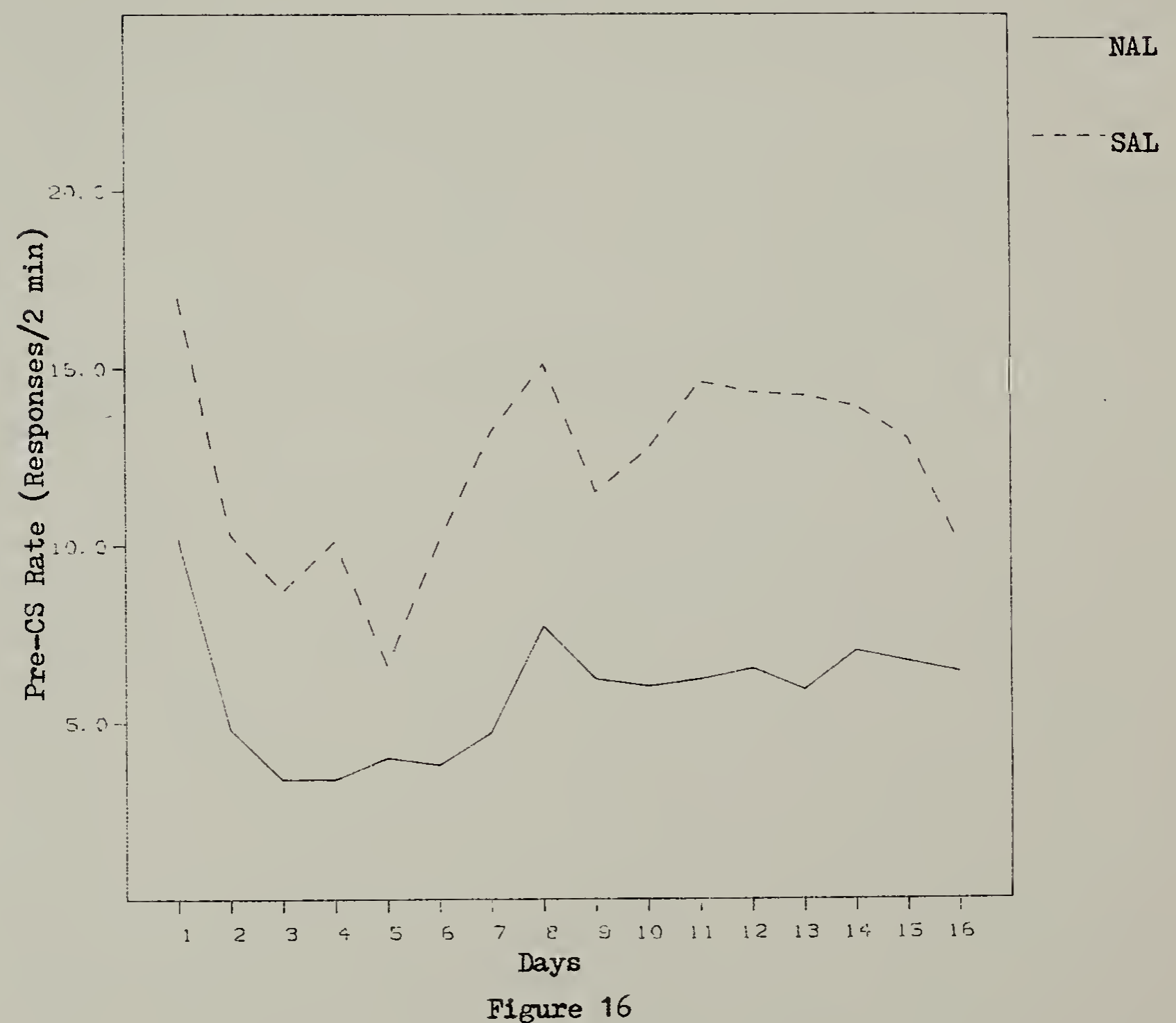


X Group interaction $[\underline{F}(15,450)=1.11, p>.10]$ was al so observed. The pre-CS rates dropped within each session for both groups (not shown) but this drop was greater for Group Saline than for Group Nalox one $[F(45,1350)=7.00, p<.001]$. The falling pre-CS rates did not confound the observed WSDs during acquisition since corrected suppression ratios were used.

\section{Extinction.}

Figure 17 plots the daily mean normal suppression ratio during extinction for the rats receiving naloxone or saline during acquisition. Both groups showed extinction of conditioned suppression to the light CS. Moreover, there was greater suppression in the naloxone treated rats than in the saline treated rats, at 1 east on the first 4 days of extinction. A $2 X$ $2 \times 5 \times 4$ factorial analysis (2 treatments during acquisition $X 2$ treatments during extinction X 5 days $X 4$ trials) performed on the extinction data indicated a main effect of Days $[\underline{F}(4,112)=5.19, \underline{p}<.001]$ and $\operatorname{Tr}$ ials $[\underline{F}(3,84)=14.32, \underline{p}<.001]$, but no interaction between drug treatment during acquisition and Days or Trials (all Fs yielded ps>.10). The expected interaction between Treatment During Acquisition and Days was not significant, but t-tests using the mean square error term from the ANOVA yielded a significant difference between Groups Naloxone and Saline on Day $1[\underline{t}(28)=2.23, \underline{p}<.05]$.

No differences in strength of conditioned suppression between the naloxone- and saline-treated groups were observed 
Figure 17. Daily mean normal suppression ratios during extinction for groups receiving naloxone or saline during acquisition. 


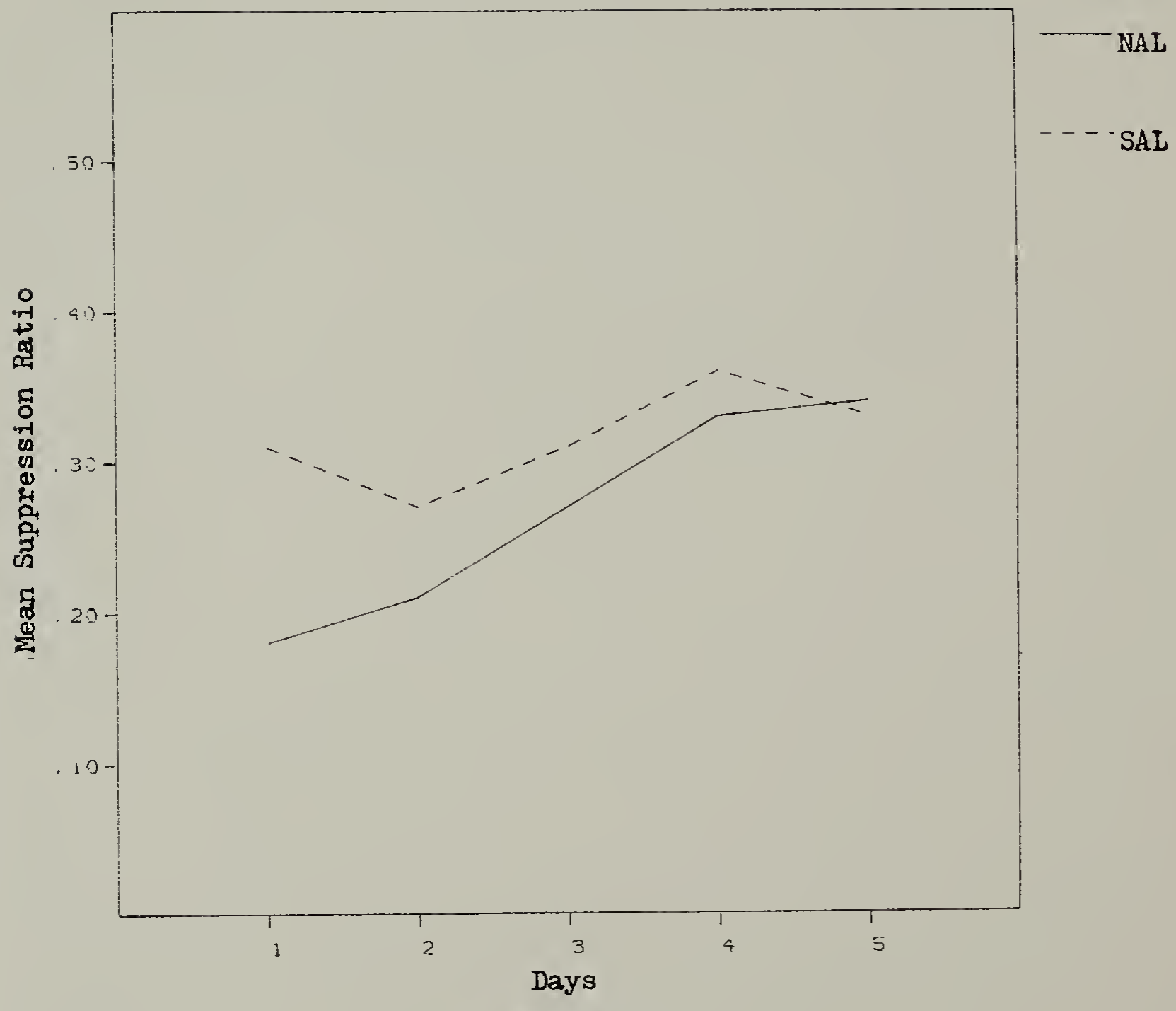

Figure 17 
during acquisition. It is not uncommon in the conditioned suppression procedure to have group or treatment differences masked by a ceiling effect. Typically these differences can be uncovered during extinction (e.g.,Annau \& Kamin , 1961). The present results indicate that al though no effect of naloxone was apparent during acquisition, differences did emerge during extinction. The effect in this experiment was not as 1 arge as that observed in Experiment 1. This is probably due to the lower shock intensities and lower drug dosage in the present experiment compared to Experiment 1.

Figure 18 presents the daily suppression ratios during extinction in terms of what each group received during acquisition and extinction. A $2 \times 2 \times 2 \times 5 \times 4$ ANOVA (2 shock intensities $\times 2$ treatments during acquisition $X 2$ treatments during extinction $\times 5$ days $\times 4$ trials) was performed on the se data. The ANOVA yielded a significant main effect of Days $[F(4,112)=5.19, \quad p<.05]$ and a main effect of Trials $[\underline{F}(3.84)=14.32, \quad p<.01]$ but no interaction between the se two factors and any other factor. Hence, all groups showed extinction of conditioned suppression and they all extinquished at the same rate.

An inspection of Figure 18 indicates that Group $\mathrm{N}-\mathrm{N}$ showed the greatest suppression during extinction compared to the other groups. Individual t-tests comparing Group $\mathrm{N}-\mathrm{N}$ with Group $\mathrm{S}-\mathrm{S}$ on each of the 5 extinction days yielded a significant difference 
105

Figure 18. Daily mean normal suppression ratios during extinction for groups receiving saline or naloxone during acquisition and extinction. 


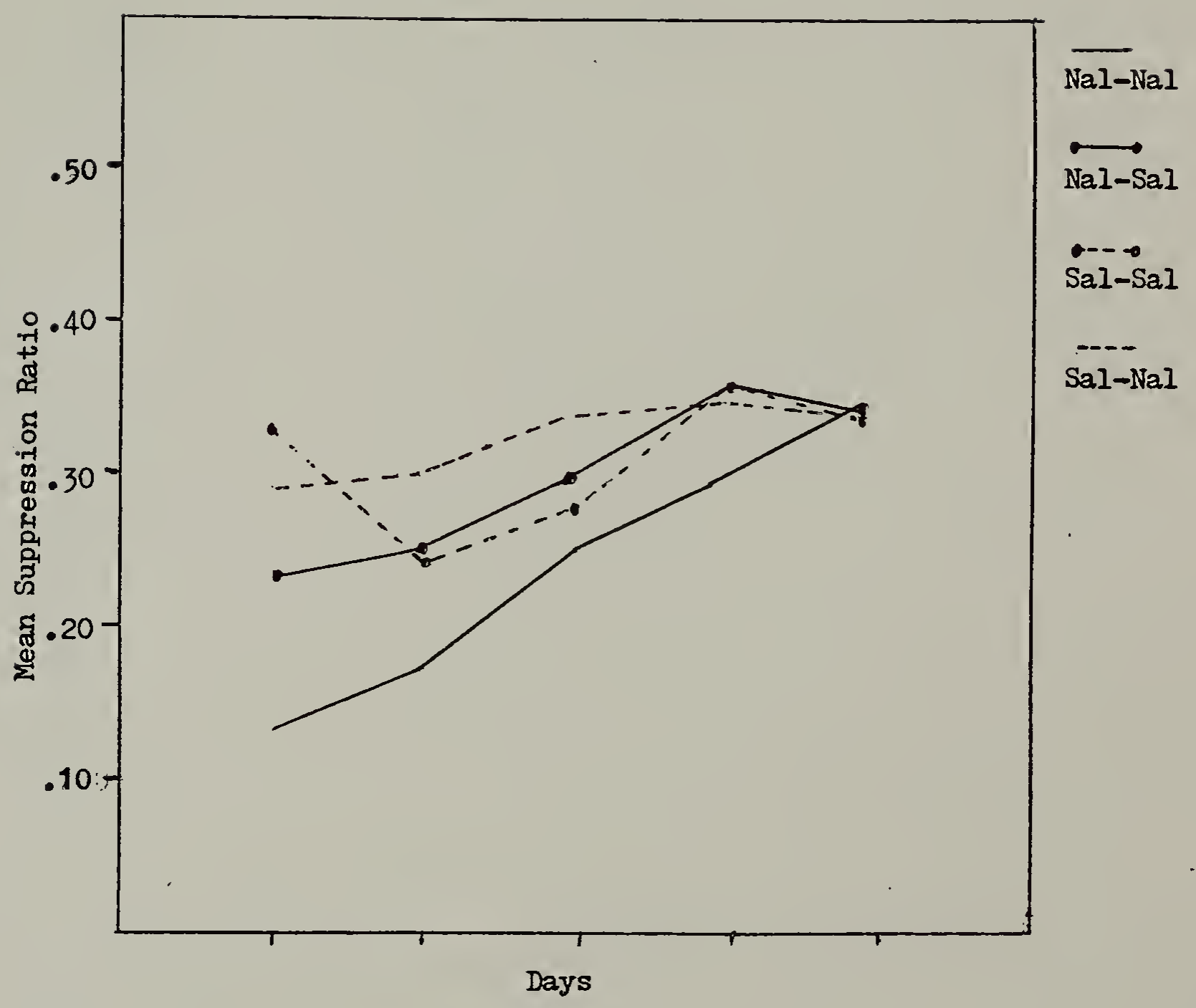

Figure 18 
on Day $1[\mathrm{p}<.05]$. This comparison is exactly that made in Experiment 1 and the result replicates the findings reported in that experiment. Group $\mathrm{N}-\mathrm{N}$ also showed marginally significant greater suppression than Group $S-N$ on Day 1 [.05<p<.07]. All other comparisons were not significant [all ps $>.05]$. Figure 18 al so suggests that switching from naloxone during acquisition to saline during extinction (Group $\mathrm{N}-\mathrm{S}$ ) weakened suppression to the CS during extinction. However, Group N-S did not differ from Group N-N on any day. Group N-S also did not differ from Groups S-S or S-N on any day.

The mean pre-CS rates during extinction for Group $S-S, S-N$, $\mathrm{N}-\mathrm{S}$, and $\mathrm{N}-\mathrm{N}$ were $12.3,15.5,12.8$, and $11.6 \mathrm{resps} / 2 \mathrm{~min}$ respectively. These rates did not differ. 


\section{H A P T E R V}

\section{EXPERIMENT 3}

In Experiment $1,8 \mathrm{mg} / \mathrm{kg}$ of naloxone administered during extinction (Group $\mathrm{C}-\mathrm{S}-\mathrm{N}$ ) did not enhance suppression relative to that seen in a group treated with saline (Group $C-S-S$ ). Since each group consisted of only four rats, I. decided to reexamine this effect with a larger number of subjects per group. To this end, four groups of rats were given conditioned suppression training. During extinction three groups were treated with 4 $\mathrm{mg} / \mathrm{kg}$ of naloxone $(n=10), 8 \mathrm{mg} / \mathrm{kg}$ of naloxone $(n=10)$, or saline $(n=9)$. The four th group was not injected with any drug $(n=9)$.

\section{Me thod}

Subjects and Apparatus. Thirty-nine Holtzman albino rats, approximately 120 days old at the start of the experiment and housed and maintained as before, were used as subjects. These rats had been used in a previous experiment in which they were shaped to barpress for sucrose reinforcement and given 5 days of barpress training on a VI 1-min schedule. After VI training, all the rats received, while blocked from the bar by a false wall, 10 US-alone (shock-alone) presentations and 7 tone-shock pairings. All received extinction to the tone CS before the start of the present experiment. The apparatus in this study was 
that of Experiments 1 and 2 .

Procedure. Immediately after the tone extinction described above was completed, Experiment 3 began. The rats were assigned to four groups, 4-Nal $(n=10), 8-\mathrm{Nal}(n=10)$, No-Drug $(n=9)$, and Saline $(n=10)$. All groups received a 2 -min light CS that coterminated with a 1-sec 1-mA scrambled footshock US. The light CS was a 7.5-W, $110-\mathrm{V}$ ac frosted bulb mounted on the rear wall of the cubicle. This was the same CS used in the previous experiments. The session length was $1,000 \mathrm{sec}$. The light trial could begin in Min 7, 9, or 12 of each session while the rats barpressed for sucrose. There were seven such sessions given one per day.

Next, all rats underwent extinction of suppression to the light CS. During each of seven daily sessions the 2-min Iight occurred as before but wi thout shock. Drug treatment did not begin until Day 4. of extinction. In earlier work I had found that the one-trial-a-day procedure produces a slow rate of extinction. I decided, therefore, that drug administration should begin after several days of extinction when conditioned suppression had become weak enough to yield a group mean suppression ratio of approximately .20. This procedure should have diminished the possibility that any drug effect would be obscired by a ceiling effect during early trials. Beginning on Day 4 and continuing through the remainder of extinction, Group 
4-Nal and $8-\mathrm{Nal}$ recelved $4 \mathrm{mg} / \mathrm{kg}$ and $8 \mathrm{mg} / \mathrm{kg}$ of naloxone, respectively. The drug was injected ip immediately before the start of a session. Group Sal ine received an equivalent volume of saline and Group No-Drug received no injections. Thus, Group No-Drug was treated exactly as on the first 3 days of extinction.

\section{Results and Discussion}

Figure 19 presents the data for Experiment 3. The top panel plots the normal suppression ratio for all four groups during light acquisition. The figure shows that all groups acquired conditioned suppression to the light with repeated daily trials [ $\underline{F}(6.210)=45.00, \quad \mathrm{p}<.001]$. A nonsignificant main effect of Groups and a nonsignificant Groups $x$ Days interaction indicate that the four groups were comparable during light acquisition (before they were treated with the different drugs).

The bottom panel of Figure 19 presents the normal suppression ratios dur ing light extinction. The arrow marks the beginning of drug treatment. A Groups $x$ Days ANOVA on all extinction days was calculated for the se data. A significant main effect of Days $[\underline{F}(6,210)=24.54, p<.001]$ and a nonsignificant Groups $x$ Days interaction $(\underline{F}<1)$ confirmed the 
Figure 19. Mean suppression ratios during acquisition (top panel) and extinction (bottom panel) of Experiment 3. The arrow marks the beginning of drug treatment. 


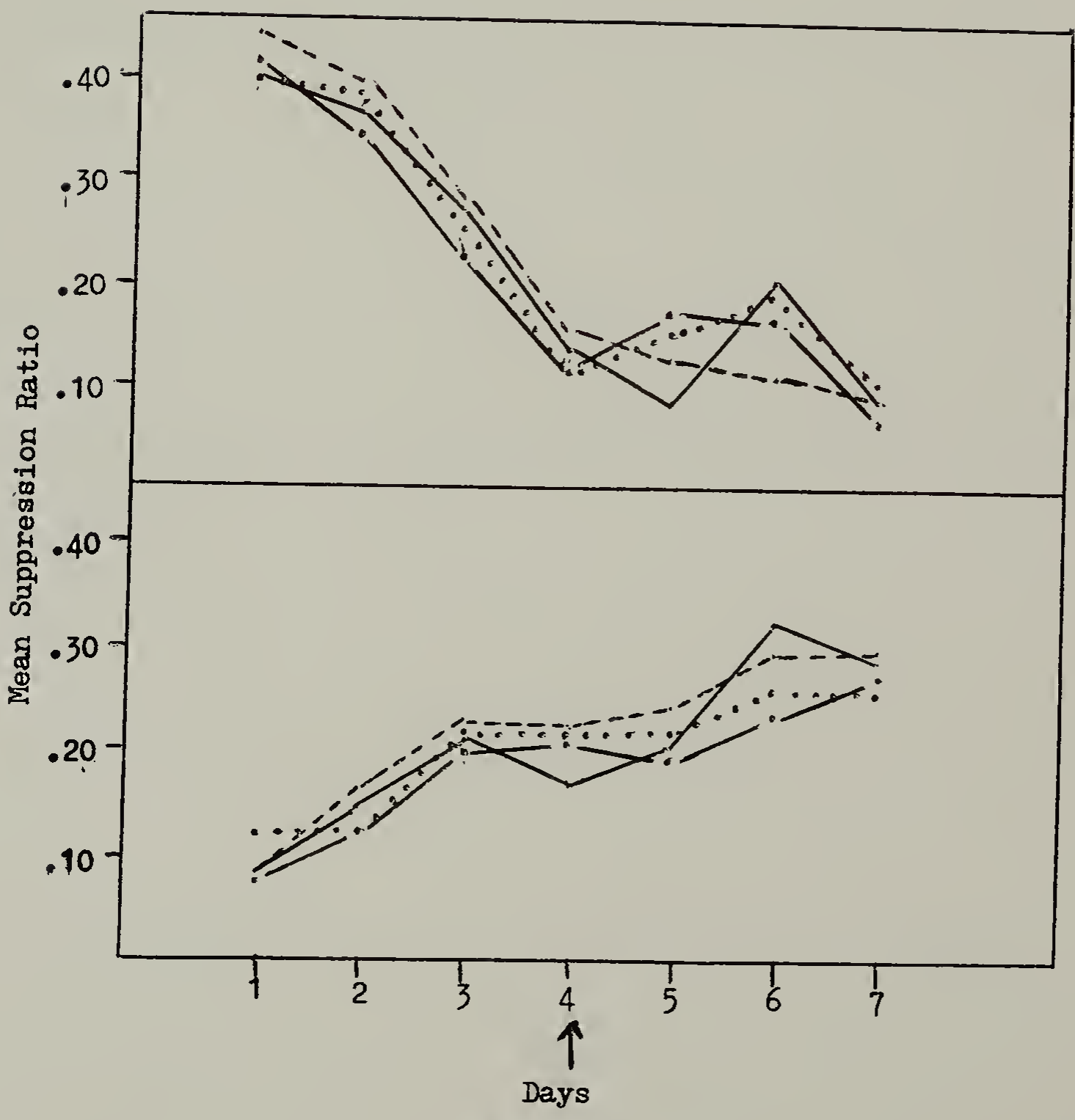

8-NaI

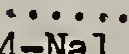

$\overline{\text { Saline }}$

No Drug

Figure 19 
observation that all groups showed extinction of conditioned suppression to the light but that the groups did not differ in their rate of extinction. A.Groups $x$ Days ANOVA on drug days alone also supported this observation.

Figure 20 presents the pre-CS rates for all groups. A Groups $x$ Days ANOVA performed on the pre-CS rates during extinction revealed a significant Groups $x$ Da $y$ interaction [ $\underline{F}(18,210)=1.7, \underline{p}<.05]$. This interaction was largely due to a drop in pre-CS rates during the last 3 extinction days in Group 8-NAL and an increase in pre-CS rates in Group Saline on the last extinction day. Thus, only the $8 \mathrm{mg} / \mathrm{kg}$ injection of naloxone decreased baseline responding during extinction.

As in Experiment 1 naloxone failed to increase conditioned suppression when given only during extinction. Both nalox one-treated groups showed levels of conditioned suppression comparable to those seen in Groups Saline and No-Drug. Fanselow (in press) and Fanselow and Bolles (1979) reported that nalox one increases resistance to extinction of context fear conditioning when given during training but not when given during extinction. Thus, it appears that naloxone does not act directly on fear. 
114

Figure 20. Pre-CS rates during extinction for all groups in Experiment 3. The arrow marks the beginning of drug treatment. 


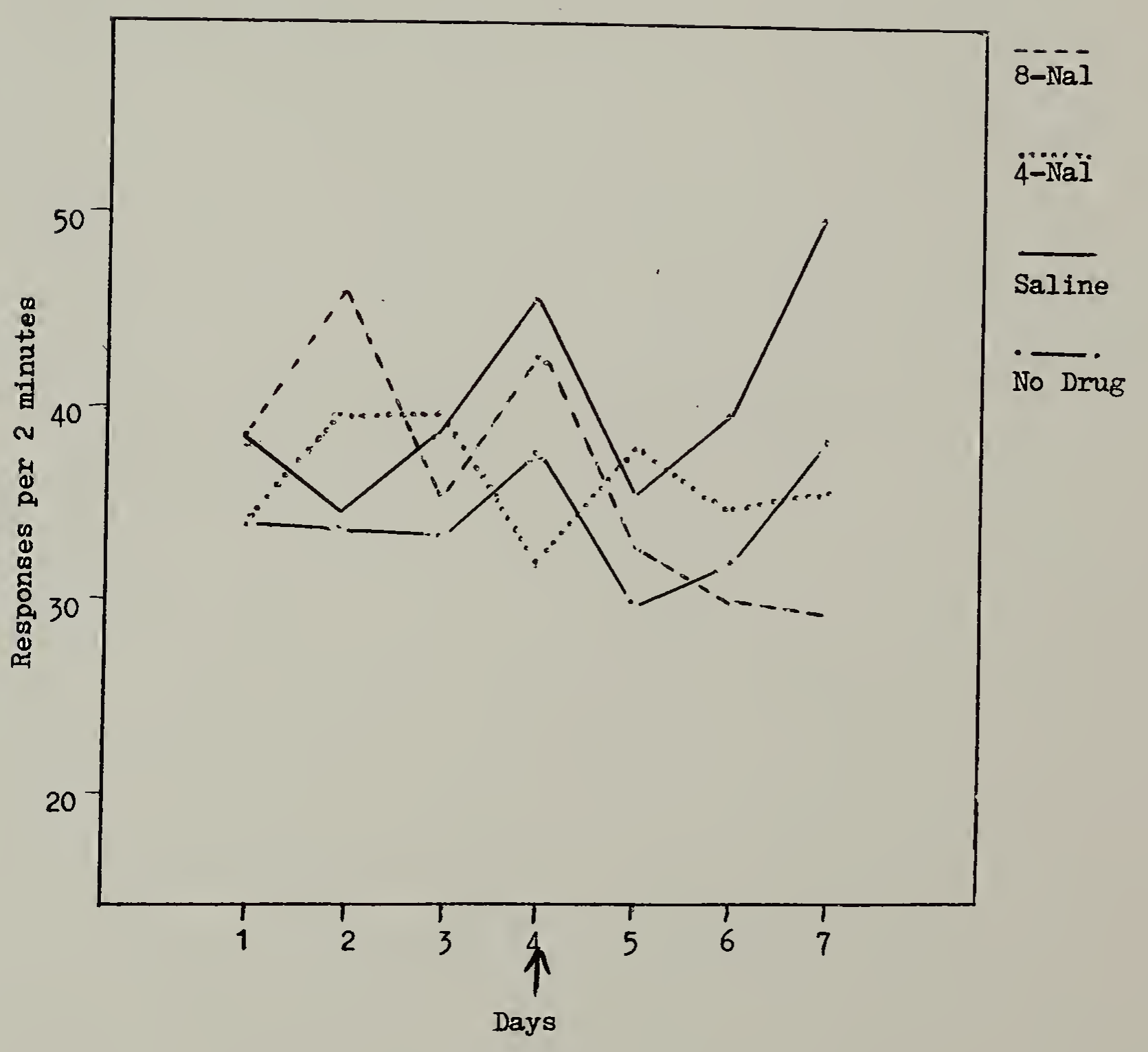

Figure 20 


\section{H A P T E R VI \\ GENERAL DISCUSSION}

The mijor purpose of the present series of experiments was to determine the effects of noloxone on the acquisition of conditioned suppression. Naloxone administered during acquisition increased conditioned suppression to the light CS (Experiment 1 and 2b), eliminated PADs (Experiment 1), increased post-US suppression (Experiment 1), depressed baseline response rates in a situation involving shock presentation (Experiments 1 and $2 \mathrm{~b}$ ), and enhanced suppression during extinction (Experiment 1 and $2 \mathrm{~b})$. All of these effects strongly suggest that naloxone increased the aversiveness of the shock US presumably by blocking a functional endorphinergic system. Even though naloxone increased conditioned suppression, it did not eliminate WSDs (Experiments 1 and 2b). The robustness of WSDs, even under conditions of high, suppression, is surprising. Why WSDs were not eliminated by naloxone is not clear. These decrements in suppression may reflect short-term CS habituation-like effects, which we wolld not expect to be affected by endorphins. However, the possibility of a nonendorphinergic hypoalgesia mechanism cannot be totally $r$ uled out.

Why did naloxone increase conditioned suppression? One might argue that naloxone did not increase the aversiveness of 
the US but caused a general suppression of motor activity. This suppression of motor activity con result in less barpressing behavior, which can erroneously be taken as increased conditioned fear. However, this interpretation can be dismissed since many papers have reported that naloxone does not affect general motor activity. Naloxone does not affect locomotor activity in a shuttle box (Fanselow, 1979), maze (Stapleton et al., 1979), or activity box (Holtzman \& Jewett, 1973) and does not interfere with the ability to press operant levers (Holtzman \& Jewett, 1973). Moreover, it is unclear kow a simple motor interpretation would explain why greater suppression is seen during the CS and post-US period than during the pre-CS period.

Another alternative explanation of the results in the present series of experiments suggests that naloxone reduces motivation for sucrose. This possibility was discussed earlier. Experiment 2a systematically examined the effect of two doses of naloxone on barpress responding for sucrose and found that naloxone caused a very small drop in VI response rates. It is unlikely that naloxone's relatively small effect on baseline responding for sucrose caused the differences in CS-elicited and context-elicited suppression found in these experiments. However, rate of responding has been reportea to be an important determinant of the action of certain drugs (Dews, 1958). It is possible that naloxone may have differential effects on responding for sucrose depending on the initial baseline rate. 
That is, naloxone may reduce responding for sucrose more when the rate is low than when it is high. Al though naloxone had only a small effect in Experiment $2 \hat{a}$ when responding was high, the drug may have had a large effect during acquisition when responding was low. This possibility remains unlikely, however, since baseline responding increased during recovery days even though naloxone treatment coritinued. Moreover, weaker resistance to extinction of conditioned suppression would be expected if naloxone depressed baseline without enhancing conditioning; tre opposite result was in fact observed.

A third alternative explanation is that naloxone affected the acquisition of conditioned suppression by increasing fear instead of increasing pain. The results from Experiment 3 as well as from Group $C-S-N$ in Experiment 1 and Group $S-N$ in Experiment $2 b$ argue against tris view. If naloxone increased fear, then one would expect increased resistance to extinction in rats treated with the drug only during extinction. This is not observed with freezing produced by fear-eliciting background cues (Fanselow, in press) or with freezing produced by a fear-eliciting discrete CS (Fanselow \& Bolles, 1979b). The present experiments extend this finding to conditioned suppression of barpressing.

A fourth alternative interpretation of the results reported here is that the drug enhances learning by enhancing acquisition processes or memory consolidation. As discussed earlier, 
however, the available data on the role of endorphins in learning and memory is unclear. Naloxone has been reported to both improve and disrupt learning. In order to argue that naloxone enhanced learning in the present experiments, one might have to conclude that naloxone al so enhances learning when given during extinction. Exactly what form such enhancement would take is not clear. Should a rat quickly learn that the CS is no longer reinforced and therefore show more rapid extinction or should the rat's memory of the inferred CS-US association remein robust, and therefore, show resistance to extinction? Nevertheless, whichever view one takes, no effect of naloxorie on extinction was observed in the present series of experiments. Thus, it remains unlikely that a direct enhancement of learning and memory processes occurred in these experiments.

The data presented here along with evidence presented elsewhere support the hypothesis that naloxone increases the aversiveness of painful stimuli. If those stimuli are used as reinforcers, then learning based upon those reinforcers will also be enhanced. Thus, PADs may result from the loss of the effectiveness of the aversive US due to the action of endorphins. This speculation implies that all Pavlovian procedures involving aversive USs activate the endorphins (see Riley, Zellner, \& Duncan, 1979 for a review on endorphins and aversive Pavlovian procedures) .

It is not clear exactly how endorphins exert their effects 
on conditioned suppression. Any of the hypotheses discussed in the introduction still seem viable with the exception of the antianxiety hypothesis. What is clearly suggested by the present results, however, is that a transactional approach to the study of aversive Pavlovian conditioning may be the most promising approach. The conditioning process appears to involve a transaction between the organism and its envirorment. In this respect aversive USs have an initial impact on the organism that influences learning. As the endorphinergic system is activated, the initial impact of the US is altered which in turn alters later learning based on the same US. A transactional approach for Pavlovian conditioning in general has been suggested el sewhere (e.g., Kimmel \& Eurns, 1975).

There are several models of conditioning that incorporate this transactional view. One is the conditioned-opponent theory (Schull, 1979). This model adds features of Solomon and Corbit's (1974) opponent-urocess theory with the theory formulated by Rescorla and Wagner (1972). The Rescorla-Wagner model is based on the central notion described by Kamin (1969) that conditioning to a CS will occur to the extent that the occurrence of the reinforcer is not already predicted by another stimulus. This relationship is formally stated in the model by the equation

$$
\Delta v=\alpha_{A} \beta(\lambda-\bar{v})
$$


where there are three sets of parameters that govern the change in associative strength $\left(\bar{V}_{A}\right)$ that accrues to a stimulus. Alpha $\left(\alpha_{A}\right)$ is the learning rate parameter of the stimulus. The vallue of $\propto$ roughily approximates the salience of each component stimulus. Eeta $(\beta)$ is the learning rate parameter associated with the US. The asymptotic level of associative strength that each US can support is represented by $\lambda$. The value of $\lambda$ increases with increasing intensity of the reinforcer. The expression $(\lambda-\bar{V})$ represents the change in associative strength accruing to $\approx$ stimulus. That is, the amount of change of conditioned strength during a trial depends on the size of the discrepancy between $\lambda$ and $\bar{V}$. The greater the discrepancy the greater the change in associative strength.

Schull equated the primary a process, which is elicited by the us, with $\lambda$. schull fur ther suggested that the $\underline{b}$-process is a compensatory CR that follows the same Pavlovian laws as other Chs. The conditioned $\underline{b}$ process he equated with $V_{A}$, the present conditioned strength of the stimulus paired with the US. Schull suggested that in aversive conditioning situations the conditioned $\underline{b}$ process may be the conditioned release of endorphins. Thus, with repeated trials, increments in tre strength of anticipatory CRs grow smaller because of the increased release of endorphins, which reduces the discrepancy, $(\lambda$ - $\bar{V}$ ). Naloxone increases conditioned suppression by blocking the endorphinergic system (and therefore reducing $\bar{V}$ ) and increasing 
the $\lambda-\bar{V}$ discrepancy. By increasing this discrepancy, naloxones removes constraints normally $\mathrm{placed}$ on the growth of the anticipatory CRs.

The PDR model is similar to the conditioned-opponent theory in that they both incorporate the conditioned antinociception hypothesis described in the introduction i.e., the conditioned release of endorphins attenuates the aversiveness of subsequent US presentations. Al thougr. the PDR model is not primarily concerned with the mechanism of conditioning (Eolles \& Fanselow, 1980) the model can account for naloxone's effect of increasing conditioned suppression, as does the conditioned-opponent theory. by suggesting that the drug reduces $\bar{v}$, and therefore, increases the $\lambda-\bar{v}$ discrepancy. Fanselow (in press) suggested that an alternative mechanism may be involved without postulating opponent processes. During repeated fear conditioning trials the $\lambda-\bar{V}$ aiscrepancy decreases as a result of increasing $\bar{V}$ and decreasing $\lambda$, the latter being due to the increasing conditioned release of endorphins. Naloxone prevents the decrease, resulting in an increased discrepancy and hence increased asymptotic conditioning.

The PDR model and conditioned-opponent theory both recognize that an organism's reaction to painful stimuli may change considerably with experience, and in turn al ter further learning involving those stimuli. Both theoretical formulations also emphasize an endorphinergic system as a possible mechanism in 
altering the response to painful stimuli. Such a mechanism receives further support by the results presented in this thesis. 
REFERENCE NOTES

Ayrts, J. J. E. \& Vigorito, M. Blocking, surprise, and post-US suppression in the conditioned suppression procedure. Paper presented at the 22nd annual meeting of the Psychonomic Society, 1981.

Ehrmán, R. N., Josphson, P. J., Schull, J., \& Spärich, C. Eehavioral effects of thie endorphin system within instrumental end classical conditioning paradigms. Paper presented at the 50th meeting of the Eastern Psychological Association. Philadel phia, 1979.

Miller, R. R., Greco, C., Vigorito, M., \& Marlin, N. E. Warning-signal effects on the aversiveness of fixed-electrode tailshock. Paper presented at the meeting of the Psychonomics Society . Phoenix, Arizona, 1979. 


\section{BIBLIOGRA PHY}

Akil, H., Madden, J., Patrick, R. L., \& Earchas, J. D. Stress-induced increase in endogenous opiate peptides: Concurrent analgesici and its partial reversal by naloxone. In H. W. Kosterlitz's (Ed.) Opiates and endogenous opioid peptid€s, Elsevier, Amsterdam, 1976.

Amir, S. \& Amit, Z. Endogenous opioid ligands may mediate stress-induced changes in the affective properties of pain related behavior in rats. Life Sciences, 1978, 23 1143-1152. Annau, 2. \& Kamin, L. J. The conditioned emotional response as a function of intensity of the US. Journal of Comparative and Physiological Psychology, 1961, 54, 428-432.

Ayres, J. J. B., Berger-Gross, P., Kohiler, E. A., Mahoney, W. J., \& Stone, S. Some orderly nonmonotonicities in the trial-by-trial acquisition of conditioned suppression: Intibition with reinforcement? Animal Learning and Behavior, $1979,1,174-180$.

Badia, P., Harsh, J., \& Abbott, B. Choosing between predictable and unpredictable shock conditions: Data and theory. Psychological Eulletin, 1979, 86, 1107-1131.

Baile, L. A., Keim, D. A., Della-Ferrá, M. A., \& NicGlaughlin, L. Opiate antagonists and agonists and feeding in sheep. Physiology and Eehavior, 1981, 26, 1019-1023.

Eelluzzi, J. D. \& Stein, L. Enkephalin- and morphine-induced 
facilitation of long term memory. Society for Neuroscience Abstracts, $1977, \underline{3}, 230$.

Belluzzi, J. D., Grant, N., Garsky, V., Serantakis, D., Wise, D.

C., \& Stein, L. Analgesiá induced in vivo by central administration of enkephal in in rat. Nature, 1976, 260, $625-626$.

Blackman, D. E. Response rate, reinforced frequency, and conditioned suppression. Journal of the Experimental Analysis of Eehavior, 1968, 11, 503-516.

Bolles, R. C. Species-specific defense reactions and avoidance learning. Psychologicál Review, 1970, 77, 32-48. Boiles, R. C. \& Fanselow, M. S. A perceptual-defensiverecuperative model of fear and pain. The Eehavioral and Brain Sciences, 1980, 3, 291-323.

Brands, B., Thornkill, J. A., Hirst, M., \& Gahidy, C. W. Suppression of food intake and body weight gain by naloxone in rats. Life Sciences, 1978, 24, 1773-1778.

Brown, D. R. \& Holtzmen, S. G. Narcotic antagonists attenuate drinking induced by water deprivation in a primate. Life Sciences, $1981, \underline{28}, 1287-1294$.

Carey, M. P., Ross, J. A., \& Enns, M. P. Naloxone suppresses feeding and drinking but not wheel running in rats. Pharmácology, Eiochemistry, and Eehavior, 1981, 14, 569-571. Chance, W. T. \& Rosecrans, J. A. Lack of effect of naloxone on autoanalgesia. Pharmacology, Biochemistry, and Behavior, 
1979, 11, 643-646.

Chance, W. T., White, A. C., Krynock, G. M., \& Rosecrans, J. A. Conditional fear-induced decreases in the binding of [3H] $\mathrm{N}$-leu-enkephal in to rat brain. Erain Research, 1978, 141, $371-374$.

Collier, A. C. Preference for shock signals as a function of the temporal accuracy of the signals. Learning and Notivation, 1977, $\underline{8}, 159-170$.

Dewey, W. L. \& Harris, L. S. The tail flick test. In S. Ehrenpreis \& A. Niedle (Eds.) Methods in narcotic research, New York: Dekker, 1975.

De hied, D., Eohus, B., von Ree, J. M., \& Urban, I. Behavioral and electrophysiological effects of peptides related to lipotropin ( - LPH). Journal of Pharmecology and Experimental Therapeutics, 1978, 204, 570-580.

De Wied, D., Kovács, G. L., Bohus, B., van Ree, J. M., \& Greven H. M. Neuroleptic activity of the neuropeptide $-\mathrm{LPH}$ ([Des Tyr'] -endorphin: DT ). European Journal of Pharmacology, 49, 427-436.

Dweck, C. S. \& Wagner, A. R. Situational cues and correlation between CS and US as determinants of the conditioned emotional response. Psychoromic Science, 1970, 18, 145-147.

El-Sobky, A., Dostrovsky, J. O., \& Wall, P.D. Lack of effect of náloxone on pain perception in humans. Nature, 1976, 263. 
783-784.

Epstein, S. \& Baum, R. Verbal hypothesis formulation during classical conditioning of the GSR. Journal of Experimental Psychology, 1971, 87, 187-197.

Fanselow, M. S. Naloxone attenuates rat's preference for signaled shock. Physiological Psychology, 1979, I, 70-74. Fanselow, M. S. Naloxone and Pavlovian fear conditioning. Learning and Motivation, in press.

Fanselow, M.S. \& Bolles, R. C. Triggering of the endorphin anclgesic reaction by a cue previously associated with shock: Reversal by naloxone. Eulletin of the Psychonomic Society, 1979a, 14,88-90.

Fanselow, M. S. \& Bolles, R. C. Naloxone and shock-elicited freezing in the rat. Journal of Comparative and Physiological Psychology, 1979b, 4, 736-744.

Foster, J. A., Morrison, M., Dean, S. J., Hill, M., \& Frenk, H. Naloxone suppresses food/water consumption in the deprived rat. Pharmacology, Biochemistry, and Behavior, 1981, 14, 419-421.

Frederickson, R. C., Burgis, D., \& Edwards, J. D. Hyperalgesia induced by naloxone follows diurnal rhythm in responsivity to painful stimuli. Science, $1977, \underline{198}, 756-759$.

Gattoni, R. C. \& Izquierdo, I. Effect of chronic posttrial saline injections on maze performance. Physiological Psych:ology, 1973, 1, 231-232. 
Gillert, V. F. \& Sparber, S. B. A comparison of the effects of naloxone upon body weight loss and suppression of fixed ratio operant behavior in morphine-dependent rats. Journal of Pharmacology and Experimental Therapeutics, 1977, 201, $44-54$.

Goldstein, M. L. Acquired drive strength as a joint function of shock intensity and number of acquisition trials. Journal of Experimental Psychology, 1960, 60, 349-358.

Goldstein, A., Pryor, G. T., Otis, L., \& Larsen, F. On the role of endogenous opioid peptides: Failure of naloxone to influence shock escape threshold in the rat. Life Sciences, $1976,18,599-604$.

Grevert, P. \& Goldstein, A. Effects of naloxone on experimentally induced ischemic pain and on mood in human subjects. Proceedings of the National Academy of Sciences of the United States of America, 1977, 74, 1291-1294.

Hall, G. \& Pearce, J. M. Latent inhibition of a CS during CS-US pairings. Journal of Experimental Psychology: Animal Behavior Processes, 1979, $\underline{5}, 31-42$.

Harsh, J. \& Badia, P. A. A concurrent assessment of the positive and negative properties of a signaled shock schedule. Animal Learning and Eehavior, 1974, 2/ 169-172.

Hernandez, L. L. \& Powell, D. D. Effects of naloxone on Pavlovian conditioning of eyeblink and heartrate responses in rábbits. Life Sciences, 1980, 27, 863-869. 
Hilgard, E. R. \& Marquis, D. G. Acquisition, extinction end retention of conditioned lid responses in dogs. Journal of Comparative and Physiological Psychology, 1935, 19, 29-58. Holtzman, H. G. Suppression of appetitive behavior in the rat by náloxone: Lack of prior physical dependence. Life Sciences, $1979, \underline{24}, 219-226$

Holtzman, S. G. \& Jewett, R. E. Stimulation of behavior in the rat by cyclazocine: Effects of naloxore. Journal of Pharmacology and Experimental Therapeutics, 1973, 187. $380-390$.

Hughes, J. Isolation of an endogenous compound from the brain with pharmacological properties similar to morphine. Brain Research, 1975, 88, 295-308.

Hull, C. L. Principles of behavior. New York: Appleton- Century, 1943.

Izquierdo, I., Perry, M. L., Dias, R. D., Souza, D. O., Elisábetsky, E., Carrasco, M. A., Or singher, O. A. \& Netto, C. A. Endogenous opioids, memory modulation, and state dependency. In Nartinez, J. C., Jensen, R. A., Rigter, H., and MicGaugh, J. L. (Eds.), Endogenous peptides and learning and memory Processes. New York: Academic Press, 1981.

Jackson, R. L., Naier, S. F. \& Coon, D. J. Long-term análgesic effects of inescapable shock and learned helplessness, Science, 1979, 206, 91-93.

Kamin, L. J. Trace conditioning of the conditioned emotional 
reaction. Journal of Comparative and Physiological Psychology, $1961, \underline{54}, 149-153$.

Kamin, L. J. Predictability, surprise, attention, and conditioning. In E. A. Cambpell \& R. Church (Eds.), Punishment and aversive behavior. New York: Appleton-Century-Crofts, 1969.

Kettlewell, N. M. \& Papsdorf, J. D. The effects of an interpolated ITI stimulus on classical conditioning of the nictitating membrane response of the rabbit. Psychonomic Science, $1967, \underline{9}, 257-258$.

Kimmel, E. Judgments of UCS intensity and diminution of the UCR in classical GSR conditioning. Journal of Experimental Psychology, $1967, \underline{73}, 532-543$.

Kimmel, H. D. \& Eurns, R. A. Adaptational aspects of conditioning In W. K. Estes (Ed.), Handbook of learning and cognitive processes (Vol. 2): Conditioning and behavior theory. Hillsdale, N. J.: Erlbaum, 1975.

Konorski, J. Conditional reflexes and neuron orginization. New York: Cambridge University Press, 1948.

Kremer, E. F. Effects of posttrial episodes on conditioning in compound conditioned stimuli. Journal of Experinental Psychology: Animal Eehavior Processes, 1979, 5, 130-141.

Lal, H., Miksic, S., \& Smith, N. Naloxone antagonism of conditioned hyperthermia: An evidence for release of endogenous opioid. Life Sciences, 1976, 18, 971-975. 
Lewis, J. W., Bentley, K. W., \& Cowan, A. Narcotic analgesics and antagonists. Annual Review of Pharmacology, 1971, 11, $241-270$

Lewis, J. W., Cannon, J. L., \& Liebeskind, J. C. Opioid and nonopioid mechanisms of stress analgesia, science, 1980, 208, $623-625$.

Libby, A. Two variables in the acquisition of depressant properties by a stimulus. Journal of Experimental Psychology, 1951, 42, 100-1076.

Madien, J.. Akil, H., Patrick, R. L., \& Earchas, J. D. Stressinduced farrallel changes in central opioid levels and pain responsiveness in the $r a t$. Nature, 1977, 265, 358-360.

Mah, C., Suissá, A., \& Anisman, H. Dissociation of anticociception and escape deficits induced by stress in mice. Journal of Comparative and Physiological Psychology, 1980, 94 , 1160-1171.

Maier, S. F., Coon, D. J. McDaniel, M. A., Jackson, R. L., \& Grau, J. The time course of learned helplessness, inactivity and nociception decrements in rats. Learning and Kotivation, $1979,10,467-487$.

Maier, S. F., Davies, S., Grau, J. W., Jackson, R. L., Morrison, D. H., Noye, T., Nadden IV, J., \& Earchas, J. D. Opiate antagonists and long-term analgesic reaction induced by inescapable shock in rats, Journal of Comparative and Physiologicál Psyctology, 1980, 94, 1172-1183. 
Marlin, N. A., Berk, A. M., \& Miller, R. R. Nodification and avoidance of unmodifiable and unavoidable footshock. Bulletin of the Psychonomic Society, 1978, 11, 203-205. Márlin, N. E., Sullivên, J. M., Berk, A. M., \& Miller, R. R. Preference for information about intensity about tailshock. Learning and Notivation, $1979,10,85-97$.

Nartinez, J. L. \& Rigter, H. Endorphins alter acquisition and consolidation of an infibitory avoidance response in rats. Neuroscience Letters, $1980,19,197-201$.

Messing, R. E., Jensen, R. A., Martinez Jr., J. L., Vasquez B. J., Somir eu-Mouret, B., \& MicGaugh, J. L. Naloxone enhancement and morphine impairment of memory. $\underline{7 t h}$ International Congress of Pharmacology Abstracts, 1978, 560. Millenson, J. R. \& Dent, J. G. Habituation of conditioned suppression. Quarterly Journal of Experimental Psychology, $1971, \underline{23}, 126-134$.

Millenson, J. R. \& Hendry, D. P. Quantification of response suppression in conditioned anxiety training. Canadian Journal of Psychology, 1967, 21, 242-252.

Niller, R. R., Daniel, D., \& Eerk, A. N. Successive reversals of a discriminated preference for signaled tailshock. Animal Learning and Eehavior, 1974, 2, 271-274.

Miller, R. R., Marlin, N. A., \& Berk, A. M. Reliability and sources of control of preferences for signaled shock. 
Animal Learning and Behavior, 1977, ․, 303-308.

Odling-Smee, F. J. The role of background stimuli during

Pavlovian conditioning. Quarterly Journal of Experimental

Psychology, 1975, 27, 201-209.

Ostrowski, N. L., Foley, T. L., Lind, M. D., \& Reid, L. D. Naloxone reduces fluid intake: Effects of water and food deprivation. Pharmacology, Biochemistry, $\underline{\text { Behavior }}, 1980$, 12, $431-435$.

Overmier, J. B., Payne, R. J., Eruckbill, R. M., Linder, B., \& Lawry, J. A. On the mechanism of the post-asymptotic decrement phenomenon. Acta Neurobiologicae Experimentalis. 1979, $39603-620$.

Overton, D. A. Dissociated learning in drug states (state defendent learning). In D. H. Efron, J. D. Cole, J. Levine, \& J. R. Wittenborn (Eds.), Psychopharmacology: A review of progress 1957-1967, Washington: Public Health Service Publication No. 1836, 1968.

Päpsdorf, 'J. D. \& Kettlewell, N. M. The effects of different interpolated ITI stimulus-conditioned stimlus intervals on the acquisition of the classically conditioned nictitating membrane response in rabbit. Psychonomic science, 1968, 10, $171-172$

Pavlov, I. P. Conditioned reflexes. New York: Dover, 1960. Perkins, C. C. fin analysis of the concept of reinforcement. Psychological Review, 1968, 도, 155-172. 
Pfautz, P.L. \& Wagner, A. R. Transient variations in responding to Pavlovian conditioned stimuli have implications for the mechanisms of "priming". Animal Learning and Eehavior. $1976, \underline{4}, 107-112$.

Ramabadran, K., Guillán, J. C., \& Jacob, J. Actions of hyperalgesic substances $\{(-)$ Naloxone, Theophyline, and 5-metoxy-N, N-Dimethyl tryptamine\} on nociceptive learning. In Leong Way (Ed.) Endogenous and exogenous opiate agonists and Entägonists. New York: Pergemon Press, 1980.

Rescorle, h. A. A model of Pavlovian conditioning. In V. $S$. Rusinove (Ed.) Niecranism of formation and inhibition of conditioned reflex. Moscow: Acadamy of Sciences of the $\underline{U} \cdot \underline{S} \cdot \underline{S} \cdot \underline{K} ., \quad 1974$.

Rescorla, R. A. \& Cunningham. C. L. The erasure of reinstated fear. Animal Learning and Eehavior, 1977, ㄴ, 386-394.

Rescorla, R. A. \& Cunningham, C. L. Recovery of the US representation over time during extinction. Learning and lotivation, 1978, 373-391.

Rescorla, R. A. \& Heth, C. D. Reinstatement of fear to an extinquished conditioned stimulus, Journal of Experimental Psychology: Animal Eehavior Processes, $1975, \underline{104}, 88-96$. Rescorla, R. A. \& Wagner, A. R. A theory of Pavlovian conditioning: Variátions in tree effectiveness of reinforcement and nonreinforcement. In A. Black \& W. F. Prokasy (Eds.), Classical Conditioning II. New York: 
Appl eton-Century-Crofts, 1972.

Rigter, H. Attenuation of amnesia in rats systemically administer ed enkephal ins. Science, 1978, 200, 83-85.

Rigter, H. Hannon, I. J., Messing, R. B., Martinez, Jr., J. L., Vasquez, B. J., Jensen, R. A., Veliquette, J., \& NicGaugh, J. C. Enkephalins interfere with acquisition of an active avoidance response. Life Sciences, 1980, 26, 337-345.

Rigter, H., Jensen, R. A., Martinez Jr., J. L., Messing, B. J., Vasquez, B. J., Liang, K. C., \& NicGaugh, J. L. En kephal in and fear-motivated behavior. Proceedings of the National Acadamy of Sciences. $1980,77,3729-3732$.

Riley, A. L., Zellner, D. A., \& Duncan, H. J. The role of endorphins in animal learning and behavior. Neuroscience and Biobehaviorel Review, 1979, 44, 69-76.

Rockwood, G. A., Siviy, S. M., \& Reid, L. D. Naloxone reduces fluid intake in rats with open gastric fistulas. Pharmácology, Biochemistry, and Behavior, 1981, 15, $319-321$.

Runquist, W. N. \& Muir, W. R. Intrasession decrements in the performance of the classically conditioned eyelid reflex. Journal of Experimental Psychology, 1965, 70, 520-525.

Scrull, J. A conditioned opponent theory of Pavlovian conditioning and habituation. In G. Bower (Ed.) The psychology of learning and motivation (Vol.13). New York: Academic Press, 1979. 
Sherman, J. E. The effects of conditioning and novelty on the rat's analgesic and pyretic responses to morphine. Learning and Motivation, $1979, \underline{10}, 383-418$.

Sherman J. E. \& Maier, S. F. The decrement in conditioned fear with increased trials of simultaneous conditioning is not specific to the simultaneous procedure. Learning and Notivation, 1978, 2, 31-53.

Sherman, J. E. and Liebeskind, J. C. An endorphinergic, centrifugal substrate of pain modulation: Recent findings, current concepts, and complexities. In J. J. Eonica (Ed.) Pain. New York: Raven Press, 1980.

Snyder, R. E. \& Papsdorf, J. D. The interaction of ITI interpolated stimuli and ISI on classical conditioning of the nictitating nembrane response of the rabbit. Psychonomic Science, $1968,12,191-192$.

Solomon, R. L. \& Corbit, J. D. An opponent-process theory of motivation: I. Temporal dynamics of affect. Psychological Review, 1974, 81, 119-145.

Stapleton, J. M.. Lind, M. D. Merriman, V. J. \& Reid, L. D. Naloxone inhibits diazepam-induced feeding in rats. Life Sciences, 1979, 24, 2421-2426.

Stapleton, J. M., Cstrowski, N. L., Merriman, V. J., Lind, M. D., \& Reid, L. D. Naloxone reduces fllid consumption in water-deprived and nondeprived rats. Eulletin of the Psychonom ic Society, 1979, 13, 237-239. 
Stolerman, I. P., Pilchèr, C. W. \& D'Mellow, G. D. Stereospecific aversive properties of narcotic antagonists in morphine-free ráts. Life Sciences, 1978, 22 , 1755-1762.

Teschemácher, H. , Opheim, K. E., Cox, B. M., \& Goldstein, A. A peptide-like substance from pituitary that acts like morphine 1. Isolation. Life Sciences, 1975, 16, 1771-1775. Wu, M., Lind, M. D., Stapleton, J. M., \& Reid, L. D. Doseresponse relationship between naloxone injections and intake of sucrose solution. Physiological Psychology, 1981, 17. $101-103$

Yang, H. Y. T., Hexam, T., \& Costa, E. Opioid peptides in adrenal gland. Life Sciences, 1980, 27, 1119-1125.

Young, G. A. Naloxone enharcement of punishment in the rat. Life Sciences, 1980, 26, 1787-1792. 

$\therefore$ a

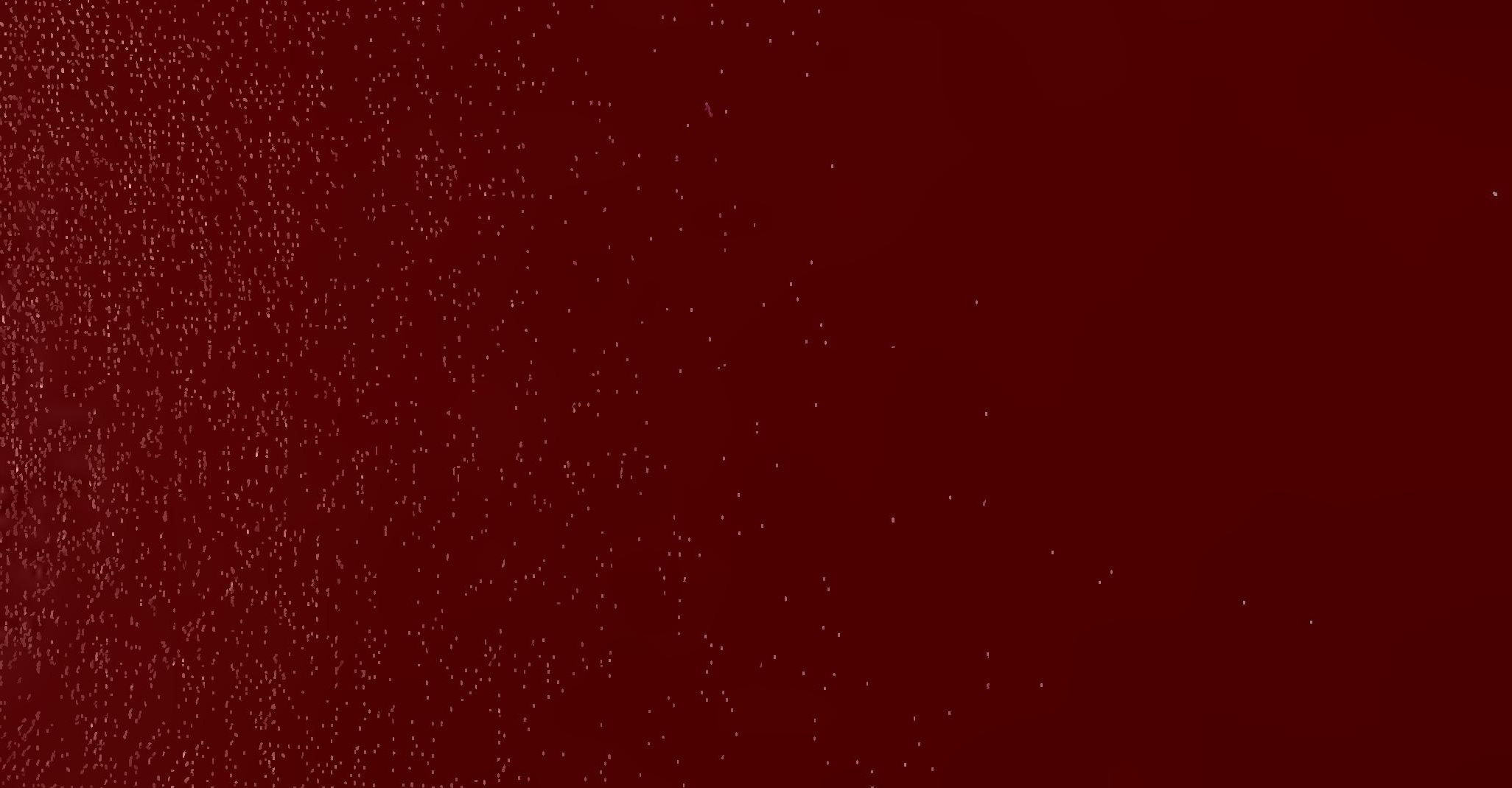

